Florida International University FIU Digital Commons

FIU Electronic Theses and Dissertations

University Graduate School

10-1-2008

\title{
The Career Development of Black Female Chief Nurse Executives
}

Joan M. Osborne

Florida International University, joanmaria7@yahoo.com

DOI: $10.25148 /$ etd.FI10022537

Follow this and additional works at: https://digitalcommons.fiu.edu/etd

\section{Recommended Citation}

Osborne, Joan M., "The Career Development of Black Female Chief Nurse Executives" (2008). FIU Electronic Theses and Dissertations. 208.

https://digitalcommons.fiu.edu/etd/208

This work is brought to you for free and open access by the University Graduate School at FIU Digital Commons. It has been accepted for inclusion in FIU Electronic Theses and Dissertations by an authorized administrator of FIU Digital Commons. For more information, please contact dcc@fiu.edu. 


\section{FLORIDA INTERNATIONAL UNIVERSITY}

Miami, Florida

THE CAREER DEVELOPMENT OF

BLACK FEMALE CHIEF NURSE EXECUTIVES

A dissertation submitted in partial fulfillment of the

requirements for the degree of

DOCTOR OF EDUCATION

in

ADULT EDUCATION AND HUMAN RESOURCE DEVELOPMENT

by

Joan Maria Osborne 
To: Interim Dean Kingsley Banya

College of Education

This dissertation, written by Joan Maria Osborne, and entitled The Career Development of Black Female Chief Nurse Executives, having been approved in respect to style and intellectual content, is referred to you for judgment.

We have read this dissertation and recommend that it be approved.

$\begin{array}{r}\text { Kathleen Blais } \\ \hline \text { Thomas Reio } \\ \hline \text { Janice Sandiford } \\ \hline \text { Ann Nevin, Major Professor }\end{array}$

Date of Defense: October 1, 2008

The dissertation of Joan Maria Osborne is approved.

$\begin{array}{r}\text { Interim Dean Kingsley Banya } \\ \text { College of Education }\end{array}$
Dean George Walker
University Graduate School

Florida International University, 2008 
(C) Copyright 2008 by Joan Maria Osborne

All rights reserved. 


\section{DEDICATION}

Dedicated to my mother, Mary, who sacrificed to make me who I am. 


\section{ACKNOWLEDGMENTS}

The completion of this remarkable journey was accomplished with the love, support, care, and guidance of several individuals. I am indebted to many individuals.

To my study participants, whom without your stories, this study would not have been possible. I am inspired by you, your strength, your passion, and your determination. To Martha Dawson, your relentless efforts helped me to locate my study participants.

To my exceptional dissertation committee, led by Dr. Ann Nevin, my champion, whose guidance, support, patience, encouragement, and generous time and commitment kept me going when I could not see the end. To Dr. Kathleen Blais, my friend and mentor, I am here today because you saw a spark in me and encouraged me to pursue my

dreams. Dr. Janice Sandiford and Dr. Thomas Reio, I appreciate your time and insightful comments and constructive criticism. You have all challenged me to do better. Dr. Douglas Smith, Dr. Mary Alfred, and Dr. Gaetane Jean-Marie; I appreciate your roles and value your guidance, feedback, and support.

To Dr. Carolyn Stewart and Sharon Crum, my bright lights, thanks for never giving up on me. To my friends, Barbara Pritchard, Debra Williams, and Faye McEwan, I appreciate the ear when faced with setback. Your kind words of encouragement kept me on track. To my colleagues, staff, and nursing students, thanks for your support, patience, and encouragement. To everyone who kept abreast of my progress and encouraged me on this path, thank you.

To my family, my mother, whose entire life was sacrificing so that her daughters would have a better life; I am eternally grateful; my sister, Janet Bushell; father Lenny Bushell; Desiree Small and family; thanks for keeping me sane. 
Finally, to my daughter, Samantha, my pride and joy, my life, I love you. Your kindness and devotion to me provided me with the strength to continue and to never quit. You have all played significant roles on this journey, and I am a better human being for having you in my life. My deepest gratitude to you. 


\section{ABSTRACT OF THE DISSERTATION \\ THE CAREER DEVELOPMENT OF BLACK FEMALE CHIEF NURSE \\ EXECUTIVES \\ by \\ Joan Maria Osborne}

Florida International University, 2008

Miami, Florida

\section{Professor Ann Nevin, Major Professor}

This qualitative study was designed to explore the career development of Black female chief nurse executives. Although a small proportion of Black female nurses have achieved positions at the nurse executive level, there remains a paucity of Black female nurse executives in this crucial position which raised the question of what factors contributed to this lack of advancement, but, more important, what factors have contributed to the success of the few who have achieved such level of success in healthcare organizations. The purpose of the study was to explore the career paths of Black female chief nurse executives with a view of understanding the factors which both facilitate and hinder the career development of these leaders in healthcare organizations. The guiding research question was, How do Black female nurse executives in this sample describe their career development?

The participants in this study were Black female chief nurse executives located throughout the United States who, for the most part, were raised in segregation with a strong family foundation. To collect data, semistructured telephone interviews were conducted with 10 Black female chief nurse executives throughout the United States. 
The transcripts from the interviews were transcribed, coded, and analyzed. Using Super's (1990, 1996), and Gottfredson’s (1981, 1996, 2002, 2005) career development theories and critical race theory (Crenshaw, 1995; Delgado, 2000) as the theoretical framework, the researcher found that the participants' career development was influenced by (a) strong support system, (b) guidance, (c) influence of diversity, and (d) servant leadership. The findings help us understand the factors that have contributed to their successes as Black chief nurse executives. With the increasingly diverse population and concurrent increasing diversity in nursing and concerns about healthcare disparities, it is imperative that organizations attract, hire, develop, retain, and advance qualified Black nurses. Future studies addressing not only the career development of Black nurses but nurses in general might be informed by the present study's findings. Recommendations are offered for nursing practice, education, and organizational policy. 


\section{TABLE OF CONTENTS}

CHAPTER

PAGE

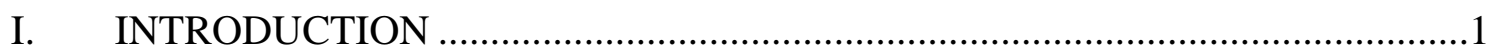

Background of the Problem ...............................................................................1

Purpose of the Study …………………............................................................

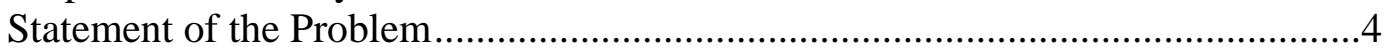

Research Questions ........................................................................................

Theoretical Perspectives .......................................................................................

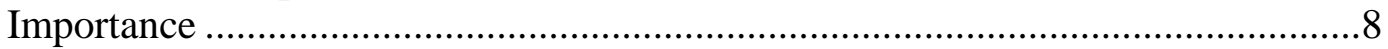

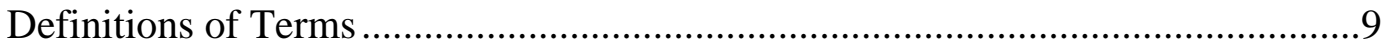

Assumptions............................................................................................10

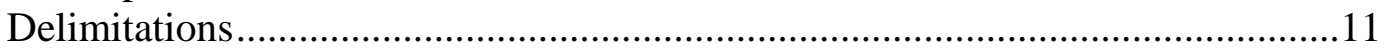

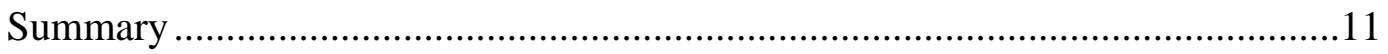

II. REVIEW OF THE LITERATURE ..............................................................14

General Career Development Theories: Super ....................................................14

Theories of Career Development of Women: Gottfredson.......................................17

Race Theories......................................................................................................19

Overall Barriers and Facilitators to Career Development of Women

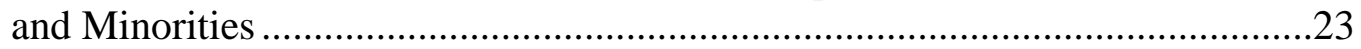

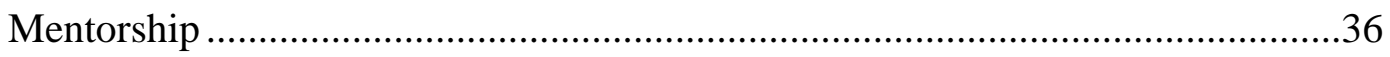

Nurses’ Acquisition of Leadership Qualities .......................................................41

Needs and Strategies of Nurse Executives..........................................................42

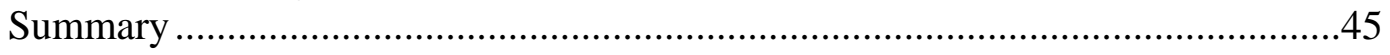

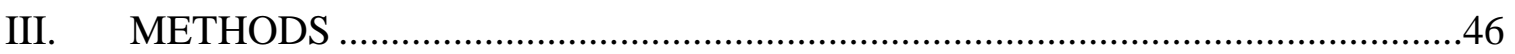

Researcher's Career Development Story ...............................................................47

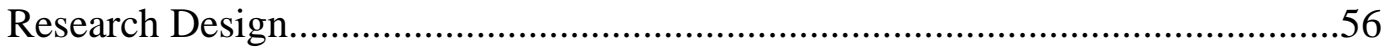

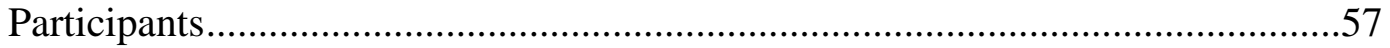

Recruitment Procedures........................................................................................57

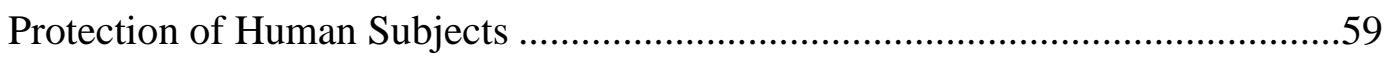

Demographic Questionnaire ...........................................................................60

Interview Guide .....................................................................................61

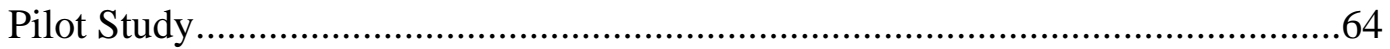

Data Collection Procedures................................................................................65

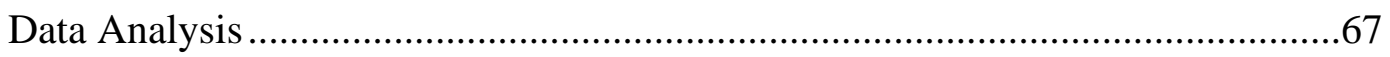

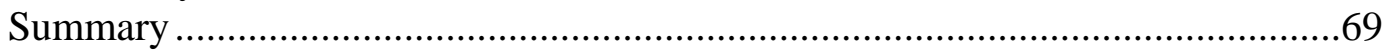

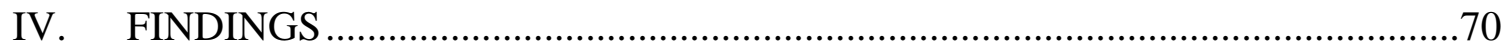

Participant Profiles................................................................ 70

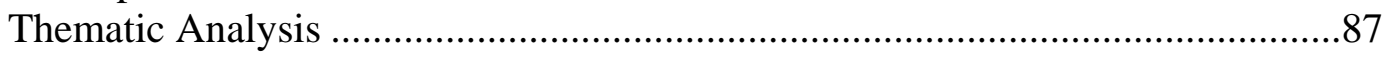

Theme 1: Support Systems ……………………….........................................87

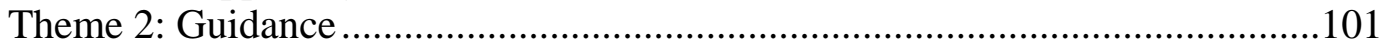




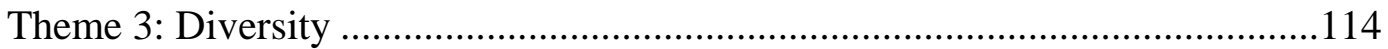

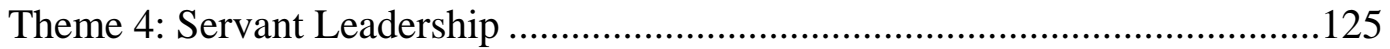

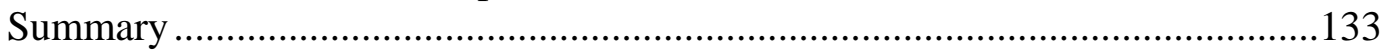

V. SUMMARY, DISCUSSION, AND RECOMMENDATIONS..................134

Review of the Study ........................................................ 134

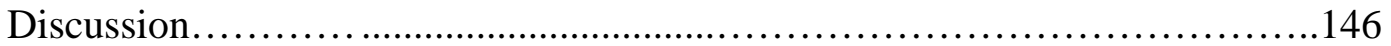

Implications for Theory and Career Development ............................................148

Implications for Practice, Policy, and Research .............................................170

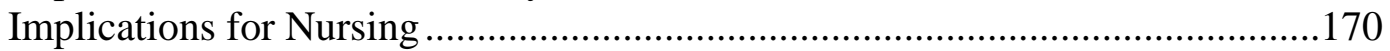

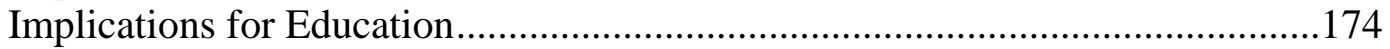

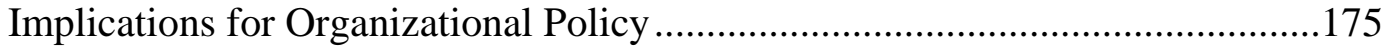

Implications for Human Resource Development.............................................176

Implications for Research ........................................................................178

Career Development of Black Female Chief Nurse Executives:

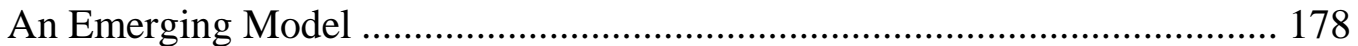

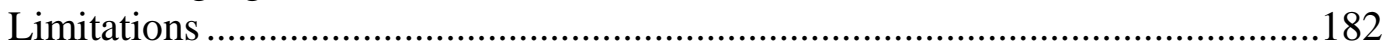

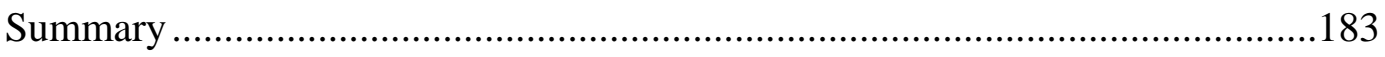

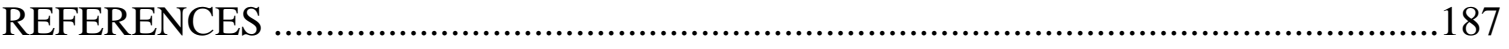

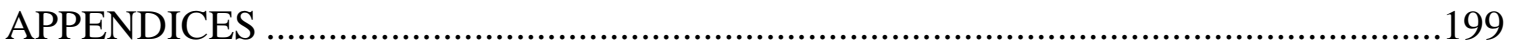

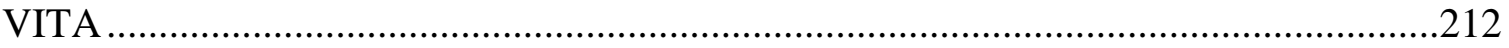




\section{CHAPTER I}

\section{INTRODUCTION}

This study explored the career development of Black female chief nurse executives in healthcare organizations. The chapter begins with the background of the problem, problem statement, theoretical framework, and research questions. Next, the significance of the study, definition of terms, and the delimitations are discussed, followed by a summary of the chapter, and the organization of the study.

\section{Background of the Problem}

Nurses have increasingly assumed leadership responsibilities in healthcare organizations (Byers, 2000; Phelps, 2005), and the demand exists for more nurse leaders (Georges, 2004). Strong nursing leadership is critical not only to nursing divisions but also to the entire healthcare organization. Within these organizations, nurse leaders create the vision and the mission for departments of nursing, shape nursing practice, and ensure delivery of quality patient care (Erickson \& Ditomassi, 2004; Georges, 2004). Moreover, nurse executives participate in the governing body, report to officers at the highest levels, and have the authority and the accountability for all nursing or patient care delivery, as well as the financial resources, and the personnel. In addition to performing their functions, nurse executives must be supported by adequate managerial and support staff (American Hospital Association [AHA], 2003).

However, cultural and racial diversity in the nursing workforce is underrepresented, especially with regard to Black nurses. Worth (2004) pointed out the slow progress of the achievement of more diversity representation from traditionally underrepresented populations (specifically Black or Hispanic employees) in nursing and 
nursing specialties. The U.S. Department of Health and Human Services (2004) reported that racial and ethnic minority groups comprised only $12 \%$ of registered nurses (RNs), of whom 4.9\% were Blacks, 3.5\% Asians, 2.0\% Hispanics, and 1.6\% other groups. Although the number of Black RNs increased by 23.7\% between 1996 and 2000, these figures revealed, that Black nurses continued to be underrepresented in nursing. In addition, approximately $5.7 \%$ of RNs were administrators or assistant administrators. The percentage of Black administrators and the definitions of these positions was not reported, but it would be reasonable to conclude that the figure was lower than $5.7 \%$ (U.S. Department of Health and Human Services, 2004).

Witt and Kieffer (2006) conducted a national survey of over 6,000 chief executive officers. The results differed between White and minority participants. They found that a higher percentage of minority individuals compared to the percentage of white individuals believed that their staffing patterns reflected the diversity of the population. On the question of greater opportunities for minorities in the executive suite, a lower percentage of minorities compared to the percentage for whites believed that there were greater opportunities for minorities in the executive suite. Healthcare disparities are a major concern in the United States. A growing body of evidence demonstrates that minorities in this country do not have access to the same level and quality of care as the majority. A report by the Institute of Medicine [IOM] (2003), titled Unequal Treatment, confirmed the beliefs of many in healthcare, specifically, that ethnic and racial minorities receive inferior care. Even minorities with insurance experience some level of healthcare disparities. The Agency for Healthcare Research and Quality (2004) National Healthcare Disparities Report measured differences in access to use of healthcare services and 
confirmed the IOM report indicating that healthcare disparities were pervasive in the healthcare system. The IOM report recommended that one way of remedying these healthcare disparities was for healthcare organizations to have a diverse racial and ethnic workforce. The voice of the Black female chief nurse executive is critical to the dialogue about reducing and negating healthcare disparities.

\section{Purpose of the Study}

The paucity of Black female nurse executives raised the question of what factors contributed to this lack, but, more important, the paucity begs for an investigation of the factors that have contributed to the success of the few who achieved such a level of success in healthcare organizations. Minorities and Black nurses are visible in the lower echelons of healthcare, in general, and nursing specifically. However, Black nurses are not often found in crucial positions of leadership (American College of Healthcare Executives [ACHE], 2002; Coleman, 2006), although a small proportion of Black female nurses have achieved positions at the nurse executive level. Alfred (2001a) found that race, culture, and identity were vital components in the career development of minority professionals in organizations dominated by the majority culture. Johnson-Bailey and Tisdell (1998) and Trusty (2002) showed that diversity issues in women's career development were largely derived from studies on middle-class White males. These studies did not take into account the socialization and experiences of women, Blacks, and other groups, such as those with low-socioeconomic status.

As Alfred (1995) observed, the experienced voices of "Black women, because of their double minority status—-female and Black—have been silenced by much scholarly neglect” (p. 10). In spite of this lack of academic attention, some Black nurses do reach 
the rank of chief nurse executives (Steefel, 2006). Rose and Larwood (1988) noted, "Professional Black women who manage to pole vault or circumvent obstacles provide an exceptional opportunity to understand how success is achieved in the face of negative expectation” (p. 15). Thus, the question may be raised, "What obstacles must Black female chief nurse executives overcome to achieve positions of leadership?”

Despite the many studies on leadership, women and leadership, and women's career development, few researchers have studied minority leadership and career development (Jean-Marie, 2004, 2006). Further, despite a number of studies on nurses and nurse leaders (Bieber, 2003; Courtney, Yacopetti, James, Walsh, \& Finlayson 2001; Fressola, 1998; Mayor, 2004), no studies were found when searches were conducted on Black female chief nurse executives and their career development. Increasing multiculturalism within the healthcare environment calls for an increasing number of Black nurse executives who need to be groomed and promoted to leadership positions (Steefel, 2006; Sullivan Commission on Diversity in the Healthcare Workforce, 2004).

\section{Statement of the Problem}

Through the phenomenological approach of qualitative inquiry and with in-depth interviews (Creswell, 2003), the present study addressed the need for understanding the experiences, barriers, and facilitators of the career development of Black female chief nurse executives. The rationale for the research focused on understanding the lived experiences and the career paths of Black female chief nurse executives who had achieved executive positions in healthcare organizations. The investigation of the career development experiences of Black female chief nurse executives were undertaken to provide insights into the factors that facilitate and hinder nurses from becoming 
executives. With this knowledge, recommendations could then be developed for healthcare organizations for the recruitment, development, and training of Black female nurse executives.

\section{Research Questions}

The guiding research question was: How do Black female chief nurse executives in the sample describe their career development? In support of this overarching question, the following questions were posed:

1. What particular individuals and events in Black female chief nurse executives’ backgrounds have influenced their career development?

2. How has the career development of Black female chief nurse executives been facilitated or hindered?

3. How have the healthcare organizations of Black female chief nurse executives facilitated or hindered their career development?

4. How do Black female chief nurse executives perceive their career development at different life stages?

5. What strategies can Black female chief nurse executives in healthcare organizations utilize in order to enhance their leadership opportunities?

These research questions provided the framework for an in-depth exploration of the multifaceted elements of Black female chief nurse executives' experiences during the development of their careers in healthcare organizations.

Theoretical Perspectives

Most contemporary theories do not adequately address the career development of racial and ethnic minorities and women. Schreiber (1999) noted, "A useful theory of 
women’s career development must place women’s career choices in the context of current social norms and beliefs about women's capabilities and acceptable roles, and must recognize the overt and covert mechanisms that contribute to maintaining these beliefs" (p. 6). Moreover, with regard to Black women, Constantine and Greer (2003) argued, “The career development processes of Black women cannot be conceptualized in isolation from cultural influences” (p. 5).

Although traditional career development theories integrate the personal, sociological, and institutional aspects of career development, these theories do not encompass other important dimensions of race. Therefore, in the present study, critical race theory (CRT; Crenshaw, 1995; Delgado, 2000) provided an essential framework from which to view the career development of Black women. The conceptual framework of this study was drawn from the literature based on career development and critical race theory. Each is briefly summarized below and is more fully developed in a critical review of the literature in chapter 2.

\section{Career Development Theories}

Two traditional models of lifespan development theories hypothesized that definitive changes occur in adults as they progress throughout life at different stages. The first lifespan development theory was Super’s (1990) lifespan, lifespace approach. In Super's theory, career development extends beyond young adulthood and continues throughout an individual's lifespan. Super posited five general stages of career development; growth, exploration, establishment, maintenance, and decline, with transitional minicyles occurring from one stage to the next. At the same time, the succession of stages is not linear but recursive. Central to Super's theory is the concept of 
self, which informs and influences career choice in vocational identity (the traits individuals bring to a vocation) and occupational self-concept (the personal meaning individuals ascribe to their traits they bring to their vocations).

The second theory addresses the lifespan development of women. Among the many theories and conceptual frameworks that have arisen in the last 2 decades with regard to women, Gottfredson’s (2002) developmental model stands out. The theory extends Super's (1990) theory by emphasizing the role of gender and socioeconomic status on career development choices. The theory encompasses the processes of circumscription and compromise relevant to both genders and includes a self-concept element. For Gottfredson, self-concept is composed of gender, social class, intelligence, interests, and values. Self-concept interacts with occupational image, which is comprised of sex type, prestige, and field of work, to determine occupational preference. Sex type refers to the degree to which an occupation is viewed as being masculine or feminine, Moreover, Gottfredson's (2005) theory considers perceptions of opportunities and barriers.

\section{Critical Race Theory}

Critical race theory draws from law theory and has its origins in the mid-1970s as a movement established by legal scholars Bell and Freeman (as cited in Crenshaw, 1995; Delgado \& Stefancic, 2000). The scholars argued that the legal system could not develop new strategies to further civil rights because it had failed to incorporate race and racism as essential factors. Critical law studies limited the ability to discuss issues of racism and injustices. The basic premise of CRT is that racism is normal in American society and that Blacks progress to success and leadership only when their progress furthers the 
agendas of Whites. A major technique of CRT is storytelling, used to transmit the indepth experiences of Blacks and other minorities and to examine, explain, and to analyze the issues facing them (Crenshaw, 1995; Delgado, 2000; Delgado \& Stefancic, 2000).

As described, the theories of Super (1990), Gottfredson (2002, 2005), and critical race theory (Crenshaw, 1995; Delgado \& Stefancic, 2000) pertain directly to both women and Blacks. The theories provided the background for this study and are explored in greater detail in chapter 2 .

\section{Importance}

This study explored the career development of Black female chief nurse executives within multiple theoretical perspectives. The study is significant in five areas. First, regarding theory, the study examines the applicability or inappropriateness of Super's (1990), Gottfredson's (2002, 2005), and critical race theories (Crenshaw, 1995; Delgado \& Stefancic, 2000) to the career development of Black female chief nurse executives. Second, regarding the literature, study findings increase the knowledge base of the nature of career development of Black female chief executives in healthcare settings. The findings also enhance registered nurses, nurse leaders, and nurse executives understanding of the influences, the facilitators, and the barriers that support or hinder Black female chief nurse executives in ascending to executive positions. Third, regarding practice, identification of important factors in Black female chief nurse executives' career development provide information for the mentoring of and by Black nurses. Further, study findings help to identify support systems for enhancing the career goals of Black female nurse executives. Fourth, findings contribute to human resource development departments in implementing strategies to identify, recruit, train, and to retain qualified 
Black nurses for leadership positions. Fifth, findings help to uncover possible prejudicial policies in healthcare organizations regarding the promotion of Black female nurses and other minority nurses to leadership positions. Study findings provide support for institutional policy changes in the selection and the promotion of Black nurses to executive positions.

\section{Definitions of Terms}

The following terms were defined as follows for use in this study:

Black. Black refers to individuals who identify themselves as Black or African American.

Career. A career is “the sequence of a person's work-related activities and behaviors and associated attitudes, values, and aspirations over the span of one's life” (Gutteridge, 1986, p. 55).

Career development. Career development denotes how individuals manage their careers within and between organizations and how organizations structure the career progress of their members. Career development is "the total constellation of psychological, sociological, educational, physical, economic, and chance factors that combine to influence the nature and significance of work in the total lifespan of any given individual” (Gutteridge, 1986, p. 52).

Healthcare organization. Healthcare organization refers to a facility that provides acute care and treatment to the sick, primarily hospitals that are accredited by the Joint Commission on Accreditation of Healthcare Organizations (JCAHO). Joint Commission on Accreditation of Healthcare Organizations. JCAHO is an independent not-for-profit organization that accredits healthcare organizations. 
Mentor. A mentor is an individual who serves as a trusted counselor or guide. A mentor may serve in informal settings, such as leisure-related venues, or formal settings, such as worksites.

Mentoring. Mentoring is a teaching or helping relationship between an individual and a mentor. Mentoring, in this study, involved any individual who acted as a sponsor for the participant, providing access, protection, training and development, and coaching as well as challenging work assignments.

Minority. Minority refers to a group of people who differ racially, ethnically, or politically from the larger group of which it is a part.

Nurse executive. Nurse executive is a general term used to identify the nurse administrator who holds the highest level of nursing leadership in a healthcare organization. The nurse executive is considered part of the healthcare organization executive team, with responsibility for strategic planning on behalf of the nursing division. Titles include vice president of nursing, chief nurse executive, and chief nurse officer.

\section{Assumptions}

Three assumptions grounded this study. First, it was assumed that the leadership roles of nurse executives with various titles were similar in scope. Second, it was assumed that the participants were knowledgeable about the duties and the functions of their positions. Third, it was assumed that the participants would respond honestly to all questions they were asked by the researcher. 


\section{Delimitations}

This study was delimited to a purposive national sample of Black female chief nurse executives in healthcare organizations. Topics explored with participants were confined to their experiences related to their career development. Research with this population was scarce; therefore, examination of the career development experiences of Black female chief nurse executives was sought.

\section{Summary}

The increasing complexity of the modern healthcare environment presents many challenges to nurse executives. One major challenge is the increasing leadership responsibilities of nurses (Byers, 2000; Phelps, 2005), as well as the demand for more nurse leaders (Georges, 2004). In nursing, as well as in any other industry, effective leaders are necessary for successful administration and development (Erickson \& Ditomassi, 2004). In addition, with the increasing national diversity in racial and ethnic groups, minorities are greatly underrepresented in the positions of both nurses and nurse leaders (Worth, 2004). This is true especially with regard to Black nurses and nurse leaders (U.S. Department of Health and Human Services, 2004). Female Black nurses and nurse leaders face the dual challenges of sex and racial discrimination in the workplace.

With the current increasing patient diversity, Black female nursing executives are needed to reflect the nation's diversity and to ensure culturally competent care. However, at present, the percentage of White nurse executives far exceeds that of Black executives, despite recognition of the inescapable link between the number of minority professionals and the quality of minority healthcare (Sullivan Commission on Diversity in the 
Healthcare Workforce, 2004). With the rapid changes in healthcare, more Black female nurse executives are needed to help guide diverse patient care, influence policy, and to mentor younger nurses (Steefel, 2006). However, the lack of diversity at the nurse executive ranks continues to be a concern for nursing as the profession strives to meet the expectations of stakeholders, employees, and patients.

The researcher's credentials to conduct this study come from two arenas. First, the researcher had completed advanced graduate coursework in research, organizational theory, adult development, and human resource development in preparation to conduct dissertation research. Second, the researcher brought her personal experiences as a nurse leader. This study was important to the researcher as a former nurse leader with aspirations of becoming a nurse executive. The researcher's experience as a nurse leader thus became the impetus for this study. The researcher was interested in learning how Black individuals have made it to the top of the nurse executive ladder.

Chapter 1 includes the statement of the problem, the purpose of the research, a brief overview of the theoretical perspectives, definitions of key terms, delimitations of the study, and the significance of the study. In chapter 2, literature is reviewed and critiqued in the following areas: career development theories, the role of mentoring, women, Black and minority career development, and leadership and nurse executive career development.

Next, in chapter 3, the design of the study is described, in addition to procedures for data collection and methods of data analysis. Findings for each research question are reported in chapter 4 . In chapter 5 , findings are discussed and interpreted in the context of the literature. 
Recommendations that are derived from the findings are related to facilitating the career development of Black nurse executives in healthcare organizations, human resource development. Finally, future research is discussed 


\section{CHAPTER II}

\section{REVIEW OF THE LITERATURE}

The preceding chapter provided the background and established the need for this study, which was designed to investigate the career development of Black female chief nurse executives. The chapter provides a review of the literature critical to the study. The chapter is divided into the following sections: (a) general career development theories, (b) theories of career development of women, (c) race theories, (d) overall barriers to the career development of women, especially minorities, (e) mentorship, (g) nurses' acquisition of leadership qualities, and (f) needs and strategies of nurse executives. A summary concludes the chapter.

General Career Development Theories: Super

Career development theories have been criticized for their lack of applicability to minorities and women (Alfred, 1995; Cook, Heppner, \& O’Brien, 2002; Kerka, 2003; Leong, 1995). Many contemporary career development theories are derived from the study and observation of White heterosexual males conducted in an era when expectations were low for women's career development. In these studies, the role of the man in attaining his career goals was emphasized over the ecological perspective of life experience, family, community, and society in shaping career development (Cook et al.). There continues to be a lack of theoretical focus on the career development of minorities, in general, and women specifically. Although contemporary theories do not address all the needs of women and minorities, neither does a single worldview of their career development. Therefore, multiple theoretical perspectives formed the foundation for this study. 
Super’s (1990) lifespan, lifespace approach extended Ginzberg’s (1972) developmental theory of three broad life stages from childhood to young adulthood (fantasy, tentative, and realistic) by arguing that career development extends beyond young adulthood and continues throughout an individual's lifespan. Super's theory is broad and encompasses career development "taken from developmental, differential, social, personality, and phenomenological psychology and held together by self-concept and learning theory” (p. 199). Super posits five general stages, growth, exploration, establishment, maintenance, and decline, with transitional minicycles between one stage to the next. At the same time, the succession of stages is not linear but recursive.

Super's (1990) initial stage, the growth stage, occurs from birth to 14 years of age. At this stage, children establish identities, have an awareness of their abilities, and explore their environment. In the second stage, exploration, which occurs between 15 and 24 years of age, the individual examines career options and faces essential developmental tasks, crystallization, specification, and implementation. In crystallization, the individual begins to formulate and to plan a career path. With specification, the individual narrows career goals, objectives, and choices. Education and training prepare the individual for the vocation implementation.

The third stage, career establishment, takes place between 25 and 44 years of age and is characterized by the individual's gainful employment. During this stage, stabilization, consolidation, and advancement tasks occur (Super, 1990). Stabilization reflects the individual's ability to settle down in the new role, perform work to validate the career choice, and to use the knowledge, skills, and abilities acquired in performing this role. Next, the individual consolidates this role and finally has the opportunity for 
advancement. The fourth stage of Super's (1990) theory, the maintenance stage, takes place between ages 45 and 64 . During this stage, the individual seeks to maintain the chosen career through the tasks of "holding on, keeping up and innovating” (Patton \& McMahon, 1999 p. 46). Finally, the disengagement stage takes place at 65 years and older. This stage is identified as a period of planning for retirement, reduced workload, and looking toward a future of greater leisure and possibly pursuit and development of hobbies (Super, 1990).

Central to Super's (1990) theory is the concept of self, which informs and influences career choice in both vocational identity, the traits individuals bring to a vocation, and occupational self-concept, the personal meaning individuals ascribe to their traits. According to Super, perceptions of self change over a lifetime and are a reflection of one's personality, needs, values, and interests. The process for developing self-concept occurs through role-playing, exploration, reality testing, and self-differentiation, all of which are enhanced through interaction with the community, school, family, and peers. Additionally, Super's theory includes 14 propositions created from several fields of career development, encompassing psychology, developmental, and learning. These propositions reflect the value of the collective views in creating a career development theory (Patton \& McMahon, 1999). For example, of importance to this study was the proposition that people differ in their abilities, needs, values, interests, traits, and selfconcepts. The nature of career pattern involves the occupational level attained and the sequence, frequency, and duration of trial and stable jobs. Career patterns are determined by the individual's parental socioeconomic level, mental ability, education, skills, personality characteristics, career maturity, and the opportunities to which he or she is 
exposed. Super's (1990) theory has been praised for its adaptability and flexibility of use by career counselors. Super was among the first career development theorists to recognize career issues unique to women. His theoretical stages apply equally to women and men and can be extremely useful for understanding career development. However, this theory has been criticized for its lack of research on racially and ethnically diverse and lower socioeconomic status populations (Trusty, 2002). Nevertheless, Super’s lifespan, lifespace approach is a well-respected overall career development theory.

Thus, the general career development theories reviewed in this chapter applied, in an overall sense, to minority women's career development. However, because the theories have been formulated primarily from samples of White androcentric males, these theories are lacking in important gender-specific aspects that must be considered. Consequently, the next section focuses on theories concerning the career development of women, an area more pertinent to the specific purpose of this study.

Theories of Career Development of Women: Gottfredson

Among the many theories and conceptual frameworks that have arisen in the last 2 decades with regard to women, Gottfredson’s (1981) developmental model addresses the role of gender in career aspirations and career development. Using Super’s (1990) theory as a framework, Gottfredson, like Super, identified stages and substages of career development. This theory, unlike Super's, encompasses processes of circumscription and compromise relevant to both genders.

Gottfredson (1981) defined self-concept, included in the stages of circumscription, as composed of gender, social class, intelligence, interests, and values. Self-concept and knowledge of the world of work influence and determine one's 
occupational preferences. Moreover, in this theory, perceptions of opportunities and barriers to careers are considered.

Gottfredson’s (2005) stages of compromise and circumscription are concerned with individuals" career development and aspirations. Compromise is defined as "the process by which they begin to relinquish their most preferred alternatives for less compatible but more accessible ones," and circumscription is defined as "the process by which children progressively eliminate from consideration occupations they think unacceptable to themselves” (Gottfredson, p. 82).

Gottfredson's (2005) concept of circumscription is especially important in career choice and development and encompasses two types of orientation, to size and power and to sex roles. The first type, orientation to size and power, occurs at 3 to 5 years of age. At this stage, children begin to distinguish between adults and children, and they make the basic distinction that adults work. The second type, orientation to sex roles, occurs at 6 to 8 years of age. In this stage, children are able to identify socially appropriate occupations based on gender. Between 9 to 13 years of age, children think more abstractly; recognize the link between education, occupation, and income; and become more aware of status. Finally, in the fourth stage, occurring at age 14 and older, adolescents focus on their identity. In this stage, they decide on acceptable career alternatives in terms of personal preference and accessibility (Gottfredson, 1996, 2005; Patton \& McMahon, 1999).

Gottfredson’s (2005) compromise stage involves influences by family and friends, finances, time, and accessibility. Additionally, one's ability to identify and to investigate opportunities for jobs and training and "personal traits that encourage exploration" (Gottfredson, p. 84) influence the choice of career. Overall, Gottfredson's theory has had 
mixed results in testing its theory for applicability to career development of women and minorities. Fouad and Byars-Winston (2005) conducted a meta-analysis of 16 studies on the role of race or ethnicity on the cultural context of career choice, which included an analysis of Gottfredson's theoretical model, and found that there were no significant influences of race or ethnicity on the career aspirations of individuals. However, Gottfredson’s model is highly appropriate for women, especially because of its concepts of circumscription and compromise as relating to socialization and sex roles. Moreover, Fouad and Byars-Winston noted that the factors of race and ethnicity should be included in assessing the context in which individuals make career decisions. Thus, for the proposed study, it was important to consider several race theories that have evolved from the Black struggle for equality.

\section{Race Theories}

A number of race theories exist that pertain to Blacks, and each has varying applicability to the present study. Although no theory directly addresses the proposed study population, several theories will be briefly reviewed first. Then a more intensive review will take place of critical race theory, the theory most appropriate to a study of the career development of Black female chief nurse executives. In this regard, Trusty (2002) stated that "the career-related perceptions and the vocational behavior of adult persons of color are inextricably tied to their previous experience” (p. 191).

Leong (1995) pointed out that most career development theories that have relevance for minority groups have excluded consideration of discrimination. Leong saw the need for this consideration to improve opportunities for Blacks and advanced that "facilitating the career development of African Americans may be one key to their 
economic, social, and psychological emancipation” (p. 8). Similarly, in a discussion on the career development of minorities, Alfred (2001) discussed the concept of “double consciousness” (p. 111), which was traced to sociologist and civil rights leader Du Bois (1903). Du Bois observed that the history of Blacks in America was one of strife and external and internal conflict in the struggle with Black and White consciousnesses. There is, nevertheless, a longing, wrote Du Bois:

To merge his double self into a better and truer self. In this merging he wishes neither of the older selves to be lost. He would not Africanize America, for America has too much to teach the world and Africa. He would not bleach his Negro soul in a flood of White Americanism, for he knows that Negro blood has a message for the world. He simply wishes to make it possible for a man to be both a Negro and an American, without being cursed and spit upon by his fellow, without having the doors of opportunity closed roughly in his face. (p. 9)

Du Bois (1903) used the writing conventions appropriate to early $20^{\text {th }}$ century writers, although today's $21^{\text {st }}$ century researchers and theorists would undoubtedly use personal pronouns that also signify the female gender.

However, it is clear that Du Bois (1903) did not advocate separatism but saw advantages to both races working together, with each supplying what the other lacked. Du Bois declared that the races must aid each other and strive to reach "that vaster ideal... of human brotherhood, gained through the unifying ideal of Race, the ideal of fostering and developing the traits and talents of the Negro” (p. 14). This development would not be in opposition to or disdain for other races, "but rather in large conformity to the greater ideals of the American Republic” (Du Bois, p. 14).

Based on this double consciousness perspective, Cheatham (1990) proposed a model specifically based on the concept of Afrocentrism. Cheatham suggested that the relationship and differences between Black culture and dominant European American 
culture, and their inherent dualism, must be taken into account in examination of Blacks' career development (Patton \& McMahon, 1999). Some of these differences, which engender discrimination against Blacks, include values of affiliation, interdependence, and work. These factors are addressed in critical race theory.

Critical race theory is particularly applicable to this study because it offers a description and an explanation of how Black women's lives are shaped in today’s world as they struggle with racism, oppression, and injustices on both personal and professional levels. The theory provides a relevant context for understanding the role of race in the career development of Black female chief nurse executives.

Critical race theory encompasses a broad view in which to explore the career development and experiences of Black female chief nurse executives. With roots in Du Bois’ (1903) writings, critical race theory began in the mid-1970s and was first developed by legal scholars Bell and Freeman in the post-civil rights era protesting the slow pace of social reform (Bell, 1992; West, 1995). As the majority White worldview continued to frame the major discourse of society, critical race theory addressed the lack of applicability of existing laws to deal with social injustices, including the roles of race, racism, and inequalities affecting Blacks.

Critical race theory (CRT) is built on three basic premises. Racism, the first premise, is seen as normal and is part of the national social fabric. The subtitle of Bell's (1992) groundbreaking volume, The Permanence of Racism, encapsulated this premise. Because racism is so enmeshed, it is a permanent aspect of Western culture, and the strategy and goal of CRT is to expose racism in all of its variations. The second premise is that the majority group supports advancement for Blacks only when the group also 
advances the causes and the interests of the majority group (Bell). This phenomenon is described as a "convergence of interests" (Dudziak, 2000, p. 107). CRT holds that race, power, and privilege are interconnected, providing an explanation and frame for the majority group that has power and how that power is exerted. Black female nurse executives, by virtue of their very small proportions in executive roles, provide an example of the validity of CRT assertions in healthcare institutions. These proportions are representative neither of the nursing profession nor of the diverse client populations (Coleman, 2006; U.S. Department of Health and Human Services, 2004).

The third premise, storytelling, provides an important format for the ongoing exploration, understanding, and discourse of and about racism. Delgado (2000) emphasized how storytelling, or extended narratives, by those who have experienced the many layers of oppression, can illuminate both obvious and subtle aspects of racism. Storytelling provides a forum to share and to build consensus and deeper meaning about the injustices and inequalities affecting minorities. As Taylor (1998) pointed out, one way to challenge the dominant societal mindset, "the shared stereotypes, beliefs, and understandings” (p. 122), is the telling of stories, which may not only challenge the status quo but may also help to build consensus and to create communal understanding. LadsonBillings (1998) observed, "Stories provide the necessary context for understanding, feeling, and interpreting” (p. 13). It is through the heartfelt telling of stories that others come to understand the duress and the hardships imposed by racism on Blacks in U.S. society. Storytelling is a way of "naming your reality" (Ladson-Billings, 1998, p. 13) that can engender camaraderie and can galvanize action toward breaking the stereotypical barriers. 
Isaksen (2000) advocated using the perspective of the storytelling aspect of CRT in student composition classes, encouraging students to write their personal narratives, even in their native language or dialect, "to negotiate the issues of race and racism both in and out of the classrooms” (p. 2). For the present study of Black female chief nurse executives' career development, the storytelling aspect of critical race theory is a powerful tool that provided, as with the Black female university educators in JeanMarie’s (2006) study, “an opportunity to hear voices rarely heard within the public domain” (p. 92).

Thus, a number of race theories offer particularly appropriate lenses through which to examine the career development of Black female chief nurse executives. Beginning with Du Bois’ (1903) “double consciousness,” race theories recognized the dichotomous position of Blacks in American society. Cheatham (1990) was one of the first to apply this perspective to career development, and critical race theory must especially be considered in an exploration of Black female chief nurse executives' career development. This theory must also be considered in the examination of barriers to the career development of women and minorities.

Overall Barriers and Facilitators to Career Development of Women and Minorities Race theorists have added to the knowledge base indicating how Black women experience the world differently from White women. For example, Byrd-Blake (2004) and Constantine and Greer (2003) revealed differences in cultural, contextual, social, behavioral, and linguistic factors. Nevertheless, it is also worth noting that Cook et al. (2002) recognized that women of color face racial discrimination, and both women of color and White women face gender discrimination, which "has created social, 
psychological, institutional, political, and economic barriers that seriously erode the actual control many individuals have over career choice and satisfaction” (p. 292). These barriers include pay discrepancies, sexual harassment, underutilization of talents, and the costs of financing careers.

Barriers to career development of women and minorities were noted as early as 1995 with the Federal Glass Ceiling Commission (1995) report. This report identified several major barriers to the advancement of women in organizations, including (a) lack of active recruitment of women and minorities, (b) corporate climates which eliminate and isolate women, (c) lack of mentoring, (d) lack of management training, (e) lack of visibility on major committees, and (f) lack of opportunities for career development. Since this report was published, many studies of women and minorities have indicated that, although career paths may be varied, barriers remain.

For example, Madsen (2007a, 2007b) conducted a qualitative study of 10 female U.S. university presidents' career paths and educational backgrounds. Eight of the participants were White, and two were Black. The purpose of the study was to explore the lived experiences of women university presidents in developing their lifelong knowledge, skills, abilities, and competencies for success in higher education leadership. In-depth interviews revealed that drive, a desire for continuous learning and development, and the ability to manage challenges and changes were characteristics of these leaders. The results also showed that most women did not overtly seek leadership positions, and their career paths to leadership were nonlinear. Barriers experienced by Black and White participants included lack of mentors, unwillingness to sacrifice their lives for their careers, and creation of their own opportunities for advancement. 
Women leaders, although not university presidents, were the participants in a qualitative study of 20 women conducted by Whitmarsh (2007). This study addressed the career planning, career decision making, and work history of women in both femaledominated and gender-neutral careers. The participants were teachers and social workers in the female-dominated group, and physicians, attorneys, and professors in the genderneutral group. All participants were identified as in the maintenance stage of Super's (1990) stages of career development. The results indicated that women in the femaledominated group experienced positive reinforcement for their careers from family members, and those in the gender-neutral group experienced support and mentoring from outside the family. The participants in the female-dominated group did not identify any significant obstacles to career advancement; however, the participants in the genderneutral group identified several obstacles to career progression, including lack of skill development and learning opportunities and having to deal with sexual harassment.

Both groups of women, in the Whitmarsh (2007) study, but especially those in the gender-neutral group, reported that they made extensive personal compromises regarding their career advancement. For example, one participant gave up her career as the first female faculty member in her department in order to support her husband's relocation. Another did not accept an offer for partnership because her husband expressed dislike toward her prospective partner. These admissions concur with the compromise aspect of Gottfredson’s (1996) career development theory, in which, "as individuals often discover, when the time comes ... they will be unable to implement their most preferred choices” (p.187). 
Gender issues also were revealed by Mayer (2001) as a factor in the career progression of four women directors in the Cooperative State Research Extension Education Service (CSREES). The purpose of the study was to determine the major influences and experiences which helped and hindered women in CSREES from becoming directors. Although not every participant identified with every theme, four major themes emerged from the study that impacted the career advancement of these four women: (a) organizational factors, (b) the importance of networks and relationships, (c) recognizing opportunities, and (d) gender issues. The gender issues especially affected the career paths of the participants. As Mayor concluded, "They had entered a primarily male-dominated field and in most states had to break a long held tradition of men only in top leadership positions” (p. 3).

Another barrier to the career development of women is the glass ceiling effect. McDonald and Hite (1998) reported on dialogues with business students in the discussion, recognition, and understanding of the ramifications of the glass ceiling effect, which was viewed not as a feminist issue but as a business strategy. The students showed understanding and occasional misconceptions about the glass ceiling but recognized how business could profit from its elimination. As a result of these dialogues, McDonald and Hite hoped to develop strategies to build awareness of the glass ceiling and to eliminate its existence through videos, readings, experiential activities, and panel discussions to build awareness of the issue.

The researchers pointed out that continuing to learn about what is important to women in the workforce and how organizations can develop the knowledge and the skills of qualified women is of paramount importance. Women who can contribute to the 
growth and the development of an organization and its employees should not be excluded from positions of leadership.

Barriers to career development in nursing were reported by Mayor (2004) in a study conducted to determine how 88 successful Black, Asian, and Caribbean nurse managers engineered their careers and overcame social and political barriers to success. The Black participants stated that evidence of racism in nursing existed and that "they were more likely to experience the glass ceilings as their careers moved to the higher grades” (Mayor, p. 104). Mayor found a clear relationship among race, class, gender, and personal characteristics that shaped the career development of all participants. Because of this relationship, Mayor recommended that education and training to eradicate racism be offered at the individual, professional, and organizational levels.

Career development of Black and other women were studied from a feminist perspective by Byrd-Blake (2004). Byrd-Blake used a feminist methodology to study the career advancement of Black, Hispanic, and White female school administrators. Barriers to the career development of Black women included (a) lack of formal mentors, (b) lack of challenging assignments, (c) greater commitments to family than to occupation, and (d) greater personal responsibility compared with those of White women.

Similar to studies of Black women, Kuo-Rice's (2005) conducted a qualitative study of the career experiences and career development among Chinese American professional women and found that a number of parallel factors influenced their career development and decisions. These factors included their life experiences, culture and gender issues, language and cultural barriers, family-career conflicts, challenges of work demands, fewer promotions, and the glass ceiling effect. Likewise, Kerka (2003) and 
Mathis (2001) studies showed that barriers to career advancement by women of color included not having an influential mentor or sponsor, lack of informal networking with influential colleagues, lack of company role models who are members of the same racial or ethnic group, and lack of high visibility assignments.

Studies of women in nursing have yielded similar findings. The American College of Healthcare Executives [ACHE] (2002) reported on seven factors which healthcare executives identified as barriers to career development. These included (a) the so-called “good ole boy” White network (i.e., a known but not publicly acknowledged affiliation of men who are White), (b) racism, (c) cultural differences, (d) lack of education, (e) lack of organizational initiatives , and (f) lack of mentors. Moreover, Black women cited racism and prejudice as the major reasons for lack of advancement in their careers. A Black female respondent stated, “As an African American female having to come up through the ranks, it's difficult to assimilate into the executive healthcare community when you are playing 'catch up'” (ACHE, p. 8). As this respondent indicated, when positions become available, minorities are often left out of the professional network because they do not live in the finest neighborhoods and cannot afford to mingle at entertainment and sports functions. However, another respondent observed that Blacks who demonstrate competence and socialize with the majority race are recognized and promoted within their organizations.

Additional barriers have been identified by other researchers. In a study exploring barriers to women's progression into nursing management in the National Health Service, Lane (1998) found that having dependent children, lack of part-time roles in nursing management, and lack of continuous employment were barriers to career advancement. 
Further, the phenomenon of "management inertia" can adversely affect a woman's career development, defined as a manager's lack of action in hospitals "with regard to developing 'family friendly' initiatives which would enable women to advance through organizational career hierarchies” (Lane, p. 184). Other researchers found that men or women without children were more likely to advance to the highest levels in nursing. In the study by Courtney (2001), nurse executives identified three major barriers to career development: lack of time, access, and proper support. In other studies, gender and divorce were also cited as significant barriers (Lane; Moran et al., 2002).

Some of the studies reviewed in this section were qualitative in nature (Kuo-Rice, 2005; Madsen, 2007a, 2007b; Mayer, 2001; Whitmarsh, 2007), and others were quantitative (ACHE, 2002; Courtney et al., 2001; Lane, 1998). The results of both types of studies showed, researchers can agree on the barriers to career advancement of women. Independent of the type of the research design, and across large and small numbers of participants, the results of these studies over a 10-year span revealed that although the precipitators of career paths may have been different for the women studied, the barriers were strikingly similar. Thus, the barriers to career advancement of women and minority women seem to be fairly constant to date and to include ostracism from established networks, lack of mentoring, little opportunity for training, and exclusion from career advancement because of ethnicity and gender.

As this review has shown, women, in general, continue to struggle to achieve executive positions. Bass and Avolio (1994) stated that although women may make better managers than men, they are faced with the glass ceiling barrier. For women of color, Constantine and Greer (2003) noted, “African American women may face intense 
struggles and challenges within work settings because their professional experiences

often take place in the context of racist and sexist environments” (p. 43).

Minority Women in Nonnursing Professions

Several studies have examined both the barriers and the facilitators of career development in minority women in various professions, and such studies may form the basis of identifying similar factors for Black women in the nursing profession. Wentling (1992) conducted a study of women in middle management which included their career development, aspirations, and perceived barriers and facilitators to their successful advancement. Thirty women in middle-level management positions in 15 Fortune 500 companies in the Midwest were interviewed. The research interview guide focused on eliciting responses to the factors that facilitate and hinder career development, career goals and aspirations, perceived barriers to attaining desired positions, and actions believed necessary to attain desired positions. Factors that facilitated career development were educational credentials, hard work, mentors, interpersonal skills, competence on the job, and willingness to take risks. Conversely, factors that hindered career development were managers who withheld guidance and encouragement, sex discrimination, lack of political savvy, and lack of career strategies. Additionally, for Wentling's respondents, the barriers to attaining aspired positions were competition, family obligation, being a woman, and unwillingness to work hard.

In an exploration of the pathways to leadership for women chief executives, Riley and White (1994) interviewed 15 female chief executives of local authorities in England from boroughs, metropolitan districts, and councils. Interviews were conducted with participants and staff, and the participants also completed a 7-day leadership and 
management diary. Analysis of the interviews and diaries showed that many of the respondents had experienced major barriers to career advancement, including discrimination, failure of men to recognize their authority, and not being promoted to positions for which they were more qualified than their male colleagues. However, several participants indicated that they perceived no barriers to their career advancement. Nevertheless, the women all viewed support and encouragement from their "women friends” (Riley \& White, p. 42) as crucial to their success.

Another study of businesswomen in corporate management, by Mathis (2001), examined the expectations, experiences, and perceptions of Black, Asian, and Hispanic women in 30 major U.S. corporations. The results showed that the women favored and recognized targeted hiring practices to increase diversity and respect for persons of different cultural backgrounds, adequate training of managers, and promotion of women of color to senior leadership positions.

Racial and gender interactions in relation to leadership characteristics were explored by Waring (2003) with 12 Black college presidents. The results of this qualitative study indicated that the issue of race was a major hindrance in the presidents’ career advancement. The college presidents identified as key characteristics for leadership and facilitators of advancement, their ability to be decisive, practice effective communication skills, and to build relationships.

Black women attorneys were the participants of Simpson’s (1996) quantitative study to examine how the women's careers developed and the ways in which gender and race shaped their career development. A self-report questionnaire was administered to 238 bar-certified Black female lawyers throughout the United States. The results showed 
that although affirmative action policies had increased the number of Black women lawyers, a "plexiglass ceiling” (Simpson, p. 176) limited their career choices. That is, promotion and job advancement were based on the ability to fit in with the predominant White culture. The results also revealed that Blacks had disparate experiences with regard to discrimination, which led to intragroup differences. As Simpson pointed out from these results, there should be no presumption "that every African American is aware of or has had experience managing either racism or sexism” (p. 186).

Professional women were also the focus of a study by O’Neil, Billmoria, and Saatcioglu (2004) with 137 women who were predominantly White (86.6\%) and were participants in MBA and executive education seminars at a Cleveland, Ohio, university. The purpose of the study was to investigate two career constructs, career locus, and career patterns. O'Neil et al. believed that these two career concepts described the inner psychological orientation and outer sociological path, respectively, of career development. The career development theories used to guide the study were Bandura's (1997) theory of self-efficacy and Hall’s $(1996,2002)$ protean career, in which the individual, not the organization, is responsible for career advancement. The study revealed three distinct career types: (a) achievers who have predominantly ordered careers and an internal career locus (that is, self-determined); (b) navigators, those who have had ordered careers and an external career locus (that is, determined largely by others' expectations); and (c) accommodators, those who have emergent careers and a career locus between external and internal. Additionally, the study examined women's career patterns and the impact of career patterns in relation to satisfaction with their career success. The results indicated that, overall, women identified as accommodators 
had lower career satisfaction than achievers and navigators. Thus, for these participants, facilitators to career development were the availability of mentors, the organization's investment in their education, and ongoing training and development. For achievers, facilitators were income and promotions. For navigators, facilitators were marriage, children, and organization (O’Neil et al., 2004).

Facilitators of career development were identified by Wilson (2004) in a qualitative study of nine senior-level Black women working in community and technical colleges in the Southeast United States. The major research question of the study was, What factors played a significant role in the career advancement of these women? The results revealed two major facilitative factors, professional development opportunities and support system. In addition, “double jeopardy” (Wilson, p. 104) experiences, such as being Black and female, had both a dual impact on their career development. Several participants indicated that, although they may had been given special opportunities because of their gender and race, they had to constantly prove themselves and that gender and race issues had both a negative and a positive impact on their career development. Minority Women in Nursing

The career development of nurses, especially female minority nurses, has also been studied by various researchers, with a focus on both facilitating and hindering factors. Moran et al. (2002) found, in their study of 205 nurse managers, that the nurse managers' careers were shaped by both positive and negative experiences, and, in many cases, career progression was unplanned. In addition, similar to Lane’s (1998) findings, facilitators of career advancement were family support and lack of children. 
In Bessent's (2002) national study of minority nurses who were members of the American Nurses Association (ANA), respondents were asked whether they felt that they were denied a promotion because of race or ethnicity. In response, 59\% of Black respondents, 53\% of Asian-Pacific Islander respondents, and 46\% of Hispanic respondents answered affirmatively. Additionally, $44 \%$ of all respondents cited educational, institutional, personal, and professional obstacles as barriers to their career advancement.

Facilitating factors and barriers were also the focus of a study of minority nurse executives by Villarruel and Peragallo (2004). These researchers conducted a descriptive, open-ended written study which examined the hindrances and encouragers in the development of 23 Hispanic nurse leaders. The major barriers to leadership included the need to prove oneself, expecting to work harder than others, awareness of one's speech patterns and accent, and lack of confidence. The major facilitators were the presence of mentors and role models and the ability and opportunity to represent one's community. Additionally, the creation of career development ladders, furthering one's education, and identifying potential leaders for development were seen as keys for the development of Hispanic nurse leaders.

Van Dyke (2006) interviewed five minority nurse leaders, three Blacks, one Filipino, and one Hispanic on their career development. One of the Black leaders was vocal about minority discrimination of Black nurse leaders. Arneatha Martin, RN, MSN, ARNP, is CEO and co-president of the Center for Health and Wellness, a healthcare center serving the predominately Black community in northeast Wichita, Kansas. Nurse Martin (as cited in Van Dyke, 2006) commented, “I think for a lot of minority 
professionals, there's not just a glass ceiling at the top-it's more like a cement ceiling. After you hit your head on that cement too much, it starts bleeding” (p. 1). Additionally, all five nurse leaders identified several facilitators of their career development, including risk-taking, strong education, avoiding excuses, and volunteering for additional assignments. They also identified three barriers to their career development, that is, lack of mentors, invisibility, and feelings of alienation and isolation.

These findings were corroborated by Seago and Spetz's (2005) results of their cross-sectional, descriptive, correlational study which investigated the advancement of minorities in nursing. The primary research question was the following: Is there discrimination? The study was funded by the Discrimination Research Centers and the Impact Funds and the University of California San Francisco (UCSF) Center for California Health Workforce Studies. The number of participants was not reported; however, the participants were minority nurses in California, and the sample was comprised of 42\% Asian Americans, 30\% Whites, 14\% Blacks, and 12\% Latino nurses. The results indicated that although more Blacks applied for promotions than other groups, they were more likely to be denied the promotion, even if equally qualified as the other candidates. Further, the report indicated that favoritism and racism were contributing factors to denial of promotion.

Seago and Spetz ‘s (2005) study yielded similar results to Mayor (2004). Moreover, Seago and Spetz made analogous recommendations: (a) to ensure that race and ethnicity are spoken issues in the workplace and that there is fair treatment of all employees; (b) to develop and enforce accountability standards for racial discrimination in nursing; (c) to reduce social isolation of minority nurses by development of support 
systems in the workplace; (d) to partner with nursing associations; and (e) to develop environments that promote diversity. However, because this study was funded by the Discrimination Research Centers and was limited to one geographic location, the results and recommendations should be viewed with caution.

In summary, studies of barriers and facilitators for women and minority women in nursing and various other professions indicated that discrimination, because of gender and race, was a major barrier to career advancement (Bessent, 2002; Mayor, 2005; Moran et al., 2002; Seago \& Spetz, 2005; Van Dyke, 2006; Villarruel \& Peragallo, 2004; Wentling, 1992; Wilson, 2004). Further, the results of these studies identified other barriers, such as uncooperative senior staff, lack of training, lack of career strategies, family obligations, and lack of self-confidence. Facilitators included family support, personal and professional support systems, adequate training and professional development opportunities, interpersonal skills, education, competence, mentoring, and role models. Although these studies explored the perceptions of career barriers and facilitators of women and minority women professionals from various standpoints, none of the studies specifically targeted the subject of the proposed research. This study was an exploration of the barriers and facilitators in the career development of Black female chief nurse executives.

\section{Mentorship}

In the above studies, mentoring was frequently cited as an important factor in the facilitation of career development (Villarruel \& Peragallo, 2004; Wentling, 1992; Wilson, 2004). Within nursing, the chief nurse executive position has emerged as one of the most influential positions in healthcare organizations. To benefit nursing and healthcare for all 
stakeholders, nurse executives must build relationships not only with other nurses but also with other members of the healthcare team. Nurse executives must have the required knowledge, skills, and abilities to act effectively and to implement necessary improvements in this ever-changing environment (Fressola, 1998; Georges, 2004; Huff, 1998).

Mentoring is a primary means for training nurse executives and an essential strategy for leadership development (Fressola, 1998). The research literature emphasized the positive socialization experiences that are fostered within the mentor relationship. For example, starting in college, Black students require access to role models of the same race and gender (Constantine \& Greer, 2003; Mathis, 2001). Especially for Black female students who aspire to nursing leadership positions in the current shortage, role models serve as reminders that, despite the many barriers to career advancement, they can still reach their goals of leadership positions (Goodin, 2003).

Not only are college role models scarce, but excellent mentoring is often absent in healthcare organizations (Phelps, 2005). Harms (1988) found that the variables influencing leadership development among presidents of selected nursing organizations revealed that parents, who were generally female, were the most influential mentors in the participants' lives. In a study examining the benefits of mentoring relationships among managerial and professional women, Burke and McKenn (1997b) established that approximately $70 \%$ of the participants had access to a developmental relationship defined as mentorship. Women professionals and managers who received more mentoring reported greater career satisfaction. However, these researchers noted that women may benefit less than men from mentor relationships. Contrary to other studies, these 
researchers discovered that higher income, career advancement, and job satisfaction were likely to be influenced by factors other than mentorship. Similarly, with a sample size of 137 executives, Courtney et al. (2001) determined that more than $40 \%$ of respondents were dissatisfied with the quality of mentoring provided to nurse executives, as well as to their opportunities for promotion. These results led Courtney et al. to conclude that organizations must play a larger role in creating opportunities for developing mentoring relationships.

Mentoring in relation to leadership and career progression was studied by Moran, et al. (2002) with nurse managers in Australia. In their quantitative study, 205 nurse managers completed a self-administered questionnaire. The findings pointed to the critical role of mentors in career advancement. Additionally, the study results showed that managers developed leadership skills randomly, and consequently a need existed in organizations for the implementation of structured leadership development.

In corroboration, according to one nursing executive in the ACHE (2002) study, in the first years of their careers, minority employees who enter the healthcare field are less likely to have important and well-placed mentors than nonminority employees. In the ACHE study, most of the minority women had White males as mentors, which many of the female nurse executives viewed as a detriment. As one respondent commented, "The average White person is totally clueless as to how past circumstances of African Americans still affect the present and the future” (p. 20). Many respondents expressed that the lack of mentors of the same race and gender placed minority women at a disadvantage in their career development. 
Cook et al. (2002) pointed out that while women of color can benefit from mentoring from those of the same race, "Whites should not neglect opportunities to mentor people of color” (p. 302), especially when Blacks are the first of their race to serve in a specific leadership position. Phelps (2005) strongly recommended formal mentoring programs to develop nurse leaders.

In addition, as Woods (2006) found, the mentoring relationship can be viewed not only as a vehicle for career progression but also as a method for learning about leadership. Woods conducted an interview with Donna Thompson, a Black nurse who was promoted from certified nursing assistant (CNA) to chief executive officer (CEO) of Access Community Health Network, the nation's largest network of community health centers. Thompson discussed the value of mentoring on her career advancement. Based on her experience, Thompson observed that it was important to obtain mentors who can help nurses develop their competencies. Rather than turning only to other nurses for mentoring relationships, Thompson noted, "I tell nurses today that when you go into orientation look for the highest ranking nurses in the organization and look to them for inspiration” (Thompson, as cited in Woods, p. 3).

The role and the importance of mentoring was studied by Hill (2004) in a qualitative-quantitative sequential mixed-method study on the development of 47 Black nurse leaders, specifically deans of nursing programs. Using Levinson’s (1978) adult development theory, Hill administered mentorship experience surveys and conducted 10 in-depth semistructured interviews. The findings showed that mentoring played a significant supportive role in the development of these baccalaureate and graduate nurse leaders. Additionally, the study results revealed that $85 \%$ of the leaders were mentored 
primarily by females. Twenty-three percent of the leaders had at least two mentors, and several of the participants had between one and five mentors. The majority of the respondents, $65 \%$, admitted to having mentors of the same race who were nurse administrators, and 31\% had cross-race mentoring relationships with predominantly White mentors.

Several of the participants with a same-race mentor stated that their mentor fully understood the issues of discrimination, barriers to career advancement, hidden racism, and biases faced by the mentees. However, some participants believed that race was not integral to a mentoring relationship. This study was particularly important because it showed that some Black female nurse leaders did not need a mentor to advance in their careers. In fact, $15 \%$ of the participants had no mentors. Nevertheless, for those participants who had mentors, the mentors opened doors to opportunities and networking, shared knowledge, provided comfort and encouragement, encouraged learning, and offered protection (Hill, 2004).

These studies provided important contributions to the mentoring literature for professional and minority women. Additionally, the studies explored the role of mentoring in-depth, not only with regard to adult professional colleagues (ACHE 2002; Burke \& McKenn, 1997a; Hill 2004; Moran et al., 2002). However, these studies did not discuss the role of family and the community in the mentoring process. In the current study of the career development of Black female chief nurse executives, these mentoring relationships and their importance to the participants were explored. 


\section{Nurses’ Acquisition of Leadership Qualities}

Influential nurse leaders must be visionaries, change agents, policymakers, and strategic thinkers. They must possess the ability to adapt and to change in the current chaotic healthcare environment (Byers, 2000; Erickson \& Ditomassi, 2004; Georges, 2004; Phelps, 2005). Several studies have identified the qualities and the range of leadership skills that are necessary for nurse leaders to perform effectively. As nursing and healthcare organizations address the need for nurse executives, a key strategy is the development of nurse leaders who can be groomed for the nurse executive role.

Fressola (1998) conducted a qualitative study to investigate how nurses learned to become nurse leaders capable of managing in turbulent times. Twenty-three nurses with executive-level positions participated in the study, which involved a semistructured interview and review of critical incidents. The results showed that nurses learned to become leaders through learning from several means, especially experiences, relationships, and self-direction. In addition, the influence of managers, networking, continuing education, membership in professional organizations, and serving on hospitalbased committees all contributed to how nurses learned to be leaders.

Another qualitative study exploring how nurses became leaders was conducted by Allen (1998) with interviews of 12 nurse leaders. The study was grounded in the theoretical perspectives of Bandura’s (1997) social learning theory and the "Pygmalion Effect” (p. 18). The Pygmalion Effect refers to the expectations managers have of their employees and the employees acting accordingly (Eden, 1984). The relevance of the theory in this study is that managers, based on their expectations of their employees, have the ability to influence the employees’ career progression. Allen’s respondents identified 
five factors which facilitated their development as nurse leaders: (a) self-confidence, (b) innate leader qualities, (c) progression of experiences and successes, (d) influence of significant people, including their managers, and (e) personal life factors, such as the impact of family, hours worked, and physical limitations due to injury.

Further development and identification of important leadership characteristics were revealed in Lindholm, Sivberg, and Udén’s (2000) qualitative study of 15 Swedish nurse managers. Through in-depth interviews, the participants identified four key leadership competencies that promoted successful leadership. They were the abilities to (a) make decisions, (b) analyze, (c) argue, and (d) present measurable results.

In summary, these qualitative studies revealed important aspects of the leadership characteristics necessary for nurse executives. The studies used extensive interview protocols, adequate sample sizes, and rigorous methods to ensure trustworthiness, such as reporting of triangulation of data and member checks. However, no discussion was offered on the results of triangulation and member checks, or how bias was controlled.

In the study on Black female chief nurse executives, remedies for such gaps were addressed in four ways: (a) including and discussing the researcher's admitted biases, (b) member checks, (c) an audit trail, and (d) triangulation of data sources. In addition, the respondents were asked about the influence of possible role models in the development of their leadership qualities.

Needs and Strategies of Nurse Executives

Nurses and nurse executives generally recognize the qualities and the needs that will contribute to their career advancement. Courtney et al. (2001) found that nurse executives identified the specific career development needs of financial management, 
human resource management, and information technology. Strategies for meeting these needs included leadership, as well as organizational and communication skills training (Courtney et al.). In a study of the leadership practices and requirements of Veteran Health Administration nurse executives, Bieber (2003) pointed out that the four most needed and essential skills of exemplary nurse executives were (a) communication skills (b) interpersonal skills, (c) integrity, and (d) visionary skills.

In Mayor’s (2004) study, leading Black nurse executives in England identified strategies they used in their career development. After extensive interviews of approximately 2 hours each, followed by member checks and further discussion of interview material, Mayor's data analysis revealed three key strategies: (a) mimicking the career development of men, (b) self-funding of professional education and academic study, and (c) developing networking and social structures. In addition, the participants identified four solutions to decrease racism: (a) to develop education and to train to eradicate racism at the individual, professional, and organizational levels; (b) to challenge inequalities and discrimination so as to improve employment practices; (c) to help every individual in an organization to acknowledge his or her role in combating racism; and (d) to develop strategies so that "Blackness" is not used to explain differences in outcomes or experiences of individuals.

With recognition of the need for skill and competency development of nurse executives, the American Organization of Nurse Executives [AONE] (2006) identified five core competencies. The AONE created these core competencies as a guide for the knowledge, training, and skills required of nurse leaders and nurse executives. These competencies are communication and relationship building, knowledge of the healthcare 
environment, leadership, professionalism, and business skills. AONE has an explicit position statement on diversity and the issues of diversity and the need for a diverse workforce are embedded in the communication and relationship-building competency.

Relating to nursing organizations such as the AONE, Georges (2004) recommended development of Black nurse executives through the use of established racial and ethnic professional nursing associations. These nursing associations offer their members the opportunity to participate in leadership programs, which not only develop the required leadership knowledge, skills, and competencies but also facilitate networking and mentorship relationships (Georges). Additionally, strategies of Black women college administrators reported in Wilson's (2004) qualitative study could be adopted for career advancement. These include accepting ownership of one’s career, investing in self, staying spiritually grounded, and developing proficiency in interpersonal skills.

These studies pointed out the major needs and strategies necessary for successful and effective nurse executives. However, no study reported how the AONE competencies were developed. In some of the studies reviewed, the researchers failed to elaborate on the study methodology, calling into question the validity of the study results (AONE, 2006; Georges, 2004). In the current study, study methodology was thoroughly described and documented (see chapter 3). In addition, although the Black female chief nurse executives interviewed were limited in number, they were drawn from a national sample to increase transferability of findings. In-depth interviews with participants encouraged them to identify their experiences and strategies in their career development. With these descriptions, respondents were asked to advise Black female nurses and to recommend strategies for their advancement to leadership positions. 


\section{Summary}

As background and foundation for the study, this review of the literature identified career development and race theories that must be considered to understand the career development of Black female chief nurse executives. Further, this chapter reviewed studies on various facets of minority career development and nursing leadership. Barriers and facilitating factors were identified, and studies were presented that widely acknowledged race and gender as primary barriers for women in many professions, including nursing. In addition, the importance of mentoring and the development of leadership characteristics, as well as nurse leaders’ needs and strategies, were identified.

However, studies on all these aspects of women, including minority and nursing leadership, had various drawbacks. Drawbacks encompassed small samples, geographical limitations, and inadequate interview protocols. In addition, this review indicated that, despite various studies on nurses and nurse leaders, no studies existed specifically on the career development of Black female nurse chief executives. The present study was designed to fill the gap in the literature on nursing, minority women leaders, and nursing executives by exploring the career development and influences of race and gender on Black female chief nurse executives in healthcare leadership positions.

In chapter 3, the researcher describes the methodology. The chapter describes the study design, recruitment procedures, and data analysis. 


\section{CHAPTER III}

\section{METHODS}

The qualitative methodology utilized for this study is described in this chapter, including the research design, participants, recruitment procedures, protection of human subjects, demographic questionnaire, interview guide, and pilot study. These are followed by descriptions of the data analysis methods. The researcher begins by explaining her career development story.

The purpose of the study was to explore the career paths of Black female chief nurse executives with a view of understanding the factors which both facilitate and hinder the career development of these leaders in healthcare organizations. The guiding research question was: How do Black female chief nurse executives in the sample describe their career development?

To address this overarching question, the participants were asked to describe their perceptions related to their career development:

1. What particular individuals and events in Black female chief nurse executives’ backgrounds have influenced their career development?

2. How has the career development of Black female chief nurse executives been facilitated or hindered?

3. How have the healthcare organizations of Black female chief nurse executives facilitated or hindered their career development?

4. How do Black female chief nurse executives perceive their career development at different life stages? 
5. What strategies can Black female chief nurse executives in healthcare organizations utilize in order to enhance their leadership opportunities?

The Researcher's Career Development Story

Research studies are influenced by the researcher's subjectivity. In an enlightening introspective article on researcher subjectivity in qualitative research, Peshkin (1988) observed that subjectivity is inevitably present from the beginning to the end of the research process. Peshkin cautioned researchers that regardless of the study problem or the design, they should "systematically identify their subjectivity throughout the course of their research” (p. 17). Reflecting on and acknowledging one's subjectivity are critical to the validity of the study findings. The researcher is an important part of the dynamic research process and brings to the research her lens, influenced by her life experiences, beliefs, values, gender, race, and occupation. It is imperative that the researcher acknowledges her biases because they can impact every aspect of the research process. The benefit of an increased awareness of her subjectivity and biases is that the researcher can take steps to mitigate the impact of these biases. Another benefit is that there can be an increased confidence that study findings accurately represent the perspectives of the participants.

In this section, I attempt to make my subjectivity public by reflecting on how my family and my community helped to shape her values and beliefs through the years of my childhood and early schooling, my subsequent career choices, my decision to emigrate from Guyana to the United States, my decision to pursue a doctoral degree. By bringing to conscious awareness the unconscious biases associated with these events, I hoped to increase the likelihood that the study findings were interpreted fairly. As the study 
progressed, I assessed and evaluated my thoughts and actions related to the study and was honest about any personal biases which could influence not only the interpretation of the study results but also the study methodology.

In my role as a qualitative researcher for this study, I became acutely aware of how my view of the world had changed and was shaped by the literature I was reading. I have listened more attentively to issues of race raised within my professional organization and within the national political arena. Rather than discard what I had heard with my previous attitude of indifference, “Oh, that does not affect me," I then wanted to make sense of what I was hearing. I wore my “race cap,” adding race as another factor, where applicable, to understand the treatment of Blacks within organizations as well as in the larger society.

Peshkin's (1988) formulation of the "I's" of the researcher was extremely helpful in this regard. Peshkin suggested that each researcher brings a series of personal lenses to each study, and the researcher must identify these lenses, or "I's," and their impact on the research and study conclusions. With identification and discussion of six of his own "subjective I’s," such as the "Ethnic-Maintenance I" (p. 18), which reflected his Jewish identity, Peshkin elucidated what the subjective "I's" brought to his research in both seeing and hearing his participants. Using his examples, I began to uncover and to clarify my own "I's" toward awareness and amelioration of subjectivities that could skew interpretation of the participants' transcripts.

In my "Positive I," I wanted to see Blacks succeed in their careers if they are the right individuals for the job. However, my "Justice I" wanted to be fair and not to believe Blacks should be promoted only because of their race. I needed to clean the lenses of my 
personal eyes (perceptions) to make sure that I did not distort the participants' truths because of the multiple prisms I used to understand race, gender, national origin, educational achievements, or status within an organization. My newfound understanding of the role of race and other factors in shaping careers made me acutely aware of my biases and subjectivities which, while acknowledged, would not be used to distort the participants' responses or to read my own into them. Maintaining a research journal of my biases and subjectivities and an audit trail were critical techniques to monitoring, identifying, and analyzing my biases and subjectivities and their potential influences on the entire research process. Further, Merriam and Simpson (2000) pointed out that the researcher should "bracket" her judgments and biases and should allow the interpretation and the meaning of the phenomena to be derived from the participants.

In addition to the various identities described above, I am a person with multiple roles. My professional identity as a nurse and my role as a nurse leader must be examined as these relate to my study. My personal career pathway should not be confused with my participants' career pathways. Their lived career experiences could be similar to or completely dissimilar from my experiences. Through the process of critical reflection on the sources of my own subjectivity, I endeavored to interview, read, and listen to the data, as well as to interpret the data so that the participants' lived experiences were showcased as accurately as possible.

My personal story relates directly to the choice of subject for this study. As a former Black nurse leader, I observed and heard the stories of many of the barriers to advancement as was discussed in the career development literature. My desire and motivation to develop a deeper understanding of the career development of Black chief 
nurse executives was derived directly from those observations. At the beginning of the research, my interest focused on the career development of chief nurse executives, but as I immersed myself in the literature and discussed the topic with my dissertation chair, I realized that I really wanted to study a more specific population, to know the answers to the question, "How do Black nurses make it to the top?"

I was born in British Guyana, and, at 11 years of age, entered an all-girls high school in Guyana. I dreamed of becoming a physician, but I am not sure if this desire stemmed from my own heart or because my mother wanted me to become one. My mother, a divorcée, was a British-trained nurse who never wanted either of her twin daughters to follow in her nursing footsteps. Although nursing in Guyana was perceived as a career choice, I never wanted to become a nurse; in fact, I hated the antiseptic smell on my mother's clothes when she arrived home from the local hospital. It also seemed that every mother or aunt in every family in the neighborhood wanted their children to aspire to careers as lawyers or doctors.

After marriage and motherhood, I immigrated to the United States to pursue medicine. However, I discovered that I could not afford the tuition. My sister-in-law, a nurse, recommended that I pursue a career in nursing because of the shortage of trained nurses in the United States at the time. She assured me that it was highly likely that I would be able to gain immediate employment upon graduation.

Although others considered me to be strong, ambitious, and career-oriented, I never felt that way. I worked hard and did what I needed to do to care for my family. That was what was important to me, taking care of my family. I considered myself to be an accidental careerist, one, who by being prepared, had the opportunity to explore career 
advancement opportunities as they occurred. Yet, an important factor in my career development occurred at my first job as a trained nurse, the role of the nurse manager. This was where I met my most influential mentor, Ms. Shari.

Ms. Shari was a Black nurse manager who had hired me to work on her unit as an assistant nurse manager, and I identified strongly with her. A very proud woman who recognized the value of family and believed that the best way to accomplish one's goals was to treat others well. She also believed that the most important resources were the human resources in her organization. Ms. Shari showed me "the ropes" and allowed me to grow. She involved me in all of the unit's activities, gave me assignments to "stretch" my repertoire as a leader so I could gain practice in leadership, and supported my need for education by making sure that I had a workable schedule to accommodate my graduate studies. At the same time, she consistently made me feel like I could conquer the world.

After I had remained in one role as a staff nurse and assistant nurse manager for 12 years, I decided that I would not commit to any specific role for a long period of time. I was bored easily with roles that did not challenge me but, instead, those roles became routine and mundane; causing me to change jobs frequently. After serving in several roles within my organization (staff nurse, nurse manager, educator, and clinical nurse specialist), I heard of the creation of a director position. I was attracted to this position because of the multiple responsibilities, which I found stimulating, for research, education, and clinical practice. I applied and was hired. After a very challenging start, I began to develop some confidence and settled into learning the facets of my position as a director of nursing. Unfortunately, as is true for many such newly appointed directors, 
even with the formal education that I had completed, I was not mentored for the position. To my later regret, I did not reach out to my peers for assistance, nor was any assistance offered.

Even though I realized quickly that there was a great deal to learn, I decided not to reach out because I did not want others in my organization to know that I was having a difficult time in the new role. To make my position more difficult, many staff members did not support me in the role because they believed I was not qualified. Now in retrospect and because of familiarity with the literature, I find myself asking what role my race or national origin might have played in my difficulties. Although I do not believe that race played a role, I also fear that I may be in a classic state of denial of what, to others, may be obvious.

I have also wondered how my own lack of confidence contributed to my reluctance to ask for help. I can remember feeling intimidated by those whom I believed were smarter than I. My self-esteem during this period was extremely low. For example, when I was promoted to director of nursing, one of my colleagues told me, "You need to network more.” Although no one had reached out to me, the expectation was that I needed to network more. His comment helped me to realize how very difficult it was for me to build the trust relationships that are necessary for personal disclosures and professional leadership. Within my organization, maintaining confidentiality was a challenge, even with human relationship personnel who, because of their roles, should have maintained strict confidentiality. This realization may have unconsciously affected me in not asking for help. As a result, any mentoring that I received was more haphazard than planned. 
I subsequently resigned, and the period after this experience was filled with exploration. For the first time in my life, I asked myself, "Who am I? What do I like? What do I want to be?” And I asked myself other, related questions. "Did I lack the resilience for this leadership work? Was I just not good enough? Did I not fit the image? Did race play a part?” These questions were raised because many Black individuals, nurses and others who were not nurses in the organization, approached me after I had resigned. Some were quite upset that I had made the decision to step aside from my position as director of nursing. They invited me to their offices and, once the door was closed, would ask, “How could you leave your position? Why didn’t you talk to me? You don't leave such a position! They are never going to hire another Black like us. You were our role model!"

For the very first time in my life, I realized that I may have lived my life with blinders on, taking the world with perceived pureness and accepting what was presented to me, with no consciousness of the dynamics around me. I was not aware that others saw me as a role model or that by serving in the leadership position, I was inspiring hope for them. Even so, I could not believe that the changes in my career had anything to do with my race. I continued, and continue, to believe that such career advancement occurred because of my work competence. Was I being naïve, or was this another example of living my life with blinders?

This crisis in confidence led me to pursue advanced studies in leadership, adult development, and human resource development. The experience helped to build my selfconfidence, and I remember the lessons taught to me by my first mentor, Ms. Shari, that I could do anything. Especially pertinent here, the experience eventually helped me to 
focus the dissertation research on the topic of the career development of Black female chief nurse executives. As I delved more deeply into the literature on the theoretical foundations for the career development of females and females with Black or minority heritages, I realized that my story paralleled the stories of those who have been successful in leadership roles. I realized, too, that I shared many characteristics with others who possessed leadership skills, that is, the ability to communicate and to give and receive feedback, self-efficacy, and resilience. I could see how lack of mentoring and my reluctance to network contributed to my lack of confidence. It was difficult for me to perceive the issue of race in my own experience, but I now realize that race has been a salient factor in the career development of most Black female chief nurse executives.

Nevertheless, I remain uncomfortable when discussing the topic, and I am not sure that race is always a significant reason for the lack of career development of Black female chief nurse executives given other important factors, such as gender, opportunity, and education. The most significant barrier to my willingness to address the race issue is that I feel that my White colleagues and some Black colleagues would accuse me of "playing the race card.” I have seen too often that when Blacks, women, and other minorities do not get what they believe to be rightfully theirs, they are perceived to blame the rejection on their race or gender. The notion that Blacks, as well as, Whites could be "color blind" and that race may not matter may be true occasionally, especially where those in power are focused only on the qualities necessary for the job.

Furthermore, the perception that no prejudice exists is equally false. The researcher's anecdotal evidence suggests that in several large healthcare organizations, the perception is that some leadership positions appear to be reserved for Whites. It may 
be that some people are more comfortable with others who are their own reflection. The code word in some organizations for hiring Whites into leadership positions is "the right image,” which for women could include being pretty and slim, not wearing wigs, no immigrant accent, and dressing professionally.

Earlier I mentioned that I had no specific aspirations for becoming a nurse executive. But I had found a voice, one I never knew existed. Now I realize, albeit with some hesitation, that I must challenge the status quo by asking those questions that are uncomfortable to hear. One Black colleague commented that there would never be a Black chief nurse executive at this hospital, “It's a very visible position, and they will never put a Black person in this position.”

In retrospect, during my tenure in this organization, I realized that I had never experienced an honest discussion about race and race relations. I truly felt alone. Was it my failure to network? Or was it the failure or the lack of consciousness in others to identify and offer mentoring to minorities to facilitate their career advancement? To explore, if not fully answer, such questions contributed significantly to this dissertation topic. Recognizing my history as a Black nurse leader, as well as my uncertainties and personal biases, I wanted to arrive at more answers to illuminate my own experiences. As both a former nurse leader and a research tool myself, I also hoped to reveal and to communicate a deeper understanding of the lived experiences of Black nurse executives. Together, hopefully the experiences of the researcher and the participants might provide solutions and encouragement for aspiring Black nurses who, because of their love for the profession and their profound dedication, deserve to advance to leadership positions in the field of nursing. 


\section{Research Design}

This study used the phenomenological approach of qualitative inquiry to investigate the career development of Black female nurse executives with nursing backgrounds in healthcare organizations. Qualitative research assumes that the perspective of another can be made explicit with methods such as observation and interviewing (Patton, 1990). A qualitative approach was chosen because, as Hoepfl (1997) noted, “Qualitative inquiry accepts the complex and dynamic quality of the social world” (p. 48) and allows for understanding the lived experience of the participants. In phenomenological research, the researcher “identifies the 'essence' of human experiences concerning a phenomenon as described by informants in a study” (Creswell, 2003, p. 15). However, as A. Tashakkori (personal communication, September 27, 2007) pointed out, an individual’s “essence” cannot be actually represented. At best, a proxy can be established of the experiences of an individual's life through deconstructing and reconstructing what the individual says or how he or she acts.

With these qualifications in mind, the researcher used in-depth interviews with Black female nurse executives in healthcare organizations to capture detailed information as they described their career experiences as nurse leaders. The interview of structured questions allowed the participants to reflect and share their feelings, thoughts, beliefs, experiences, meaning, and, in essence, their "stories" about the phenomena of their career development. This method reflects Alfred’s (1995, 2001b) observation in her own research that the purpose of the interview was to help a participant "get to the depth of her experiences so that together we could reconstruct her life history in order to determine the forces that have shaped her life career” (p. 127). 


\section{Participants}

The participants for this study were drawn from Black female nurse executives currently employed in hospitals in the United States. The participants held executive positions with titles that included vice president of nursing, nursing administrator, chief nursing officer, and chief nurse executive, and similar titles denoting executive rank. The study included a total of 10 participants for collection of data that had depth, complexity, and richness (Creswell, 2003; Delgado \& Stefancic, 2000). In addition, a minimum sample of 12 has been shown to produce sufficient data for "saturation," that is, collection of in-depth data in which no new themes are revealed (Guest, Bunce, \& Johnson, 2006, p. 59).

\section{Recruitment Procedures}

For recruitment of the participants, the snowball, or networking, sampling technique was used (McMillan \& Schumacher, 2005). In snowball sampling, each individual contacted is asked to recommend another participant who meets the criteria for inclusion in the study. This type of sampling promotes "locating information-rich key informants” (Patton, 1990, p. 176). Because of the difficulty in identifying participants for this study, the snowball sampling technique was utilized. However, a major limitation to this technique was the possibility that those referring other potential participants would have similar life histories and points of view. Thus, the most comprehensive possible range of participant experiences would not be captured. In addition, some participants may not have been able to offer referrals to others, increasing the difficulty of obtaining other participants. 
Furthermore, because of the difficulty in identifying and locating participants for this study, the researcher explored national organizations presumed to have the largest number of nurse executives as members. The researcher contacted several leading healthcare associations, including the American Hospital Association, the American Organization of Nurse Executives, and the National Association of Healthcare Executives. However, the researcher was informed that none of these organizations collected data about the number of Black chief nurse executives. Therefore, potential participants could not be identified. Subsequently, the researcher contacted the National Black Nurses Association (NBNA), founded in 1971. NBNA is a professional nursing organization representing over 150,000 Black nurses. The organization's mission includes facilitating the professional development and career advancement of Black nurses in emerging healthcare systems. To locate participants, the researcher, who is a member of the NBNA, made initial telephone contact with the president of the NBNA, explained the study, and requested assistance in identifying and locating potential participants. While the organization's directory was not provided, a board member of NBNA provided assistance in identifying and contacting potential participants. The participants for the study had to meet several inclusion criteria. They had to (a) self-identify as Black, (b) have had at least 10 years nursing experience, (c) served in the position of chief nurse executive in a Joint Commission-accredited facility, and (d) have held the highest level of nursing leadership in a healthcare organization. As each participant was identified, contact was initiated. Gall, Gall, and Borg (2003) described the process of initial contact as one in which the researcher contacts potential participants, provides details of the study's purpose, and requests their participation. Once individuals 
agreed to participate, individual interviews were scheduled. In accordance with this description, the researcher recruited participants and scheduled the interviews.

\section{Protection of Human Subjects}

Application for permission to conduct the study was made to Florida International University’s Institutional Review Board (IRB). Upon approval from the IRB, as well as approval from the researcher's dissertation committee, the College of Education's Office of Advanced Graduate Study (OAGS), and the University Graduate College (UGS), the researcher made the initial telephone contact with the NBNA president, as described above, and then telephoned or emailed the nurse executives who were possible participants to determine their eligibility and interest in participating in the study.

Once the potential participants indicated an interest in participating, the researcher sent an introductory letter, which included the purpose of the study and the extent of their participation (see Appendix A). The potential participants were also sent an informed consent (see Appendix B), to assure them of their confidentiality in connection with their participation. The researcher also informed the proposed participants that there may be two interviews. The first interview could take approximately 60 minutes. The second interview in which they would have the opportunity to review and to verify their transcribed interviews, could take approximately 45 minutes. In the end, only one interview was conducted.

In the informed consent, the participants were informed that the interviews would be audiotaped, with notes taken by the researcher, and that both tapes and notes would remain secured for the period of time required by the IRB. After this period, to further protect their anonymity, these materials would be destroyed. The participants were 
further informed that the transcribed data would be accessible only to the researcher and her supervisor and would be stored in a locked box in the researcher's home, accessible only to her. For reporting of information in both the dissertation and any articles published from it, the participants were assured that their identities would be protected by the use of pseudonyms. The participants were also informed that there was no perceived risk of participation in the study. They could withdraw at any time with no detrimental effects to them with regard to their institutions or positions. Both participants and the researcher would sign the informed consent.

\section{Demographic Questionnaire}

At the start of the first interview, participants were asked to complete a short demographic questionnaire (see Appendix C). This questionnaire was used to describe an overall profile of the participants. Although this is a quantitative measure, such a questionnaire is often used in qualitative studies for demographic purposes (Hoepfl, 1997; Patton, 1990). Based on the demographic factors revealed in the literature review, the demographic questionnaire (see Appendix C) was comprised of 15 items that requested the participants' title, age, marital status, race/ethnicity, highest degree earned, years of work experience as a nurse, years of work experience as a nurse executive, years in present position, number of individuals supervised, and size of organization (e.g., number of beds, number of full-time equivalent employees supervised, and budget).

Demographic data were collected in qualitative studies to more carefully and comprehensively describe the sample (Creswell, 2003). In addition, since the sample was purposive and delimited to Black female nurse executives, demographic data helped to ensure that a purposive sample had, indeed, been identified. Furthermore, demographic 
data could provide the impetus for future explorations, such as differences between the experiences of nurse executives who are part of large versus small healthcare organizations.

\section{Interview Guide}

Appropriate to qualitative research, data were collected through individual indepth interviews. This method follows Bogdan and Biklen’s (1998) observation that interviews "gather descriptive data in the subjects' own words so that the researcher can develop insights on how subjects interpret some piece of the world” (p. 94). An interview guide (see Appendix D) with a series of semistructured questions was created to guide the participants in providing indepth information about the experiences that shaped their career development. This method encouraged full responses from the participants, with the additional opportunity for follow-up questions to obtain data-rich responses (Creswell, 2003).

The framework for the interview guide was based on the research questions, which explored the career development of Black female nurse executives. The questions were derived from the review of the literature and theoretical frameworks (i.e., Delgado \& Stefancic, 2000; Gottfredson, 2002, 2005; Super, 1990). The interview guide was adapted from Alfred’s (1995) interview guide, which explored the professional development of Black tenured female faculty members in mainstream White universities. Alfred's (1995) interview guide was comprised of 7 sections and 68 domains designed to explore participants’ lives, careers, and bicultural experiences from childhood through adulthood, encompassing psychological, sociological, and organizational factors. These 
domains were intended to be "nondirective, open-ended, and flexible” (p. 52) so that the participants could speak freely about their experiences.

Although Alfred’s (1995) guide was primarily concerned with the participants' development of biculturalism and the factors that influenced them as female Black faculty in White universities, many of the concepts were applicable to the present study. For example, the first and second research questions requested important early influences on the participants' careers in terms of both individuals and events. Alfred's first section dealt with important early influences on career orientation. Her third section dealt with schooling and career orientation. The third and fourth research questions requested facilitators and barriers to the participants’ development as Black female chief nurse executives. These questions reflected Alfred's questions in her second, fourth, and fifth sections on community influences, college and mentoring, and the participants' conceptions about being Black females in American society.

Alfred's (1995) fifth research question requested the participants' views on how their organization had helped or hindered their career development. This question reflected Alfred's questions in her sixth and seventh sections on career orientation and the institutional and tenure process. The sixth research question requested the participants' evaluation of their career development, reflecting Alfred's questions in her sixth section on career orientation. Finally, the seventh research question reflected Alfred's questions in her seventh section on the tenure process, although adapted for nurses, in which the participants were asked for their advice to other Black females on attaining tenure and nurse leadership positions, respectively. Table 1 shows the relationship of the research questions to the interview guide questions. 
Table 1

Correspondence of Research Questions and Interview Guide Questions

Research Questions

Interview Guide Questions

1. What particular individuals and events

$1,2,3,6,7,8,9,10,11,12$

in Black female chief nurse

executives' backgrounds have

influenced their career development?

2. How has the career development of Black female chief nurse executives been facilitated or hindered?

$4,5,8,10,12,13,14,15,17,19,20,21$

3. How have the healthcare

20, 21, 22, 23

organizations of Black female chief

nurse executives facilitated or

hindered their career development?

4. How do Black female chief nurse executives perceive their career development at different life stages of development?

5. What strategies can Black female 22,23 chief nurse executives in healthcare organizations utilize in order to enhance their leadership opportunities?

It should be noted that some interview questions were applicable to more than one research question. This technique provided the researcher with an opportunity to assess the consistency of the participants' self-reports as well as to gain a deeper perspective about the participants' lived experiences by looking at the same question in different contexts. Based on the research purpose, theory, and literature, research questions and interview questions were developed. The research questions provided direction for the 
study and determined the methods to be used, either qualitative, quantitative, or mixedmethods, for the study (Onwuegbuzie \& Leech, 2006). Additionally, while referring to mixed-methods but applicable to qualitative studies, Onwuegbuzie and Leech explained:

Research questions in mixed methods studies are vitally important because they, in large part, dictate the type of research design used, the sample size and sampling scheme employed, and the type of instruments administered as well as the data analysis techniques (i.e., statistical or qualitative) used. (p. 476)

With the constant comparative data analysis method of coding, comparing and analyzing data from the interview questions enhances the opportunity for (a) attaining data saturation, (b) obtaining rich-thick data which answers the questions, and (c) quality themes from the reduction and integration of the data.

The interview guide for the current study provided direction for the interviewer to explore salient topics and to ask auxiliary probing questions derived from the review of the literature and theoretical framework of the study. In addition, Questions 24 and 25 gave the participants an opportunity to contribute further information. Using the guide also increased the likelihood of consistency in the questioning of the participants.

\section{Pilot Study}

Following the approval of the study, a pilot study was conducted to provide feedback about the interview guide in terms of its utility, clarity, and completeness. The pilot study involved a purposeful sample of five Black female nurse leaders from South Florida healthcare institutions. At the interview meeting, the participants received a copy of the informed consent, interview guide, and demographic questionnaire. The pilot study had multiple purposes: to (a) permit a preliminary review of the research questions, (b) gain feedback from the participants, which could lead to improvements in the interview 
process, (c) determine ambiguities in the interview guide questions, (d) evaluate the interview procedures, (e) assess the interview guide, and (f) provide insights into biases or design flaws (Borg \& Gall, 1989).

During the interview, the researcher noted questions that were difficult to understand. Revisions to the interview guide were made based on the pilot study findings and the collective input of the researcher, the participants, and the dissertation research committee member. Specifically, two questions were added, two were deleted, and the order of the questions was changed. The questions were organized into specific categories to allow for a smoother, more logical transition of questioning during the interview. Additionally, based on the review of the interview transcripts by the dissertation chair and the expert reviewer, the researcher gained an increased awareness of her tendency (a) not to follow the interview guide, (b) to ask leading questions rather than open-ended questions, and (c) to insert her own stories and opinions into the interview prior to asking the questions. In summary, the pilot study gave the researcher an opportunity to assess her communication skills, refine her ability to collect field notes, enhance her skills at recording data both electronically and in writing, and to observe the effects of recording on the actual interview process. The pilot study process increased the researcher's awareness of and commitment to (a) follow the interview guide, (b) ask open-ended questions, and (c) refrain from inserting her own stories and opinions during the interviews with the study participants.

\section{Data Collection Procedures}

When eligibility had been established, each participant received a packet containing the introductory letter explaining the purpose of the study, two copies of the 
informed consent, a copy of the demographic questionnaire, and the interview guide. Each final participant signed both copies of the informed consent, one copy returned to the researcher by mail, and the other was kept by the participant for her records. The researcher also requested the participants' curriculum vitae as further sources of data and in preparation for data triangulation. The researcher contacted the final list of participants by telephone and scheduled telephone interviews with the participants who were located in various areas throughout the United States.

At the start of each interview, the researcher reiterated the purpose of the study, assured the participant that her anonymity and confidentiality would be maintained, and expressed appreciation for her participation. Next, the researcher introduced the interview guide and answered any questions about procedures or concerns. The researcher audiotaped the interviews and took notes as well as entered reflections in her research journal immediately after each interview. On completion of the interviews, the researcher transcribed each transcript and listened to the recording of the interview to ensure that each transcript was transcribed accurately. Transcripts were read several times, and the researcher initially made notations to analyze the data and to identify the emerging themes and codes. The interviews were completed in 2 weeks and transcriptions were completed in an additional 4 weeks. After completion of the transcriptions, the transcripts were sent via email to the participants for checking the accuracy of their transcripts and for clarifications (Morse \& Field, 2003). The participants had agreed to provide feedback. None of the participants made corrections on the transcripts. 


\section{Data Analysis}

Categories of data were identified and codes established related to the participants’ personal and professional development. Data were analyzed to identify emerging themes and patterns (Creswell, 2003; Giorgi, 1985). The constant comparative method of data analysis was used to discern the meanings that the participants gave to their lived experiences as Black female nurse executives through deconstruction and reconstruction of their communications (A. Tashakkori, personal communication, September 27, 2007).

In qualitative research, typically four key elements are used to support rigor: credibility, dependability, confirmability, and transferability. Credibility of the methods was enhanced by the pilot study, which helped to establish the validity and the logistics of the interview protocol, as well as the data analysis process. That is, the pilot study yielded data that addressed the research questions, thereby validating the interview protocol. Credibility of results was also enhanced by the process of member checks (Creswell, 2003; Guba \& Lincoln, 1981).

An audit trail of the research process was established by the researcher and analyzed by a 15-year Black female career development specialist who served as director of career development at a local university. In addition, data from the participants’ curriculum vitae were analyzed to validate information provided about their career development. Dependability of results, which cannot be confirmed without credibility and confirmability, was ascertained by the selection of the participants and the subsequent verification by the researcher of the curriculum vitae explaining their career development experiences. 
Within-method triangulation was used to enhance the validity of the research by comparison of the interviews for themes and insights (Newman \& Benz, 1998). Themes within each individual interview were compared with themes across the interviews. In addition, a researcher's log, a detailed account of the researcher's journey, was maintained throughout the study. This log served as a method to enhance study reliability and to reduce bias. The log included the researcher's personal reflections of emotions, thoughts, feelings, conflict, beliefs, biases, values, anger, understanding, and interpretation of the data.

Critical to the rigor of the study was the researcher's recognition of her subjectivity regarding the research and data analysis. Peshkin (1988) articulated the need for researchers to identify their own subjectivity and biases during the research process. Peshkin pointed out that this identification allows researchers to become keenly aware of how their subjectivity may influence the entire research process, including the study findings. Identifying, acknowledging, and recording these biases at the beginning of this chapter enhanced the credibility of the study. Following Peshkin's recommendations, the researcher recognized her subjectivity as part of the research process and identified and disclosed biases in order to make meaning of them in the research. Thus, to guard against this researcher's subjectivities interfering with the trustworthiness of data analysis, two methods were employed: (a) the researcher set aside the analysis and interpretations for a period of time and then returned with greater detachment and (b) an audit trail check was conducted by a respected and trusted colleague.

The audit trail further verified the rigor of procedures and crosschecks, wherein an independent evaluator follows the researcher's description of the steps, methods, 
decisions, choices, insights, and thought processes in which the researcher engaged to arrive at interpretation (and reinterpretation) of the data (Morse \& Field, 2003). Performed correctly, the audit trail is one of several verification strategies (Morse, Barrett, Mayan, Olson, \& Spiers, 2002) that add to the reliability and validity of this qualitative inquiry. As Morse et al. (2002) indicated, “Qualitative research is iterative rather than linear, so that a good qualitative researcher moves back and forth between design and implementation to ensure congruence” (p. 10). The researcher interacts with the data in a "self-correcting" analysis, so that "the fit of data and the conceptual work of analysis and interpretation are monitored and confirmed constantly” (Morse et al., p. 10). Thus, keeping in mind the iterative nature of the research procedures, in the audit trail process, the colleague reviewed the researcher's procedures in terms of data collection, transcription, analysis, coding consistency, and written results. The colleague provided feedback in both oral and written forms and verified the researcher's adherence to stated procedures.

\section{Summary}

This qualitative study was designed to explore the career development of Black female chief nurse executives in healthcare organizations. In this chapter, the researcher described the study, population, research design, interview guide, data collection procedures, and methods of data analysis. In chapter 4, the findings of the procedures are presented, including findings of the data analysis of the interviews and relevant themes. 


\section{CHAPTER IV}

\section{FINDINGS}

This chapter presents the findings of the study which examined the career development of Black female chief nurse executives. Data were collected through interviews and a review of each participant's curriculum vitae. Transcripts of the interviews were reviewed and analyzed. The findings are reported in two parts: (a) the participant profiles and (b) the themes that emerged.

\section{Participant Profiles}

The profiles of each participant were constructed from their curriculum vitae and interview responses in addition to information from the demographic questionnaire. To capture their respective voices, the researcher selected representative verbatim remarks to illustrate each participant's career path to the executive suite.

Table 2 presents a summary of the demographic profiles. Included in the profiles are the pseudonyms for the participants, their ages, their educational level, years as a nurse and years as a chief nurse executive (CNE). The profiles are listed sequentially according to the dates of their interviews.

The participants in this study were Black female chief nurse executives who were located primarily on the East Coast of the United States in areas such as New York, New Jersey, North Carolina, and Georgia, with one participant each from Kentucky and California respectively. All the participants were born in the United States. Two of the participants had West Indian heritage, with parents from Barbados and Jamaica, specifically. The participants ranged in age from 41 to 69 years, with an average age of 57 years. On average, these women had over 25 years of experience as nurses and served 
as chief nurse executives from 4 to 18 years, with 9 years the average length of time as a chief nurse executive.

Table 2

Summary of Demographic Profiles

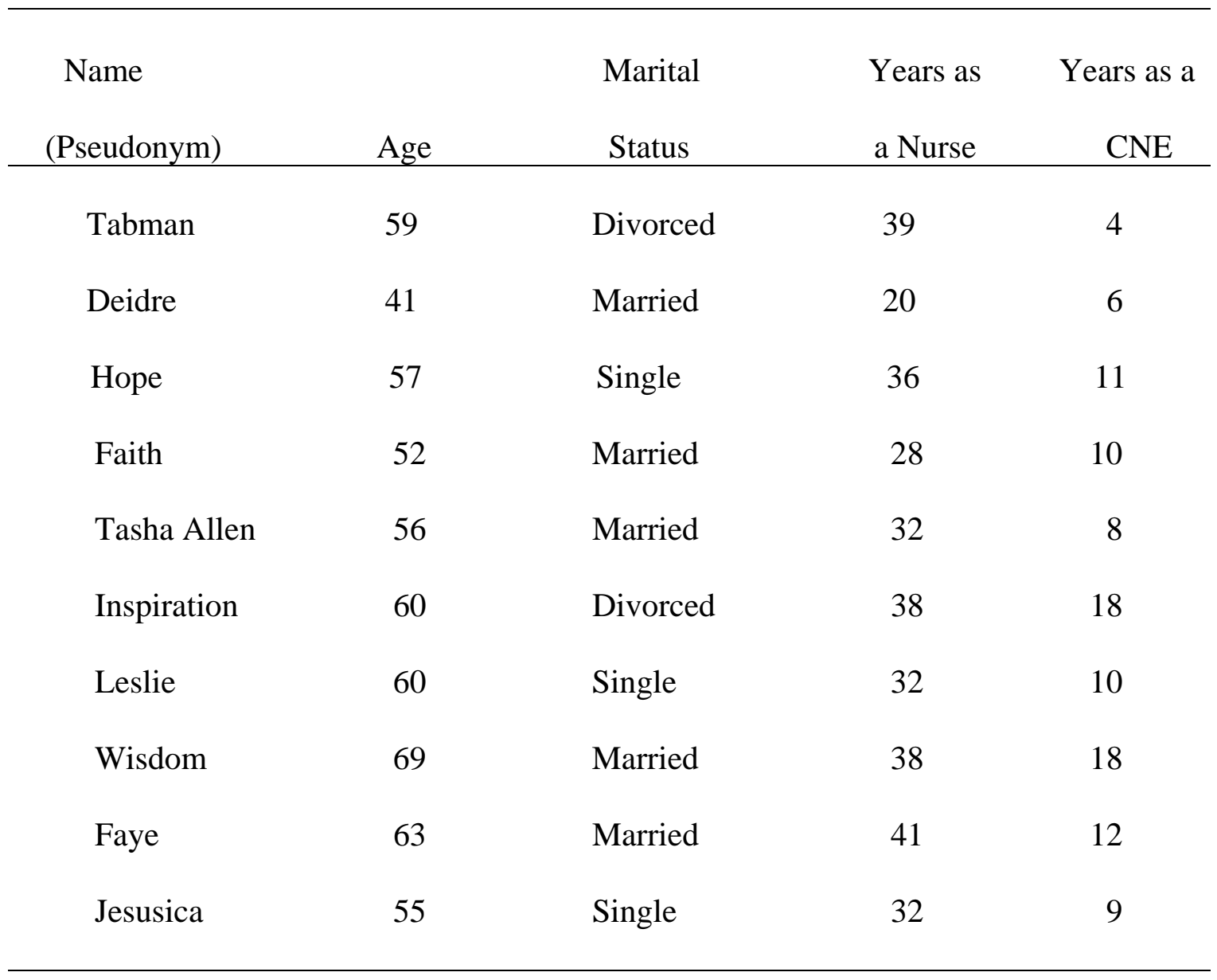

Note. CNE = chief nurse executive.

All participants had earned master's degrees, and 2 of the 10 individuals had earned doctoral degrees. One was currently pursuing her doctoral degree. Five of the participants were married, three had never been married, and two were divorced. The participants were equally divided between those who did and those who did not have children. All 10 participants held executive positions in organizations that were 
accredited by the Joint Commission. Their positions included responsibilities for an ethnically diverse staff. They were employed in organizations with sizes ranging from 250 to 1,250 beds and full-time staff ranging from 270 to 12,000 employees. The size of the budgets managed by these executives ranged from $\$ 6$ million to $\$ 82$ million. In addition, the participants' curriculum vitae were reviewed to provide evidence of academic and professional achievements. The researcher constructed a profile for each participant based on interpretations of the interview and the curriculum vitae.

\section{Tabman}

"I've had a lot of good support and barriers where things just cropped up all along, and I was very, very adamant about blowing them away, dissolving them, or climbing over them."

Tabman was a determined divorced 59-year old African American of Barbadian heritage who was 20 years old when she started her nursing career. Tabman grew up in a working middle-class neighborhood in the Upper West Side of New York City, an economically, ethnically, and culturally diverse neighborhood. Her entire maternal family lived on one block next to Central Park. Tabman described an amazing life and childhood. The middle child of five, she was raised by a stay-at-home mother. Tabman described her father, a mason, as "a wonderful, hardworking, brilliant man who, unfortunately, never really excelled to his full potential because of racism in this country.” For Tabman, she experienced racism as a young child from teachers and school administrators. She continued to encounter racism in college, which was a major concern while attending college.

Tabman knew from her early childhood that she wanted to be a nurse. She recalled, "My family would fall out laughing because I would be the first one with the 
peroxide and the bandages for all the children who bumped their knees, and I actually had my own little nursing kit.” Her mother supported her dream of becoming a nurse by obtaining nursing kits which Tabman used to practice nursing on family members. Tabman understood her mother's strong support for her career when, upon the death of her mother, she learned from her aunt that her mother also dreamed of becoming a nurse. Tabman, who identified herself as "a product of the 60s" and was very conscious of rights and ethics, was involved in the Civil Rights Movement and considers Malcolm X among her heroes.

Tabman described herself as academically gifted and credited her parents for instilling in her the value for education. Tabman yearned to attend college and, fearful that she would not because her parents could not afford to pay for college, decided that she would have to be responsible for obtaining scholarships. After Tabman graduated from high school, she was fortunate enough to receive scholarships to attend college and completed her associate of science degree in nursing.

Although she never had children of her own, Tabman became an advocate for children and dedicated her life to working on issues related to children. As a new nurse, in addition to discrimination, she faced the reality of observing and dealing with disparities of care in healthcare. As a nurse executive, Tabman used her position to advocate for children and to address the issues related to inequalities in healthcare. If not for her desire to serve others and to remain engaged in these activities, Tabman stated, "I really would have left a long time ago.” 


\section{Deidre}

"When there are more people who look like you guarding the doors and people that you know, you can expect more doors or opportunity to be available to you."

Deidre, 41 years old, was the chief nurse executive (CNE) and chief operating officer (CNO) of a 102-bed facility in the southeastern United States. Deidre, a Black woman with an Italian name and the youngest of five children, was born and raised in a rural town in West Virginia. The age range among the children allowed Deidre to observe what they did, right or wrong, and, according to Deidre, made her “probably wiser and more introspective” about herself at a young age than most of her peers. Deidre has been married for 14 years and is the mother of a 5-year-old daughter.

Deidre describes her mother and father as "wonderful parents," who emphasized education and were extremely supportive. Growing up Deidre was a "book worm.” She loved reading and participated in book clubs. As a student, Deidre always strived for A's and considered anything less than an A as a failure. She stated, "I was wired that way and having that kind of support system growing up where you could not fail was invaluable.” Her early childhood in rural West Virginia exposed her to the effects of racism, which, as she became an adult, prepared her to deal with the impact of racism throughout her life. Deidre’s mother was the early influence for her choice of a nursing career. Her mom was a nurse, a professional woman, which was atypical for that time. At 4 years old, Deidre observed an incident in which her mother went into what she termed, "nurse mode to save a life” when a neighbor was injured after falling through a glass door. Deidre recalled with a sense of pride her mother leaving for work in her white uniform, white hat, white stockings, and white shoes. At some point, because of her interactions with 
physicians during her visits to the hospital with her mother, Deidre considered becoming a physician. Deidre entered nursing school, an associate in science degree program, and still planned to become a physician. After graduating, she went to work in an academic setting and became the first and only Black nurse at that time to work in the open heart surgery unit. While working as a nurse, Deidre observed the life of the medical residents and physicians and decided that that life, the long hours on the job, was not for her. Deidre decided that nursing would allow her to have the greatest influence on healthcare and, instead, obtained a bachelor of science in nursing degree and graduate degrees with an emphasis on business. Additionally, being the youngest of five children, and always having to take orders from her older siblings, she decided at a young age that she wanted to be the boss. She recalls wanting to be the leader because "I was tired of all my older siblings and two parents telling me what to do.”

Deidre considered herself progressive, a risk-taker who looked at opportunities rather than titles in selecting roles. She also described herself as a pioneer, self-motivated with a need to serve. Because racism had been a major influence in her life, Deidre believed that one of her important roles was to open doors. As she said, she wanted to "make the path a bit smoother, a bit wider, and a bit brighter for the next person who came along and happened to look like me.” Her definition of career development was "looking for opportunity and the ability to gain experience" rather than titles. For her, career development was not a linear process, and she had accepted horizontal and downward roles because it helped to broaden her skills and to enhance her career opportunities. 
Deidre had held her current CNO and COO positions for 4 years in a facility where, according to Deidre, people of color as well as people of color in leadership positions were a rarity. Her other roles included vice president and director of corporate compliance. She had no desire to become a chief executive officer (CEO), although she did not rule it out. Ultimately, her desire was to retire "into teaching.” Her future goal was to teach people who aspired to careers in healthcare. To that end, her current plan was to gain varied experiences which would enrich the knowledge and the skills required to teach in academic settings.

\section{Hope}

"My mother would say, 'knowledge is power, you know; it can't be taken away from you'; and I guess being a child that grew up in the Civil Rights Movement, you know that knowledge is power."

Hope, a single, energetic 57-year-old woman with a very positive attitude, was born in New York of Jamaican parentage. She had never been married and had no children. Although there were other family members who were nurses, her early childhood influences to become a nurse occurred at the age of 10 when her cousin was admitted to a local hospital. He was very sick, and Hope was impressed by the nurses who cared for her cousin and the impact they had on his recovery. Particularly, Hope was impressed with the ability of the nurses to explain and to teach the family and her cousin.

Family had always been very important to Hope. The elder of two children, Hope grew up surrounded not only with her own nuclear family but also a large extended family. She described every event as a family event, even going away to college. The message conveyed to the children at an early age was that they were going to attend college and do better in life than their parents had. Hope, who stated that she had 
achieved her career objectives, had served in several nursing leadership roles, including director of nursing. Hope's goal was her commitment to helping others and to teaching people how to care for themselves, especially those who were less fortunate, may not have understood the healthcare system, or who were just afraid of the healthcare system. Faith

"I never, ever defined myself in terms of a position or really even in terms of a career track. I've really defined myself in terms of being able to be good and do good. Being able to expand in the broadest scope that would allow me to be good and do good. So with that broad kind of framework, there is always ample opportunity to be good and do good."

Faith was a woman of faith and integrity with a heart full of love who was energized by assisting people to help themselves and to grow into being the best that they could be. Faith became an RN in 1980. Faith grew up and still lived in a rural community. At the time of the study she was married and the mother of three adult children. She had nine living brothers and sisters. As a child, church was a central part of her life and still was. Her parents separated when she was 9 years old. As she was growing up, Faith worked in the orange groves to assist her mother in paying bills and obtaining food. Faith described herself as a brilliant student. Her schools were integrated when she was in fifth grade. Her foray into nursing began in a nursing home when she applied for a position as a dietary clerk. The nursing home was in the midst of a strike and was recruiting nurses and nursing assistants. Faith was hired and trained as a nursing assistant. While employed at the nursing home, the director of nursing apparently observed Faith and indicated that she would be a "wonderful nurse.” Faith decided to pursue a nursing career. 
One of the major skills she learned from her mother, which Faith believed was so relevant to effective leadership, was the importance of building relationships with everyone no matter whom they were, even with individuals who were considered prejudiced. Faith observed that everyone communicated with her mother in a respectful way.

Faith believed that people must live their own experiences and build on their own foundation. Faith explained, "I love nursing; I love community; I love teaching. [I am] probably someone who has less patience for what I would describe as probably foolishness in terms of excuses versus efforts.” Faith's advice as a leader was:

To believe strongly in what you have to offer and don't be willing to give it up. If you're willing to give it up, anything will shake you. So it does and what it means for me is that, if I know that I have what it takes and I know that I have the gifts, talents, and I know that I'm supposed to lead this nursing service, then if I can't lead it here, I will lead it somewhere else. So it is to me, it's that you know what you're going after, and it doesn't really have to be a position per se.

Therefore, with Faith's love for nursing and teaching, her goal was to focus on developing nurses because she believed that nurses would be the ones who shifted the dynamics as they related to improving the overall health of communities.

\section{Tasha Allen}

"I'm not a limelight person, if you will. I don't need to have the light shine on me. I'm more of a "we." I'm a team member. I always give credit to the people who do the work and get the work done."

Tasha Allen, a compassionate woman, was the fourth of eight children who grew up not really poor because, according to Tasha Allen, she had a great deal of love and plenty to eat. Tasha Allen had two working parents and from early childhood, she recalled her parents teaching the children that if they could not be first, they should never 
be last. Her parents worked hard to provide a living and with tough financial constraints, fed those less fortunate than their family. The value Tasha Allen learned was that if she had anything, she needed to share and to help others. As a child, Tasha Allen was an avid reader; she had a curiosity for knowing and a quest for knowledge. Tasha Allen liked to be challenged. Her parents pushed the children toward excellence, involvement in the community, church, and school. Church, faith, and believing that God would always make a way and provide were cornerstones of their lives.

Tasha Allen remembered that she wanted to be a nurse from age 4. Tasha Allen, a nurturing person, wanted to care for people. As a child, she actually cared for animals and for her sisters and brothers when they had colds. Tasha Allen did well in school, enjoyed learning and learning to be independent. Coming from a large family, and being the fourth child, Tasha Allen knew that there were financial concerns about whether or not she would be able to attend college and pursue her dreams. To support her dreams of becoming a nurse, Tasha Allen worked at age 13 washing dishes, cleaning bathrooms, always with a goal of becoming independent and pursuing her dream of being a nurse. While a senior in high school, she attended night school and became a certified nursing assistant. Her goal was to use the moneys acquired from her job as a nursing assistant and from scholarships to pay for college and to pursue her dreams of becoming a registered nurse. Because of her commitment to helping and to sharing with others, Tasha Allen spent most of her money on other individuals and little toward her own career.

Tasha Allen's role as a certified nursing assistant (CNA) in Georgia allowed her to work with and to learn from registered nurses. During that period, as a CNA, Tasha Allen also witnessed racism and healthcare disparities, a different standard of treatment 
for her Black patients as compared with her White patients. This inequality in care for these patients made Tasha Allen determined to do more so that these patients could receive the best care possible, even if they were not given access to the most current treatment. Tasha Allen earned her bachelor of science degree in nursing, a master’s degree in nursing, and was certified in psychiatric and adult mental health.

Tasha Allen had overcome several personal and professional challenges to accomplishing her goals. She remained committed to family, her patients, and to lifelong learning. Her agenda was to make healthcare equitable for everybody, regardless of social or economic resources. She believed that if she could receive the best care when she was ill, then the homeless person should have access to the same level of care.

\section{Inspiration}

"Career development is about a journey, and those individuals that see the position or the acquisition of a certain degree as the journey, are short-sighted. It's about a journey towards leadership and that journey towards leadership is one that is always evolving. It has lots of twists and turns. It has potholes that you will step into, but if you can continue to keep moving forward on a journey, and learning every step of the way, you will enjoy becoming a leader. It's about becoming a leader. It's not an end-point." It's a journey towards leadership and that journey towards leadership is one that is always evolving."

Inspiration was a 60-plus year-old nurse executive, divorced with no children, who described herself as "a nurse executive with research and community service and health policy experience who utilizes her knowledge and skills on a variety of levels to make a difference.” Inspiration was born and raised in Arizona as the eldest of 12 children who grew up with a multigenerational family. Inspiration had the pleasure of having both a grandmother and a great-grandmother alive until she was about 12 or 14 years old and credits them with being a major influence on her life. Inspiration became interested in a career in nursing at 7 years old, which stemmed from her being a very sick 
child with asthma. These illnesses resulted in frequent visits to hospitals, and nurses made an impression on her, their compassion, their caring.

Inspiration had always been involved in church, thus helping to shape her career. Inspiration held a variety of roles, including staff nurse, nurse manager, and director of nursing research. She wanted to be both a clinician and a researcher. Therefore, she welcomed opportunities to stay engaged with patients at a variety of levels involving the community and had conducted several research studies on the topic of access to healthcare and to closing gaps in health disparities. She continue to serve on several regional and national advisory boards that focused on the issues of access to care and health disparities.

\section{Leslie}

"I think there is still that little bit of you've got to be twice and good and work twice as hard in order to measure up to the same standard as someone who is not Black, who is mediocre."

Leslie was a single woman with no children who grew up in southwest Georgia. She was the third oldest of four children (three girls and one boy). Leslie represented herself as "conscientious, goal-directed, focused, hardworking, workaholic, and an overachiever who sets and expects high standards.” Leslie grew up in a nurturing home with a strong work ethic in which schoolwork and good grades were emphasized. Her father was a hardworking individual who provided for the family. At an early age, Leslie was taught to be independent and that she would have to work for whatever she wanted in life.

Leslie's early career goal was either to become a nurse or a fashion designer. Her uncle had a daughter who was a few years older than Leslie. The girl who had studied fashion design and was not successful at the career. Leslie's uncle recommended that 
Leslie pursue her career in nursing. Leslie’s parents and family were extremely supportive of her, but, because the family was poor, they could not afford to send her to college. However, she graduated from high school and attended college at Valdosta State University, in Georgia, where she obtained her BSN. Leslie also earned two master’s degrees, one in psychiatric nursing and one in nursing administration. Leslie was certified in nursing administration and had spent most of her career as a nurse in the field of psychiatry. As a nurse, Leslie’s first love was to direct patient care. She described her advancement into leadership as occurring by chance when she was asked to interview for a leadership position and accepted the challenge when the position was offered to her.

If Leslie were not in her current position, she probably would have been either a clinical nurse specialist or nurse educator. As she pondered retirement, which was five and a half years away, she relished the idea of providing bedside care while educating nurses.

\section{Wisdom}

"The reason why I love wisdom so much is because to me, wisdom is the ability to appropriately and timely apply knowledge so that you always get the desired results. You will get results, but you want the desired results.”

Wisdom explained herself as “a very open, outgoing, mission-driven, focused person who is strong in faith and who has high expectations.” Wisdom, the firstborn of eight children, grew up in a coal mining community with parents she described as “wonderful” and who are now deceased. According to Wisdom, her parents taught her the importance of values, ethics, respect, and what was important in life. Wisdom believed in God and was always taught "God first” in her life. 
Wisdom credited her parents with teaching her management skills. Because Wisdom was the firstborn, she was placed in charge of her siblings when her parents were away. Through this experience, Wisdom learned organizational skills and how to control the environment. Wisdom had not realized how financially poor they were because, according to Wisdom, material things were not important in her family. Growing up, Wisdom was an "A” student who was committed to making a difference. She could be found, on many evenings, on her big porch, creating and telling stories to the neighborhood children. She also served as president of several of her school clubs, a testament to her early leadership development. School was very important to Wisdom. Wisdom learned the value of mentoring when, during elementary and high school, honor students were expected to serve as mentors for struggling students. Teachers expected everyone to learn. Because of the school environment, Wisdom was motivated and encouraged to learn and to participate in several activities geared toward student development, including spelling bees, debate, chemistry, and future nurses clubs.

Wisdom recalled that in her early childhood, she formed her desire to be a nurse, a nurse who made a difference. While attending nursing school, Wisdom was always looking for ways to make things better for others. Because of segregation and racism, Wisdom could not attend college in her local community and had to move to Atlanta to attend a nursing program that granted diplomas. Wisdom graduated from a 3-year diploma-granting nursing school and became an intensive care unit nurse. She realized that, in order to get the respect the role of a registered nurse required and deserved, she was going to have to add more credentials to her name. Wisdom had since obtained her graduate degree in nursing administration. 
Throughout her life, Wisdom had dealt with many barriers, real and perceived, but Wisdom interpreted these barriers as opportunities. Wisdom grew up and experienced being an African American in a segregated society with memories of the Ku Klux Klan riding through the neighborhood. Wisdom had vivid memories of a cross burning and running into her house out of fear of the Ku Klux Klan.

Wisdom talked about the role of God and divine intervention in her life and stated that, in addition to her parents, Jesus Christ was a mentor. Because of the role of her faith in her life, Wisdom indicated that the biblical principles served as the framework for her as a leader and for the application of her leadership skills. Wisdom, who considered herself blessed, is the married mother of two adult children. She was content in her current role with no plans to pursue any additional executive positions. Wisdom had a radio ministry program, a bible study program, and was very active in her community. Faye

"Once you got out there and you were in the academic world, and you saw all of these other, very bright faculty and faculty that cared; faculty that were demanding of you, wanted you to do your best, then you saw a different side of what it meant to be knowledgeable; to use critical thinking; to use the theories. You began to integrate all of the knowledge, skills, mentors, experience; and it made sense to you."

Faye was a 63-year old African American female who became a practicing nurse in 1967. She was a mother and wife and a grandmother of five grandchildren and believed in God. Faye was raised in a segregated society by an aunt, although her biological mother played a role in her upbringing. Faye grew up in close-knit family in an environment with a great deal of love, faith, and belief in God. Faye was taught as a child that since she never knew who was observing her to always "put your best foot forward." Faye's childhood was spent working on a farm, and she also drove a school bus. School 
was important, and the children were allowed to attend school. Faye was the high school salutatorian and she wanted to be a teacher, but won an essay contest sponsored by a local newspaper that paid for the entire 3 years of nursing education. Because she was poor, this was the only way to pay for college, so she chose nursing as a career where, in her words, “I could make money.” Faye began her nursing career in 1967, graduating with a diploma program from Lincoln Hospital School of Nursing in Durham, North Carolina. Faye continued her education at North Carolina Central University where she earned a BSN degree and a graduate degree from the University of North Carolina in Chapel Hill in Health Policy and Administration. Her nursing career spanned a myriad of nursing settings: the operating room, neurosurgery, plastic surgery, and the burn unit.

Faye had had roles as an assistant director of nursing and quality assessment coordinator for the organization. Additional roles included preceptor, mentor, clinical nurse specialist, and faculty of the local university school of nursing. Faye’s work setting was at an institution designed to provide care for the underinsured, uninsured, and the working poor. As a nurse, Faye was most concerned about the quality of care her patients received and the quality of support her nursing staff received.

Faye continued to be an advocate for nursing and nurses but spent a great deal of her time giving back to her community. She raised funds through grants to host health fairs and to provide free mammograms and prostate screenings for the poor in her community. Regarding her career development, Faye was ready to retire. She had learned that to succeed as a leader, "you have to be versatile. You have to not take yourself seriously, and you can't feel that you know all the answers either, you know. You've got to be able to laugh at yourself." 


\section{Jesusica}

"So you're the nurse, but you've got to be global; got to be a little bit bigger than that, but you don't have to forget that you're a nurse; and just love it and thank God that you have the opportunity to be able to do it."

Jesusica was a single, 55-year-old African American who had been a nurse since 1976. She earned both undergraduate and graduate degrees in nursing and was currently enrolled in a Ph.D. program. Jesusica explained that she was competitive and always had the propensity for excellence. Jesusica had spent most of her career working in academic settings and had held leadership roles starting at age 23 when she became a nurse manager. Jesusica credited the daytime soap opera General Hospital for the inspiration to become a nurse. Jesusica pointed out that when she was in elementary school, she observed one of the characters, a nurse named Lucille, who was always sitting at the desk and knew everyone. Jesusica remembered thinking, “I could do that.” Jesusica’s idea of nursing was that she would sit at a desk all day. Jesusica also convinced her mother to purchase a doll with a nursing kit and little bandages so that she could practice nursing. Jesusica was an individual whose motto was “committed to giving my best.”

Jesusica saw her future career as a leadership consultant and was committed to mentoring and developing new nurse leaders. Jesusica believed that preparation was key to success as a nurse leader and was a proponent of educational development, both formal and informal learning for nursing leaders and believed that even without mentors, one could succeed as a leader. As a chief nurse executive Jesusica stated, "I knew I had to be prepared to be at the table. I did not want to be invited to the table and just be a guest, not partake of the meal, if I may be metaphoric here; but I wanted to be able to participate.” 


\section{Thematic Analysis}

In this section, the researcher presents the results of the cross-case analysis. Themes were defined and illustrated with verbatim excerpts from the interviews. Outlier themes were also identified, that is, those representing themes that emerged from responses of individuals or smaller groups of individuals. In the cross-case analysis, the researcher also looked for themes that were derived from the theoretical frameworks and the literature review. The four major themes which emerged were (a) support systems, (b) guidance, (c) diversity, and (d) servant leadership. Each theme is described below with verbatim quotes from the participants to illustrate the theme.

Theme 1: Support Systems

The first theme that emerged, support systems, refers to the level of involvement and influence by parents, extended family members, spouses, friends, peers, staff, mentors, role models, church, and organizations in helping to develop and to shape the career development of these nurse executives. The support systems for these women were strong. In particular, their nurturing families, whether it was the nuclear or the extended family, were a significant source of support for these individuals as they selected and pursued their education and their career. While the participants made an independent decision about pursuing their nursing careers, it was the family support and encouragement which allowed the participants to pursue their dreams. Many of the participants described growing up and having a positive childhood, along with their siblings, in a nuclear family. Common among all women was the value of support from family and friends. They had wonderful parents, for many, both a mother and a father and both were mentioned as a source of support and influence on their children. 
There was also a very involved extended family, including aunts and uncles who were a part of not only raising the children but also involved in holiday celebrations and vacations. These traditions continued when the women reached adulthood and found themselves returning home for holiday celebrations and spending vacations with extended families.

\section{Supportive Family: Parents}

Parents, both mother and father, were mentioned by all the participants as significant sources of support and influence in their lives and, by extension, their career development. The support from parents included support at an early age for their daughter's interest in a nursing career providing nursing dolls and first-aid kits. Some mothers were realizing their own dreams of becoming nurses through their daughters. Two individuals had mothers who were nurses, and they visited the hospitals with their mothers. The participants learned from their parents that they could do anything, that they were bright, intelligent young women who could accomplish their goals. Being average was unacceptable for these women who, in order to succeed, had to be prepared and be better than others. They were taught that knowledge was power and that knowledge, once acquired, could not be taken away. Through their parental influence, they learned about empowerment, self-definition, family relationship, finance, treating people with respect, managing different perspectives, and the importance of hard work.

Jesusica, Tabman, Tasha Allen, Wisdom, and Deidre all shared sentiments surrounding the role of their parents in supporting and influencing their careers. They had wonderful parents who expected them to succeed. As Jesusica expressed, "My biggest supporter has been my mother all the way through.” Likewise, Wisdom's father taught 
her, “Don’t you ever give power to anybody to the point that they can determine what kind of day you had. You determine what kind of day you have by the way you set the tone for that day.” Deidre's father provided her with the type of assurance which encouraged her to be a risk-taker. She added:

Having that kind of support [of her parents] growing up where you could not fail was invaluable, and I think that's what has allowed me to look at my career, and progression in career in a different way, because I've never been afraid to take a risk because, I knew when I left home, my father always said, You can always come back; and with that type of assurance, what would you not try and do. So I was really blessed to have a stable, two-parent family upbringing.

In addition to the support provided by their parents, Jesusica, Tasha Allen, and Wisdom learned several leadership and life lessons from their parents. As Jesusica shared, although her mother did not have the credentials or the education, she learned finance and relationship building from her mother. She learned the value of hard work and taking care of one’s family from her father. Likewise, Tasha Allen learned about networking from her mother who emphasized that if she wanted "to succeed in life, we always had to be better than the next person in terms of achievements, in terms of hard work, in terms of even physical appearance.” Wisdom's parents taught her about "leadership, values, ethics and what's important in life. In fact, that's where I learnt my management skills. I was the firstborn so I had to be in charge of my siblings when my parents were gone.”

Supportive Family: The Extended Family

Beyond the nuclear family, the extended family support and influence were also critical to these individuals. Their strong tight-knit families were always encouraging and supportive of their career and life endeavors. The extended family included husbands, 
grandparents, siblings, aunts and uncles. Family mattered; they were positive influences on the participants, helping to shape their young and maturing lives. The extended family provided guidance as these young women sought to make decisions about their careers, leaving home to pursue their education and the trepidation which came with such a decision. Family members provided the foundation, structure, and focus. They set high expectations, encouraged reading and joining the library, ensuring that homework was completed, giving additional homework assignments, and allowed their children to participate in speaking competitions. These women were expected to attend college even when their parents' financial picture could not support this effort. The support and influence of the family members extended beyond college. As these women entered the world of work, they continued to need someone with whom they could discuss the successes and challenges they encountered. For Inspiration, her family was encouraging in terms of her career. "They helped me to make some decisions about leaving home and being willing to go out on a tightrope to advance myself. and they’ve always been supportive of any endeavor I take on.” Similarly, Tabman described the influence of her grandmother as she was growing up. Her grandmother believed in her abilities and, according to Tabman,

My grandmother would be the one to appear before the teachers if I came home and said teacher told me that I was not smart or if I was told that I couldn't be a nurse. She would make sure she, and she had to go up a hill, and I have these beautiful visions of my grandmother, a little heavy set, but the way she walked, she would go up that hill and sort out everybody.

In addition to the support of the extended family, supportive spouses were vital to the career development of these women. Spouses provided encouragement, were their confidantes, and undertook the leadership roles in the home, making it possible for the 
women to study, quit working at times, and dedicate time and effort to nurturing their careers. Many of these men became responsible for raising the children in the absence of their wives. They also encouraged their wives to pursue career advancement. As Tasha Allen stated, "I think that my upward mobility or my achievements in terms of nursing are because my husband has always pushed me by saying, 'You're doing the job anyway, why not accept the positions?' "

Four of the participants with spouses expressed sentiments that they could not have made it without their spouses’ support. For example, Faye’s husband was very supportive of her pursuing both her undergraduate and graduate degrees and took the responsibility for the family. Similarly, Faith’s husband braided the hair of their daughters and drove Faith to school and, because gas was expensive, he remained in the car until the end of classes to take her home. As Deidre stated, her husband is:

The soft landing...we've been married for 14 years. We've been together and married for 12 and so he's been kind of my soft landing spot, keep home and work very separate. He is an introvert and I think I married my father in that regard and that works very well for me. It gives me a place of respite on a daily basis and I don't intermingle the two. It networks very well for us. I, of course, have to socialize a lot in my role, this role and my prior role and I don't intermingle the two. There are work functions, social functions; I go alone because I like to keep my personal and my work life very, very separate.

Supportive Others: Teachers, Mentors, Role Models, Friends, and Colleagues

Mentors, role models, faculty, friends, and colleagues played instrumental roles and were influential in the career development of these individuals from high school to college with faculty friends and role models and continuing into their current careers with mentors and colleagues. While the mentors, role models, faculty, friends, and colleagues could be distinct individuals, one individual could serve in several roles. As might be 
expected, parents were also identified as serving in these roles. The diverse mentors in their careers, many of whom were not in healthcare, influenced them by helping them make the right choices at the right time in terms of acquiring knowledge and utilizing that knowledge in their profession. An informal, rather than a formal, mentoring relationship existed between the participants and their mentors. Mentors assisted when the participants struggled with the issue of trying to achieve balance between their desire to advance professionally and their need to stay home with friends and family. The mentors were individuals who cared not only about the participants' human resource development but identified them as individuals with potential, and helped them to reach their potential. Mentors aided the participants to reflect on their actions and encouraged them to do their best. They provided insights and taught them the organizational culture, how the organization and its people performed and functioned. In some relationships, mentors remained available to the participants after the work relationship ended, a friendship developed, and the bond between the mentor and the participant became stronger. In the nursing organizations, in addition to their leaders, other staff nurses on units often served as mentors. Some mentors saw potential in the participants and were inspirational and encouraging in terms of wanting the participants to succeed and progress. The mentors discussed other career possibilities and introduced participants to opportunities to build their skills, such as attending workshops to improve their public speaking abilities. Others encouraged participants to write and publish their work. To illustrate, one nurse suggested to Faye, when encouraging her career advancement, "Who said you can stop here? You have to go on and she just kept pushing us. We're going to need Black leaders and you all are young now.” And Jesusica explained the importance 
of the role of her mentors, “They're not going to make life easy for me, but they're not going to make life impossible.”

Also critical to the development of the participants was the influence of role models. Role models were individuals whom the participants admired. They desired to emulate the role models' behaviors, characteristics, knowledge, and skills they demonstrated. As evidenced by the responses of the participants in this study, these individuals were, at times, known to them and served dual roles as both role models and mentors. Several role models, including parents, were not necessarily in the nursing field. Some of the role models were individuals who had been successful in life either by running their own businesses or by helping to move forth significant policy changes and launching new programs that would benefit society.

For Hope, her role model was Sharon Smith (pseudonym), a vice-president of nursing who taught her to be a risk-taker. As Hope explained, "her way of thinking [was] out of the box; [Sharon] was a really good role model for me. She was fair and honest and would explain things, was visible to staff. So she was a good role model.” Likewise, Jesusica's mentor, a brilliant nurse leader, encouraged risk-taking. As Jesusica explained:

She was the one who had a Ph.D. One of the most brilliant nurse leaders that I think I've ever had the privilege of working under, but she also, she did not wear it on her sleeve. She was down to earth. She didn't feel threatened by you. She was able to engage with you and she was able to give you, both the freedom to grow and the freedom to make errors. So I really respect her to this day. She was one of the individuals, actually, that was responsible for me moving into a senior position.

In Inspiration's view, the role of mentor was to help others “to see the possibilities in their lives and to help them to do life's work that is beneficial to them.” Inspiration believed that benefits went beyond remuneration to refer to "feeling like you made a 
difference; then you're more likely to be passionate about the work and less likely to see work as burdensome.” Inspiration, Deidre, and Tasha Allen alluded to illustrious individuals in their lives who served as both mentors and role models. These individuals appeared in their lives as early as middle school and continued through their careers. Inspiration revealed that significant mentors and role models for her were leading Black women in healthcare. Inspiration explained:

Dr. Lucy Baron is a role model because she was the first Black editor of Nursing Research and that journal, as prestigious as it is, benefited from her leadership and under her tutelage. She's been able to help many others who wanted to get into the business of writing and has helped them to significantly improve their skills. Others like Dr. Eleanor McCoy, who has been a renowned leader and who again taught leadership from a different perspective and helped to advance it. Dr. Lloyd, who also used her knowledge and her skills to be able to move this nation forward, in terms of, mental health issues. So many different individuals who I admire, but those individuals that I just named, were my mentors.

Tasha Allen’s mentor, her first nursing supervisor, again challenged her to be a better

nurse and to consider becoming a nurse leader. Tasha Allen explained:

She was very professional, very motivated, very into self-development, very ethical. She was a mentor for me. She was always pushing me to give more, to volunteer for more, to challenge myself to be a better nurse and she, as I think about people who really played a part in my becoming me, I think she gave me my first view of what a true nurse leader was about and her name was Cathy Jason; and she'll forever be in my mind in terms of the epitome of a professional nurse. She went to conferences. She wrote articles about post-anesthesia recovery room nurses. She was just a true professional. She was a true leader, and she didn't accept anything less than what was best. She was quick to discipline; very quick to discipline, but she was excellent; she was a great role model and mentor for me.

However, not everyone was successful with respect to mentors. Deidre expressed, "I haven't been fortunate enough, until probably the position I'm in right now, to even have mentors of color quite honestly or people that could really be confidants along the way.” 
Teachers and faculty who cared were concerned about their students and their performance. They took time to inspire and to motivate their students. Teachers and faculty also served as role models and mentors. Education was emphasized in all the participant households. It was perceived to be a catalyst for a better life. So teachers and parents contributed to creating a nurturing environment, an environment of learning, of discipline, of risk-taking, of belief in self and accomplishments. Teachers were demanding; they wanted the students to excel. These expectations from the faculty allowed the students to value education and to gain an understanding of what it meant to be knowledgeable. The participants reported that their teachers taught them to use critical thinking skills. As they entered their nursing education, their teachers encouraged them to apply theories in nursing. The teachers and the school formed a structure where students participated in debates, academic competition, and the arts. Every child was expected to succeed, especially since the teachers were part of the community, attended the same church, and, in most cases, knew the parents

As they advanced in their careers, the participants integrated the knowledge, skills, and experiences learned from teachers who, along with their parents, encouraged excellence and inspired their students to excel. Deidre discussed her science teacher as an intellectual who challenged her. She stated:

Probably the most remarkable thing for me as I went through middle school was I happened to have a science professor who was a retired college professor from UNC and that was the first time where I think I was really impressed by a person of color who was such an intellectual and that I remember, as one of my favorite teachers, Mr. Craig (pseudonym), who challenged in different ways, because he simply was on a different plane, even though he was teaching middle school and so those experiences are the things that kind of shaped and prepared me for the experiences that I've had in my career and currently have in my current position even. 
Overall, while role models were perceived as positive influences and supports for the participants, Faye identified negative experiences with role models. In Faye's words:

The worst people in the world were my role models, because they were the people I didn't want to be like. The rude nurse or the nurse that did not have any tact. The nurse that was careless. The nurse that didn't take the time to hear what the patient had to say. The nurse that was just rude. The nurse that didn't want to continue any type of continuing education. Just wanted to stay where they were. So for me, it was the nurse, it was the worst nurse at times, were the role models.

In short, negative role models demonstrated behaviors that Faye did not want to emulate. Supportive Colleagues and Friends

From school to the advancement of their careers, friends and colleagues were influential in providing support and playing significant roles in supporting the participants as they pursued their nursing degrees. Friends often provided a strong social network important to the well-being of these individuals. A network of friends was available at a moment's notice during the high and low points of the participants' lives and careers. Friends were the individuals whose relationships were formed either during childhood, college, or work who listened to the participants and were available to come to the aid of the individuals when needed. They were trusted to provide a sense of objectivity for the participants when situations arose. Collegial relationships, while not necessarily supporting the career development of the participants, were also a source of support providing objectivity and emotional strength. They assisted the participants in arriving at resolutions to problems.

Additionally, some colleagues provided assistance with their career development with assignments designed to develop required knowledge and skills. As Faye recalled the influence of her high school friends, "It was the four of us and we all are graduates 
from Lincoln Hospital School of Nursing. We all got our B.S. degrees and our master's degree at the same time. So we were a support for each other.” Deidre echoed Faye's experience regarding the influence of friends this way: “That's been an important thing for me, at least to have friends who have similar experiences to bounce things off of and that support, those particular friends, were what really got me through graduate school because we supported one another.” For Tasha Allen, her institutional colleagues were supportive of her work. She said:

My colleagues, they are very supportive of me. If I, if we present an idea or we have an initiative that we need to implement to improve the care, they usually rally around me and do whatever it takes for us to get it done, because in the end, we all are better for it; and I'm always open to input.

Support systems were critical to the success of these individuals. The family laid the foundation; the participants built their careers; and the support systems of friends, peers, spouses, children, and colleagues encouraged and nurtured their careers. For many of the participants, these influential individuals were inspiring and offered guidance during their career progression. Fortunately, the majority of participants had mentoring relationships and positive role models during their careers. Because of the bond with their families and communities, these women understood that their success was a success not only for their families but also for their communities. They learned that their accomplishments and achievements were important to their people. Their family members displayed the work ethic and the value for work and for performing a job to the best of one's ability that the participants wanted to emulate. Also, teachers, colleagues, and peers were major influences on their careers by shaping and influencing them and preparing them for their careers, their lives, and the world outside. 


\section{Organization and Community Support}

As the individuals advanced in their organizations, many of their organizations offered support in terms of education, training, and development. These women understood that, in order to advance or to remain competitive, they could not remain stagnant. They took advantage of the opportunities provided in their organizations which allowed them to advance in their careers. Their zeal for learning also created within them the need for furthering their education. Common among most organizations was to provide the time and the financial support for the executive to attend seminars and workshops; however, a great deal of the learning was self-initiated. All participants indicated that their organizations provided tremendous educational assistance, supporting them in the development of their careers. Hope, Faith, and Jesusica explained how their organizations provided support. Hope stated:

By financially supporting me attending specific conferences like the American Organization of Nurse Executive (AONE) or Black Nurses Association (NBNA), but more recently a lot of the Institute of Healthcare Improvement (IHI) conferences on patient safety.

Faith explained:

They've pretty much supported anything I wanted to do in terms of growth and development. This institution, the reason I've stayed here is because it's always been very supportive of advancement. As long as I've been here, I have never, ever known a need to exist that the right people didn't appear to make sure those needs were addressed and then a lot of them address those needs and just move on.

Similarly, Jesusica noted:

I've had a lot of support in terms of them paying me to go to workshops, to seminars and even paying for my associations, to be involved in associations. I had one CEO that I think that very much invested, in terms of me growing and growing and moving in different directions. Making sure that I was in different circles and things. We did a lot of traveling together. 
In contrast, Tasha Allen alluded to the importance of self-initiating professional development experiences. She stated, "All of the personal growth, seminars, workshops that I go to, I'm given the time but it's self-initiated and of course, they do allow, they do give me the time to do it.”

As nurse executives have the ability to work in the community and serve on boards of various organizations, Deidre discussed the support of a community organization in her executive role. According to Deidre:

Three board members are people of color and they have certainly taken great pride and interest in my survival and have been the kind of people who mentor me and give me feedback and give me insight into approaching things because they have been, or were born in this community and so they know a lot just by nature of their experiences as well. So this has been the first opportunity where I've ever had that type of close mentor with and by people who also see and understand the details and the issues that are being addressed.

However, in contrast, Jesusica was not the beneficiary of as much organizational support in her career as she expected. She explained, "I also think that, by the same token, support probably wasn't as large as I would have wanted it to be in terms of reaching my next step in my career.”

As organizations and the community supported the participants in their careers, other sources of support and influence came from their spiritual base, the church, the church family, and the Bible and its principles, which helped to shape some of the participants' career development. The participants' belief in God and their spirituality was created by their parents. There was a strong reference among several participants to "God first and everything else after.” Having this spiritual influence and seeking directives from this influence was important to the participants. Faye stated, "I was brought up to have faith and believe in God.” 
God was their foundation and strength. The church was a place for some to develop their early leadership and speaking skills as they participated in debates, church plays, and teaching Sunday school. Jesusica added:

I think my church has played an extremely big part, again, in what I do, because I did the nursing, both as an art and as a science, but I had to take it another step up to the spiritual aspect as well because I don't think that we can be just human beings we're both physical and spiritual and mental and not address the spiritual things. So with me, again, I think when I hear people say now the thing about mind, body and spirit. I say oh I've been hearing that for years, I just didn't use it that way.

For Faye, several nursing assistants attended her church when she was growing up so she knew that nursing could be a good way to earn a living. Faye also observed that those who were nurses tended to enjoy their work. Additionally, the church elders knew her parents and grandparents. As a result, they were always inquiring about her progress at school and providing a sense of support and encouragement. Jesusica shared an example of support from a church member when she said:

I had another person that was very close to me growing up that was an elderly gentleman that was both in my church and also in my community and as I said when my father died I was very young, so we were aware of the fact that we didn't have plenty of financial resources; but when I first started through college, if that gentleman had not taken his own personal time to drive me back and forth to college for three years until I could afford to buy a car, I probably wouldn't be here today. I wouldn't be a nurse. But it was somebody that took the time and said, "I know she wants to do this."

Wisdom clarified, "My mentors are my parents and Jesus Christ; and that's just me.”

To summarize, the context of the support for the career development of the participants consisted of the role of spirituality, the family, nuclear and extended, their social support, friends and peers, the organization and their colleagues, and the community. As the women recounted their stories, the family was the most significant 
source of nurture and support for these women. Of note was the role of women in the lives of these participants, particularly mothers and grandmothers. Additionally, the role of friends and the creation of strong bonds with these friends was also a source of support. Friends were influential, very supportive, encouraging, motivating, and inspiring these women, especially when there was doubt. For those women fortunate enough to have mentors, they were found both within and outside their organizations. Many expressed concerns about not having a formal mentoring relationship, not that the lack of the relationship prevented career development, but how a mentor might have further enhanced their career development.

In addition to their organizations, the participants benefited from community affiliations, which were described as critical not only for providing support, but also for the participants developing skills and attributes necessary for enhancing their abilities to lead. In the early stages of their career development, many of these women faced challenges in their careers within the organization. Overall, these women received training and development, support, and encouragement. Additionally, the spiritual foundation of the participants and the support from their church and community aided the individuals in their career development.

\section{Theme 2: Guidance}

Guidance emerged as the second theme and encompassed the participants’ career decisions, career paths, career happenstance, career facilitators, career barriers, and the effect of career resilience. Many participants identified rather early in their childhood that they wanted to be nurses, but the participants' interest in leadership emerged only after (a) someone identified their potential, or (b) they believed that the influence 
achieved by attaining such a role would be best for their nurses, patients, or communities. The theme of guidance includes guidance for the career decision to enter a nursing career, guidance in educational preparation, guidance along the career path, guidance into nurse leadership and the executive suite, guidance to overcome barriers or challenges, and guidance beyond the executive suite.

\section{Career Decision: Nursing Career}

While all the participants identified nursing as their career choice early in childhood, few had plans to enter the realm of nursing leadership. Decisions to enter the nursing profession ranged from a participant being ill as a young child, as a child having an ill family member, including parents, or as a way to help people. For those with an ill family member, the nurse, participants were impressed by the care provided by nurses. Inspiration explained that her desire to become a nurse stemmed from her frequent hospitalizations because, "I was a very sick child with asthma, in and out of hospitals quite a bit, and nurses made an impression on me, and that's what made me desire to become a nurse ever since I was 7 years old.” The illness of Deidre's parents became her calling to a nursing career. She explained, "Unfortunately, my parents were in poor health as I got older and that gave me a personal incentive and passion to be in health care and being a nurse I think was the grounding thing for me.”

Tabman’s reason for a nursing career was that "since I was small, I think I saw nursing as a way to help people who I just wouldn’t help.” Having parents, other family members, or friends as nurses also influenced the participants' career choices.

Deidre said, "My mom was a nurse and that was a big influence.” Hope added, "There are some people in my family who are also nurses." 
For Faith, her nursing career started quite by accident.

I actually started as a nurse in the system, in a nursing home and actually at that time I wasn't, I really didn't know much about nursing. I was actually applying for dietary clerk role and they had a strike at the nursing home and they were looking for nurses and nursing assistants. So they talked to me into training as a nursing assistant. I just loved being a nursing assistant. The director of nursing at that facility at that time, apparently, was watching me and said, "You know, I think you would be a wonderful nurse. Have you considered going to RN School?” And of course, I hadn't at the time, but once she brought it up, I started thinking about it. When I was able to attend, I did. I've been in nursing ever since.

For Wisdom, her choice for a career, considering the era, was between nursing and teaching. As Wisdom recalled:

It was either a nurse or a teacher, because females were not doing all the things females should now. So I didn't want to be just any nurse, go to work, come back home. I wanted to be a nurse who made a difference. So even when I was in nursing school, I was always looking for ways to make things better, even as a nursing student.

\section{Education Preparation}

As evidenced by their interviews and a review of their curriculum vitae (CV), no one career preparation track took these participants to the executive suite. Returning to school and obtaining undergraduate and graduate degrees, which was self-motivated, provided the participants with the educational preparation required for career advancement. However, Wisdom, the oldest participant in the study, progressed to an executive position without undergraduate or graduate degrees. She subsequently received both an undergraduate and graduate degrees. Degrees ranged from bachelors of science degrees, master's degrees in business administration and healthcare administration, nursing and education, to doctoral degrees in nursing and business administration. All participants earned their master's degrees. Three held doctoral degrees with one enrolled in a doctoral program. 
Deidre emphasized the importance of educational diversification when she stated, "I think I’ve had doors of opportunity opened because I decided to diversify my credentials...it gives, I think, an important strategic advantage to us in health care as nurse executives.” For Tasha Allen, the impetus for pursuing advanced degrees was due to her not receiving a promotion she believed she had earned, even though, as she explained, she had filled the position on an ad hoc basis for 11 months prior to applying for the position. During the interview process, she realized, "I interviewed against a nurse who was from another city, who did not have the same level of experience that I had, [she was given the position] and I realized immediately, that it was about race.” She decided to return to school to earn her Bachelor of Science in Nursing (BSN) degree:

During that time, I went back to school because I hadn't focused on a degree and that was something that was a, I'd say for me it was a hindrance, even though it didn't seem to be a hindrance for some of my colleagues. But I went back to school, received my BSN in '88; continued to go to school; received a master's degree. In between, the master's and the BSN, I received certifications, ANA Certification in Psychiatric and Adult Mental Health Nursing.

Overall, participants decided to return to school, continuing their education. The participants valued education and understood its connection to their career development and success. Ultimately, as individuals committed to life long learning, the participants agreed that education, development, and training, provided vital knowledge, skills, and experiences necessary for their careers.

Career Path

Career paths to the executive suite were diverse and ranged from entering the profession as a nursing assistant, serving as staff nurse in a variety of settings, school nurse, educator, clinical nurse specialist, nurse manager, director of nursing, risk 
manager, quality manager, and chief operating officer. Common among all participants was that they started their forays into leadership with the charge nurse position, a role which assigns responsibility for nurses during a specific shift. Additionally, all held positions as nurse managers. Beyond the charge nurse and nurse manager roles, each participant had followed diverse routes to accession to the executive role. In addition, the participants' career paths did not show a linear trajectory but reflected the participants' willingness to gain valuable experiences, knowledge, and skills by pursuing roles rather than pursuing titles. For example, Jesusica wanted to become a cardiovascular clinical nurse specialist, so, immediately upon graduating with her bachelor of science degree in nursing, she gained valuable nursing experience by working in an open heart critical care unit in a university setting. While many of their careers were established and maintained in the hospital setting, several participants, including Tabman, ventured outside the hospital setting to expand their careers. Tabman recalled, "I left Mount Sinai to work at this program called the Door, a very special adolescent program, and again, I felt that that experience helped craft and mold my belief systems.” She also worked as an advocate with the International Institute of Health for adolescent empowerment and established adolescent mental programs in St. Croix.

Inspiration's 38-year career path led her to a variety of roles, including "staff nurse, nurse manager, director of nursing research, and director of multiple different areas across the organization.” As a nurse executive, Inspiration had the opportunity to serve as a clinician and a researcher and still stay engaged with patients. Similarly, Hope's career development demonstrated her diverse career path: 
I was a staff nurse until I got promoted... to do in-service education and then I went to a nurse manager position and then got promoted to assistant director of nursing, then heard about a V.P. of nursing, went to that and when managed care came about, I decided well maybe I'm going to need to make a change and then I became medical office administrator for a medical company, and then I realized I really missed the hospital setting so I came back to that as a chief nurse executive.

\section{Career Development: To Nursing Leadership and the Executive Suite}

Becoming a nurse was the participants' career foundation, but the impetus for achieving leadership and progression to the executive suite was because of inequities in patient care, poor treatment of nurses, and the sense of wanting to make things better. For Jesusica, her leadership talent was recognized from childhood, as she explained:

When I looked back through my childhood, it was almost like, I always wanted to be that lead person and I always just had that propensity for excellence. I wanted to always, not necessarily outperform someone else or compete with someone else, but I always competed with myself. I always wanted to be the best that I could be.

Faith and Tasha Allen were appointed to executive positions. For Tasha Allen, she was appointed as an interim chief nurse executive when her healthcare organization was in immediate jeopardy of losing its Joint Commission accreditation. On the other hand, identifying gaps in her organization and working on solutions to those gaps provided Faith with her career development advancement opportunities. As Faith stated, "So the doors open that way... when I became VP, I was not interviewed for the position and I was appointed the position.” Jesusica captured the essence of pursuing an executive career when she said:

When I made the decision that I wanted to really go into nursing leadership and that I wanted to, one day, [to] become the chief nurse executive in the top nursing organization, because we have these title proliferations where we change them around. But when I made that decision, the one thing I knew is that I had to be prepared to be at the table. I did not want to be invited to the table and just be a guest and not partake of the meal, if I may be metaphoric here. 
Another feature of the career paths for these women was career happenstance or a chance event which characterized the manner in which several of the participants became engaged in leadership positions. Jesusica, Hope, and Leslie were among the participants who accidentally embarked on careers in nursing leadership. As Jesusica expressed so succinctly, "Leadership for me was never really a part of my career plan. I tell people sometimes, I think I got into leadership by default, but it was definitely a calling.” Hope concurred, "I had never really thought about administration until I was asked to interview, just for the sake of it; for a job.” Similarly, Leslie explained, "I’ve not always wanted to be a nursing administrator. I kind of wound up here by chance.” Jesusica's leadership role was by default where two individuals were allowed to vie for a position and the capabilities of both were assessed and, according to Jesusica:

They were looking at both myself and someone else for the leadership of the unit, and it was interesting the way the person explained it to me as I received the position. They explained to me that there were certain feelers that they were putting out there and they were just waiting to see who would take the initiative or who would be motivated to go ahead and accomplishing those tasks without being specifically told to do so and I just emerged, and stepped up to the plate and did. So in that process then they decided to approach me about accepting the leadership position of the unit. So from that point on, I would say that I basically shaped my own career.

Similarly, Tabman was invited by an African American individual with whom she had previously worked to serve as an interim chief nurse executive "as she was asking the sitting chief nurse to leave and that was a profound kind of experience.” She subsequently accepted the role of chief nurse executive, a position she had held for over 4 years. Unfortunately for Jesusica, her career path was influenced by the lack of any clear opportunities for career advancement in one organization. According to Jesusica, who stated that she shaped her own career, when she queried her boss about potential career 
advancement opportunities, the boss said, “I’d never really given it a thought because you're so good; I didn’t think we could keep you here.” Jesusica explained why she left the organization,

And I saw that both as a compliment but kind of also like an oxymoron; because if I'm that good, you should be trying to keep me, but then what you're telling me is, you really don't think that within this organization, that you all don't have something to offer me that will want me to stay. So I simply took that as that wasn't really the answer that I was looking for because I do know that there were other colleagues here, some who are younger than me, that also were not African Americans, that she did have a plan for where she thought they would go. So I basically said, in that case then it would not behoove me to continue to stay here. I've been here for 5 years. I need to start looking, and I did, and that's how I ended up leaving that particular community hospital setting and going back into a university hospital setting.

While organizational and career longevity, staying in one organization throughout one’s career or one role for an extended period of time, were noted by some participants, career complacency was not. For two of the participants, Wisdom and Faith, the church and the bible influenced their career development. Wisdom explained, "In reference to developing me and coaching me and all of that, I'm strictly driven by biblical principles.” Similarly for Faith, “[I have] always been involved in church since I was a staff nurse in undergraduate school and that helped to shape my career.” The participants who mentioned the church discussed the importance of seeking guidance from a higher power before making specific career decisions.

\section{Career Barriers}

The Black female chief nurse executives faced many challenges and though some used the word "barriers" during the interview, the barriers seemed to be an annoyance, something that would impede them from their goals. Those barriers surrounded age, youth, inexperience, race, office politics, gender, physicians, and unethical colleagues. 
Jesusica and Tasha Allen discovered that after being promoted to nurse manager positions in their mid-20s, the challenge became supervising older adults who were not receptive to receiving directions from younger managers. Because Tasha Allen had been functioning in the interim nurse manager role for 3 years, she did not view inexperience as a nurse manager as the only reason for the challenge. Tasha Allen viewed this challenge as being not only about her youth but also about her race. Deidre concurred on the issues of race when she said, "I think, quite honestly, the greatest barrier, and it is sad to say, it still remains color.” Office politics, as described by Jesusica, were a challenge for her. She said:

I felt it was more of a hindrance than a help, because of the politics. You know just the politics that you get into in an organization and you just had to become politically savvy, that not everyone of your colleagues was going to love you and support you; and you just have to be able to identify those individuals or learn how to work with them as well as to learn how to work around them, and sometimes, just learn how to out-work them.

Lack of information sharing was another challenge raised by Tabman, "The people I work for don't share any information.” While office politics were a challenge for Tabman, for Hope and Inspiration working with colleagues who lied and "who were just vicious, who try to undermine you” was their challenge. According to Inspiration, "Despite what might be going on in the organization or with a group of colleagues, people can be resentful and you can either just acknowledge that it exists and they can be jealous. You can acknowledge that it exists, but not be influenced by it.” For Faith, her friends were her challenge. As she started her career, her challenge was not to listen to friends who were discouraging her from pursuing her career. "When I first told some of my friends that I was going into nursing, some people thought that I wouldn't get 
accepted because they didn't think that many Blacks could get accepted into nursing at the time in an RN school.” She added, "I think that the one thing I could not do, being Black and female, is to listen to my friends because if I listened to them, it was always about what was not possible versus what was possible.”

Wisdom summarized the participants' views of barriers when she stated, "I think there could have been some perceived barriers, but I didn’t interpret them as barriers. I interpreted them as opportunities, you know, to even do more.” She added, "I never saw barriers. A lot of people would have said, 'Well, your color could have been a barrier.: No. Or your social status. No, I didn’t see it. I always saw it as opportunities.” Similarly, Inspiration added:

I think that they, what I would probably say, there have been times when individuals within the organization, may not have been on the same page as I was. I don't see that as a hindrance, I just use [the term] "a difference of opinion" and I don't allow that difference of opinion to shape my experience. I just acknowledge that it exists and move on.

As for Denise, “My greatest barrier? I didn’t have a barrier. I did achieve my career objectives.”

\section{Career Facilitators}

Family, friends, mentors, and organizations were among the career facilitators for the women in this study, whether it was obtaining support from faculty while in college, through additional reading or assignments, or mentors. For two participants, Leslie and Tabman, addressing the issues of inequalities and healthcare disparities for those in lower socioeconomic status were career facilitators. Inspiration's career facilitator stemmed from her ability to "know the importance of letting go and not trying to hold on to perceived highs when they are beneficial to you. That's what has enabled 
me to move forward.” For Tabman, being involved with a very powerful hospital and working with the mayor served as a facilitator for her career. She said:

I think my past work with the mayor in these kinds of organizations that I had, my credentials also gives me the ability to plough through and plough up some of the things that stand in my way at work. Those have been facilitating in my career.

Unlike other participants, Inspiration`s career facilitator was her decision to remain in one organization for her entire career. As Inspiration explained:

I believe, and my career has proven that, that with knowledge and skill and the willingness to be able to open up to possibilities, you can overcome those barriers not only through your personal ability and knowledge, but to aligning yourself with a variety of individuals and having very diverse mentors in your professional career.

Career Resilience

Career resilience reveals how these executives dealt barriers to their career development. Keeping focused on the mission and vision of their organizations aided the participants in aligning their roles for the betterment of their stakeholders. Several participants, from school throughout their careers, displayed career resilience. Persistence, negotiating skills, relationship-oriented, the ability to analyze a situation, confidence, willing to go the extra mile, and a "never-can-quit" attitude were identified as characteristics of these women dealing with career barriers. Tasha Allen explained that while she attended college, "Every day I tell myself, you're a step closer. As long as you stay in the program, you're a step closer. Nobody can take away your dream, and I made my way through school.” Regarding career barriers, Tabman said, “I was very, very adamant about blowing them away, dissolving them or climbing over them.” Establishing her own reward system for the work she accomplished as a career executive was critical for Inspiration's survival in her executive role. She said: 
So anyone who keeps up with what's going on in the profession knows that this role ... does not come with a lot of rewards. You must make your own rewards. It's not about financial rewards. ... I think people can also try to hold you back, but that won't occur if you're strong enough in your beliefs and you align your beliefs with the mission of the organization. So you are perceived as a must-have and therefore you will gain much than being bitter by someone who is being resentful and just jealous of you.

Illustrating her reasons for not quitting, Deidre described how she experienced a

humiliating situation when a voicemail circulated in her organization after she applied for an executive position. She said:

I had a choice to make at that point in time. I could decide to withdraw from pursuit of the position or I could decide to insist on being there; being present; participating; doing the job and changing their perceptions by experience if nothing else and it was a tough decision to make, because I worked and I ended up, for the next 3 years, working with those same people whom I know had that sentiment. Yet, I had to get the job done with them and through them and it was crushing. It was crushing quite honestly.

It's been more of a self-motivation and a call to service quite honestly. I believe that I have a responsibility as a person of color, as a leader, as a person who has opportunity to forge the way and open up new territory and try to correct some of those ingrained thoughts and ideas, and so I really kind of, that motivates me, because I believe I'm a pioneer, in especially stepping in the roles that no one like me has ever served in before.

I'm a risk-taker and I probably confront them head-on. Again I just have that sense of responsibility in trying to open the door and keeping it open for other people who certainly are worthy and deserving and prepared for an opportunity and I just try to be that example when I see injustice, I call it what it is. That's not necessarily popular, but necessary; very necessary. Because I think, quite honestly, until you have someone who's different; until you have some diversity at the table, the norms, right or wrong, are the norms and I think you get to a point where, you don't see anything wrong until you have somebody who's diverse enough at the table and brave enough to say, wait a minute, have you ever thought about what it's like on the other side? And so, I am the kind of person who will speak to those things.

Jesusica, however, has benefited from working with those leaders whom she believed had valued the presence of Blacks in executive positions. She explained, "I feel that I've also 
been blessed that I've been in the right place at the right time. Some people were actually looking for an African American to put in certain positions and I was there and available for that.” And, in the end, according to Wisdom, "I think if I had just seen myself as Black, and I am Black, but if I had seen that as a barrier, I wouldn't be here now.” Jesusica expanded on her comment by explaining how she handled the experience of being Black in the American culture. She said,

I knew that in our culture, in the USA, there are certain things that are just not going to go away. They're just not going to go away. You have to rise above all that; and in rising above all that, make sure you, make sure one, you have confidence in yourself; make sure number one, you know what your personal goals and visions are; and what does sit tight and fits in with the mission in an organization that you're in, say a hospital. You've got to make sure of your personal things first. You've got to be comfortable in the skills and talents you bring to the table. You've also be willing to go back and get them; and even if you have them, you've got to make sure they are validated and they have to be validated by a certifying body.

Beyond the Executive Suite

Although the participants in this study were over 50 years old and some were talking about retiring, many were still interested in pursuing additional executive roles. For those discussing retirement, it does not imply the end of their careers. Many saw themselves taking on other roles in their post-retirement phase. The participants admitted that continuing to learn and to grow in their executive roles was preparing them well for their post-retirement careers.

Many saw their current roles as chief nurse executive as attaining their career objectives. However, two participants (Deidre and Jesusica) were open to becoming chief operating officers or chief executive officers. Jesusica pointed out, "But I would never leave any part of my nursing foundation, because I would always be a nurse.” 
Varying reasons and experiences led these participants to pursue nursing leadership, including unfair practices, healthcare disparities, and a belief that one could do a better job. While they believed they had to prove themselves, some identified early in their childhood that they wanted to lead, they wanted to be in charge. Several role models, while not providing explicit knowledge, were implicitly demonstrating the required competencies for leadership. These individuals provided additional stretch assignments, such as volunteering for new roles and responsibilities.

\section{Theme 3: Diversity}

Doors may not just swing wide open for you. You have to look for where there's a crack or, again, where there's an opportunity and match your abilities with whatever that opportunity is. (Faith)

In this study on the career development of Black female chief nurse executives, diversity as a theme emerged from the data analysis as some participants explained its impact on their career development. Race was the most prominent category related to diversity and for some, the issue of race and racism was voluntarily addressed while others only discussed the topic when it was raised during the interview. The role of Black leaders, racial issues in patient care, gender, having a voice, and having to be twice as good were additional categories which emerged to create the diversity theme. Wisdom, Faith, Tasha Allen, and Jesusica were among the many participants who grew up in a segregated society during the era of fighting civil rights and against inequalities, a time when integration was forced upon them. These experiences served as an inspiration for overcoming challenges in life. These participants were never ashamed or embarrassed by who they were and from where they came. The communities that nurtured, protected, and produced these individuals were vital to their survival. They learned to look beyond the 
color of their skin, not ignoring the fact that racism existed and, in some cases, was manifested against them to the larger, more complex problems facing society and how they could best alleviate these problems.

Although racism was perceived as a barrier, the participants did not allow the negative impact of racism to affect their career development. All the participants, even those who were bused to schools during the advent of court-ordered integration, did not perceive themselves as victims. Even though no one in this group saw herself as oppressed or a victim, each viewed racism as another challenge which each had to overcome. The women did not attain their positions by being weak; they understood that they had to be "twice as good and work twice as hard, be prepared twice as much" as their other White colleagues. Fortunately for these women, they had strong foundations and were raised by families who told them earlier in life that they were great individuals capable of achieving any goal. These individuals were given the foundation and the expectation that in order to accomplish their goals, they would be better prepared, more knowledgeable, and be one step ahead of other individuals.

\section{Black Leaders}

Whether they were a student in the nursing program, a leader, or a nurse executive, several of the participants discovered that they were, at times, the only African Americans in their nursing programs, leadership and executive positions, and at meetings. They believed that they had to bear the responsibility for how Blacks, in the future, would be defined and perceived. Faith explained, “When I was being recruited after my master's degree, I was primarily the one who was cutting the path. You weren't going to go into an organization and find another five or six of you, maybe one or two of me.” 
As a result of this lack of Black leadership, others envisioned the need to nurture and to develop future Black leaders and encouraged several participants to advance in their education and careers. Jesusica, Deidre, Faith, and Wisdom noted that they were pioneers for their profession as one of the few Black executives in their organization. They understood that their career advancement brought with it the responsibility and burden for, in Deidre’s words, "being able to sit at the table” and engage in the discussion about nursing, nursing care, disparities in healthcare, and health care in general. Jesusica commented on the lack of Black leaders:

We already know that, even today, there are not that many African Americans that are in leadership positions, especially within nursing and, therefore, I didn't have that many people. In the leadership program at the time back in '84, I was the only one; and even when I was doing my clinical specialty, the cardiovascular nurse specialty aspect of the program, out of 50 some students, it was two Blacks. I didn't really come up during the time where I was going to find African Americans employed, and I think again, I was coming up in that era where I don't think that many Caucasians were thinking about African Americans as going into leadership roles, not especially those who wanted to aspire to that top office.

Race Issues in Patient Care

Faye, Tasha Allen, and Tabman entered the nursing profession, and they witnessed the disparities in healthcare, which framed their commitment to caring for those less fortunate. Their early experiences with racism and their subsequent observations of disparities in healthcare for those with low incomes propelled them into nursing leadership. As Tabman said:

The impact of racism becomes like the dynamic tension that continues to catapult me, to drive me. I think, I guess, I really become outraged when I recognize disparities, injustices, and efforts by others to ensure that people who are of a different economic level or lower economic level or of a different color or culture, are not provided with the same equal chance. 
Tasha Allen explained her observations of racism, during her early career days.

A lot of racism was prevalent during that time, and we always worked on the south wing, because of segregation, and as I watched the nurses care and provide for the patients, it gave me a sense of wanting to do more to ensure that they receive the best care that I could provide for all of my patients, even if they were not given access to the most up-to-date treatment.

Unfortunately, racism toward the participants was also displayed by patients placed in their care who did not want care provided by Black nurses and physicians who did not want their patients cared for by Black nurses. Tasha Allen and Wisdom described their experiences. Tasha Allen learned:

When I graduated, when I first graduated, the physicians wanted, one in particular, wanted me to address him as sir and say "yes sir" and "no sir," and I had been taught as a child that yes and no was suspicious. I share with you that they moved me from the south wing, which is where the predominant population of Blacks were, to the northeast and west wings and, of course, one of the physicians didn't really particularly care for me to provide care for some of his clients, but I was there based on my competence and my determination to be the best at whatever was doing. In the long run, though, we had a mutual respect for each other. We developed a mutual understanding, but he was a barrier.

Wisdom commented:

When I first started at Children's, they called White nurses, “miss.” They called African American nurses, "nurse." So when I came as one of the two African American nurses that Children's had at the time, I came in calling myself "miss," and it really upset some of the doctors who were not used to that. In fact, one of the doctors he would call me in and I would say identifying unit and say Miss. Wisdom; and he would say Nurse Wisdom. I say, Miss Wisdom; Nurse Wisdom; I said Ms. Wisdom. So he came up one day and he had the supervisor with him, the nursing supervisor, and the nursing supervisor says, Dr. $\mathrm{H}$ has a problem with the way you answer the phone. I said I'm willing to talk about it, and he mentioned what happened and I said, I am Miss Wisdom. And he says, When are you going to realize you're Nurse Wisdom? I said, 'Sir, you can call me anything you want to. I will always call myself what I want to be called, and I want to be called Miss Wisdom.”

Conversely, Faye had to deal with the patients' perspective of care from Black nurses.

Faye added observations about how she learned to recognize racism and bias. 
You learned to recognize racism. You learn to recognize racial biasing. You learn to recognize that there were some patients who didn't want you anywhere around them. You recognize that there were some patients that were glad to see you and wanted to accept the care that you provide.

In the end, as Faye explained, her experience made her, rise above the prejudice and the idea of someone not wanting care for you because you are Black.” When dealing with the issues of racism, Faye viewed her race as an asset. She said, "Being Black has been my greatest asset. It allows me to sometimes say some things that other people wouldn't be allowed to say, and I would be heard."

Inspiration, a preeminent nurse leader who had worked in the same healthcare organization for over 38 years described her experience with racism which had existed throughout her career. According to her, "racism continues to exist today; and that is the perceived prejudice, sometimes perceived, sometimes real, of organizations and particularly those organizations that one would title as mainstream organizations.” Inspiration commented that as an African American, she believed that, at times, prejudice had hindered her in her career and in terms of what others perceived when they saw her. Deidre corroborated Inspiration’s experience and commented, "I think, quite honestly, the greatest barrier, and it’s sad to say, it still remains color, quite honestly.”

Inspiration shared that in her own institution, when "I’m making rounds, I can see the surprise on some of the patients' faces when I introduce myself as the vice president of nursing." When she attended speaking engagements, and this was prior to people sending her biographic information, along with a picture to the conferences, many individuals throughout her career, expressed their surprise when she arrived and discovered that she was African American. Inspiration stated, “They didn’t expect an 
African American executive to be able to speak about Topic A or Topic B.” Deidre shared similar experiences:

Growing up in West Virginia, the population of people of color is less than three percent so I had the opportunity to be the first and the only in a lot of different things and different ways. So I think it prepared me for the reality of the situations I found myself in professionally now, because I've been the first and the only Black and the first and the only female in just about every role I've ever had in a leadership capacity and in that setting, growing up in a place like I did, has made me quite comfortable. When I look around the room and there is no one as far as the eye can see who looks like me, I'm not taken aback by that. I can tell my audience often is. What I realize is, they're sitting there, they're looking at me and their mouths are hanging open and they appear to be paralyzed, I realize that they are stunned, and they marvel at the fact that someone who looks like me is leading the session or at the front at the podium and that is different for them and that I realize they are having that experience, but I've had that experience my whole life and so I step outside of myself periodically to observe them observing me.

I've been afforded an opportunity to get my foot in the door and, quite honestly, sometimes I got my foot in the door quite unseen because they saw my resume or they saw my credentials, they saw my name, they talked to me on the phone and they painted a different picture than who presented as a person of color and so I've had experiences of literally being given jobs over the phone and then when you get to the stage of actually having the face-to-face interview, that look of jawdropping shock prevails, and there's nothing different other than the fact that the reality of this is actually a Black woman, hits them. And I've seen it. I've actually seen people who have interviewed me and subsequently hired me, admit it to me, that we had no idea that you were Black.

While the participants may have been hurt emotionally by someone who made a snide remark or questioned their abilities, what they learned from these experiences is, as Inspiration, similar to Faye, said, “to rise above that if I am to be of any use.” While it has been a challenge, they know they could overcome the challenges. Their life experiences, including their childhood experiences, certainly prepared them, to some degree, to expect these situations. They understood that many aspiring nurse leaders would not want to, as Inspiration noted, “put themselves in that position, where they're going to be challenged daily, not only by the work but by the fact that you're African 
American at a high level in the organization.” Inspiration concluded, "I believe that being a female in a nursing profession is to be expected. Being African American in a top role is not to be expected and, unfortunately, there are not as many individuals as you would like to see in these roles.”

Proving their worth and abilities as Black women remained a challenge for some participants. As Jesusica and Deidre explained, because of career succession planning and probably without a degree, given their capabilities and knowledge, they would have advanced faster were they White. In Deidre’s words, “As a Black female, one must be more qualified in order to succeed” and have similar opportunities as Whites. They have seen those with less qualifications advance because they were not Black. They perceived that Blacks would not be promoted without the requisite qualifications. Jesusica explained:

We were kind of given that expectation that in order to succeed you're going to have to be one step ahead of the game. You're going to have to be a little bit better. You're going to have to know just a little bit more. So I think we have a tendency to approach life a little bit differently. I can't say we, I mean me. I can speak for myself. So I've had a tendency to approach life a little bit differently because not only did I feel that I had the burden to be as good as I could be, but I also knew that if I was the first in so many situations and positions, then I would also be leaving a pattern and an impression as to what people would perceive about other minorities as to whether or not they can do the job or how effective they could be in the world.

However, for Faith:

It's not to focus on the fact that I'm a Black female. I tend to see myself more as what I'm trying to achieve. I rarely define myself as a Black female. It's kind of like I rarely define myself as the vice president of nursing because I'm very relationship-oriented and so when I'm working with my folks, I'm working with them from that standpoint in terms of whatever the higher calling is. So if I'm in the board room, and look around and say okay, you know, I'm the Black female in the room so how will I get the board members to listen to me or to pay attention to what I have to say or whatever. I start from the premise of what the message is. 
Deidre recounted a terrible experience once when interviewing for an executive position. A colleague campaigned against her attempts and left a voice message which circulated to other colleagues questioning why anyone would want to take orders from a Black woman. Deidre commented that while she was qualified for the job, she concluded that "regardless of credentials, regardless of experience, unfortunately, it's still, at the end of the day, a lot of the challenges and a lot of the obstacles, still center around the color and do you look like us enough?” Deidre added:

I was the first person of color or the first woman to serve in the role and you know, that has given me a sense of responsibility where certainly I get weary, I won't quit because I know if I quit, then unfortunately, society still sees each one of us as a representation of all of us. Work is a battle. It's a battle on a daily basis and I need a place of respite. I have a sense of responsibility for one, for being Black and for being a woman, to try to make the path a little brighter and wider and smoother for the next person who comes along. Most of the positions I could say that I've been in, either did not exist before, they were new positions, or I was the first person of color or the first woman to serve in the role and you know, that has given me a sense of responsibility where certainly I get weary, I won't quit because I know if I quit then unfortunately, society still sees each one of us as a representation of all of us.

Tabman's experience with racism was similar. Tabman won a scholarship and attended an associate degree program in liberal arts in her hometown. Tabman remained at home and did not accept a scholarship to a southern school because she was very afraid of encountering racism, which she believed was more prevalent in the South than in the North. Remaining at home did not shield Tabman from the pain of racism. Tabman described her experience with racism in this way.

I lasted all of one semester [at the college] and told them where to put their scholarship. It was the most racist environment I had ever been in my life. There was a full live Klu Klux Klan of Long Island in New York City, who literally shot at one of the students. There was a very good nursing program However, the director of the program did everything to discourage the Black nursing students, 
and I got the message very early. Some of the students I witnessed that semester who should have been progressing on at the later semesters were terminated would also share with me that that was their attitude.

In the end, Tabman concluded that an education was important because, "In order to break out of any oppressive situation, you have to be empowered.”

Wisdom entered the field of nursing during the segregation era and worked at the same hospital in which she was currently a vice president. Wisdom recalled having to enter the hospital through a different door than her White colleagues; she had to eat her meals in a cafeteria designated for Blacks. However, those experiences, along with her childhood experiences of seeing the Ku Klux Klan riding through her neighborhood, influenced her perspective on life and her career. Wisdom stated:

I actually learned a lot of things that I practice now, when I was growing up. Well, I was blessed with, and another thing, when, I grew up in segregation okay. I know about the Ku Klux riding through the neighborhood. I know about running into the house out of fear. I know about the cross burnings in the back. I know about all that stuff. So I was brought up to the point wherein that should not determine how far you go in life. So a lot of my drive is motivation. I was also taught that God first, and everything else will follow, and that's pretty much me in a nutshell. I would still say that I was blessed. I was blessed to be here at the right time.

When Tasha Allen moved with her husband to a United States military base in Germany, she applied for a position as head nurse of a psychiatric unit (her clinical specialty) vacated by the untimely death of an individual. She believed that she was qualified for and would get the position, especially since the other individual who applied, who was White, was a colleague with gynecological nursing experience. The position was not given to Tasha Allen but to the individual without psychiatric nursing experience. Tasha Allen explained, "I was aware that I was more competent; I was fully aware that my knowledge base exceeded hers, but my color was the barrier; my race.” 


\section{Race and the Being Twice as Good Phenomenon}

A frequent refrain for several participants throughout their interviews was the need to be twice as good as their colleagues in order to be successful. Hope expressed the sentiment regarding the performance expectations of Blacks. She said, "You had to be twice the nurse the White students were in order to get any praise or any accolades. I still believe that you have to be twice the nurse executive.” Similary, Leslie surmised:

I think that there are some people, well not everybody, but there are some people who, at first glance, at first meeting, underestimate your intellect, your commitment, your general knowledge of your job and what you're going to be doing. Because for some people, I think, there is still that little bit of, you've got to be twice as good and work twice as hard in order to measure up to the same standard as someone who is not Black, who is mediocre.

\section{Impact of Gender}

As participants of a female-dominated profession, the women in this study perceived no basis for gender concerns. Additionally, advancement in the profession of nursing, a predominantly female profession, was not necessarily seen as outstanding because it was an expectation.

However, other participants in the study perceived their gender was a challenge in a male-dominated society. As Tasha Allen explained:

I didn't allow myself to not be respected by the physicians. It influenced my career choices, but it also hindered me in that, I was Black female.

I think that I've been second-guessed or sometimes because of my gender, in dealing with, as I stated a predominantly male leadership team or executive team, often I've been told I'm too compassionate. I'm not as objective as I need to be. So maybe that's just being a female period.

Faith summarized her experiences this way, "I think any female, whether Black or White, in a predominantly White male world, will struggle ... If you're able to overcome and focus on [the] issue, it's easy to get at what you're trying to get at.” 


\section{Voice Visible Invisible}

Another subtheme was being the visible invisible person, which occurred to several participants where their voices were disregarded in meetings. Several participants discussed the challenges of being female, where the ability to lead is questioned, and recommendations are ignored. For these participants, being Black females in a predominantly White male executive world, they still struggled, at times, for their voices to be heard. The participants needed to use another voice to be heard and to give credence to what they had to say. Even in these circumstances and challenges, they remained focused on the issues, the desired outcomes, and learning what it took to achieve their goals. These participants sometimes experienced that their ideas and recommendations were not validated. For example, Faye explained, “If I'm in a meeting and they're talking and I'm the only African American in the room and they would be talking about different issues and patient care, it was almost as if I wasn’t in the room.” She further explained that when such situations arose, she made a decision when to address or ignore the event.

Then there were times when you would make suggestions and people would ignore it and then someone else in the room, White, would make the same suggestion and then it was, oh what a good idea. And sometimes, if I felt like it, I would say, "So what was different from what she said and what I said?" if I really wanted to push the issue, and I just listened for the response. Then there are some times, if it didn’t really matter, I just didn't respond.

Tasha Allen concurred:

My proposal that I made was totally overlooked but a gentleman sitting next to me obviously heard it, understood the value of it, rephrased it, but said the exact same thing almost that I said and it was accepted readily and of course, that was not pleasing to me. But then when I thought about it, it mattered not, whom the idea came from, it was a win-win situation. So I had to stop and look at it that I actually won. It was a win-win situation for me, even though it was not attributed to me as my idea. 
Being Black and experiencing racism, although a challenge, was not a barrier that impeded these women in their career development. As Wisdom expressed it, "It challenged me more. I had to be better than the best. I had to give more; sacrifice more. I had to prove more, and I don’t think that has changed and I don’t think that will ever change.” She further expressed the sentiments shared by many participants that in her career and life, “I don’t see color. I really don’t. I see people. I see people. I evaluate people and deal with people based on what they bring to the table, and it has nothing to do with the color of their skin.”

Faye, Wisdom, and Deidre offered recommendations for handling racial issues. Wisdom cautioned, “Black executives can’t go into settings with a chip on their shoulders, but they have to hold people accountable for what they say. You have to hold those people accountable.” Deidre emphasized the need for dialogue about race and racism and the lack of diversity in healthcare and leadership.

Theme 4: Servant Leadership

Whether planned, appointed, or by happenstance, once these women accomplished their career goals, the next step in their career development became a sincere, at times. obligatory desire to give back. This desire to give back became their life purpose, the sense of caring, about patient, nurses, and the need to make a difference to the community was the final theme which emerged from this study. As these women advanced in their careers and became successful, their passion for nursing and patient care became strongly evident. Nursing was their foundation; it was in their hearts; leadership and serving in the executive role enabled them to live their passion. The participants would always be a nurse first, involved with direct patient care, and a nurse 
leader second. These women realized that they had to perform; they had to complete the mission of nursing with passion and represent nursing.

Nursing was their foundation and their first love. Obstacles were not reasons to divert them from their mission. They understood that if they were going to lead nursing and represent nurses, they had to still be a nurse and be knowledgeable about nursing and the people they served. Their nurses had to know that their leaders were committed to the profession. The successful nurse leader had a commitment to a work force which touches the lives of patients and could assist patients to achieve their health goals and bring them as close to wellness as possible. This was the most rewarding part of their leadership role. The women learned to use their positions of leadership not for the benefit of self but for the greater good of their staff, the patients in their care, and the community. As they advanced in their careers, these women also became more powerful patient advocates. For example, Tasha Allen expressed her agenda this way, "[I want to] make health care equitable for everybody, for all patients, regardless of social or economic resources... if I'm able to receive the best care for whatever my illness is, then the homeless should have access to the same level of care.”

Passion for Nursing

The participants were not only passionate about the ways patients were treated but the way nurses were treated. They advocated for policies that would affect and benefit the greater community. Inspiration indicated that the role of health professionals is to "not only be client-focused at the individual level but, more importantly, to try to improve the capacity of the healthcare system to deliver care to all people. That's what drives my commitment in health policy.” 
Jesusica agreed with Inspiration and wanted to see more nurses involved in creating policies. She enthusiastically stated:

It [nursing] was just in my heart, I was destined to be a nurse. To me, nursing was my planned career. That was my planned career. Management, sometimes I say I got into it by default but I enjoyed it. I love the journey. I would do it over again. Yes, I probably would. Any aspect of nursing, I would do it again. I love it.

To determine if one was truly committed and passionate about nursing, Jesusica also added:

I tell people, you need to ask yourself is this something that, on my worst day and at the end of my worst day, I can get up the next morning and still be excited about it. You still think you want to do this. Because I tell people on my worst day when I feel like everybody is just going to beat up on me for nothing, alright I lost every battle that I had, I could go home, go to sleep, think of something creative, innovative and go back in the next day just as energized as I could be.

Likewise, Tasha Allen explained:

These are the people that no one else wants to care for. If they close down the facility, I'm not sure where our clients will receive their care. We have become family to them, and there are clients that we have that have been with us 3 years or more. We're their family and those nurses that are truly nursing, nurses and in nursing for the love of high care.

I wanted them treated like I would want to treat myself or one of my family members in terms of care, in terms of respect and dignity. Not for their care to be based on their ability to pay or who they were or who they weren't. And I guess I became a patient advocate back then.

Faith concluded, "I believe that nurses will be the one that shifts the dynamics as it relates to improving overall health and community." To facilitate the development of nurses who will have an impact on the health of the community, Jesusica identified and mentored them. Jesusica explained, “I’ve been very pleased that I've mentored so many high school students into nursing.” 
Reflecting on the personal beliefs and values of the participants provided a lens to understanding their passion for nursing and their commitment to giving back to the communities they serve. As Faith reflected:

One must keep your eyes on your goals, build on your own foundation and ask, "How can I be the most helpful? How can I create the most good?" So that's how I kind of ended up in all of these different kinds of activities.

For Jesusica, "In the end, ... was I going to take that introspective look and say, 'did I truly do my best?’ And if I did my best, then I was going to be satisfied with that.” Similarly, Deidre said, “I tell people to pursue your passion and not a title and don’t hold on to a title or position, simply for the sake of doing so.” In Tabman's view, doing the right thing was important and, more importantly, as she said, "Do right because it’s right to do. Don’t do right because someone’s watching you.” Leslie agreed:

I want to see things done right, I tend to, you know, I do what is required to get the job done. So that means working extra hours, and I do that. I don't like half doing anything. So before I do that, I will put in long hours. But I believe that, you know, if you're going to do something, you should do it the right way.

\section{Community Involvement}

Based on the participants' philosophies, passion, and persona, as a result of their success, these participants became active and activist in their communities. In service, they were giving back to their communities while ensuring the visibility of nurses and their organizations. The participants served on civic, social, national, and local nurses and healthcare associations and on the boards of Fortune 500 companies. According to Jesusica, “So as you're giving, you're also learning.” They participated in organizations where they helped to shape policies and procedures to address healthcare disparities, serving the poor, underprivileged, offering free care. They had seen their parents work 
hard, valued the support they received from their communities, and understood that with these "blessings," they had to help someone else. In turn, the participants benefited, by learning business development, leadership, finances, communication, and networking skills.

Faye, for example, developed relationships and learned to write grants while serving on the Colon Foundation and then used that expertise to write grants and raise money for health fairs, "for those patients that could not afford a mammogram or prostate screening.” Faye added:

Well, we call it our "spa day" and women are invited in from the community and they have mammograms. They have a faculty from Duke that would come in and give us a lecture on imaging. I invite the community college to come in, beauty college to come in a do facials and nails. I invite the physical therapy school to come in a do back massage

Similarly, Inspiration described how she had used her numerous roles, knowledge, and skills to help the community and, vice versa, the community has collaborated with her organization in research projects. Inspiration summarized, "I made sure that I was involved in the community because leaders just cannot be tied to the organization of influence. You had to know also how to interface with the larger social structure within your community and your society.” Inspiration and Deidre shared their sentiments regarding their service to the community. Inspiration explained, "I've always been about how could someone use one's knowledge and ability to help the larger society and still I've been very active in community organizations and served as president for several of them. I see that it's a give and take.” And Deidre added, “it's been more that, being in a position has given me an opportunity to serve.”

\section{Staff Development}


Servant leadership is also evidenced by the participants' commitment to formal mentoring and developing nurses and nurse leaders. They became committed to, giving back, to teaching leadership and management principals and skills, emphasizing critical thinking and problem-solving and the importance of continuing education. As nurse executives, the participants felt responsible for instilling a sense of confidence in the abilities of nurses, empowering them to manage, and teaching them when and how to make decisions that would benefit the greater population. The participants understood their mission, vision, and challenges within their organizations. They understood that their role was to help the organization attain its goals. Nurses currently interested in leadership positions have had the wisdom and the expertise of these executives whose organizations, with the encouragement from the executives, were hosting leadership training and development programs and yearlong management fellowship and residency programs. Career ladder leadership programs and succession planning were established. The goals of such programs were to prepare future leaders with the required leadership competencies, certifications, skills, and abilities for executive positions.

Faith’s organization had dedicated and targeted leadership support programs for African American nurse leaders, and members were sponsored for an annual retreat and attendance at the National Black Nurses Association meetings and Black Nurses Day on Capitol Hill. In Jesusica’s organization, she identified:

Those individuals that you think are rising stars and you begin to invest in them. For example, and I have to be honest, I haven't just done this for African Americans, I've done it for Caucasians as well. But like I've identified those directors who I think have the potential for going further and I've put them through my Wharton management program; or I would put them through other. Sometimes I'd let them select the leadership program that they wanted to go into. 
I've mentored two nurses at the mid-level, director level into CNO positions. That's my joy. Whether I'm mentoring somebody to go into nursing or mentoring them to take a nurse manager, mentoring them, I see this as part of my role now. To make sure that that next generation who wants to go there and can get there and can get there quicker and without as many bumps in the road.

Faith also emphasized the need to develop future leaders. She said:

We need to just begin to identify and groom other nurses, but we need to start finding them early. We need to almost get back to the time that they are in undergraduate school or as soon as they become, you know, move from their first year of being a nurse; and I think we need to start looking at the charge nurse as the entrance level into nurse leadership positions and really begin to groom those people and encourage them to apply for chart nurse positions and then give them educational support to do that; and encouraging them to look at nursing as a career pathway and go ahead and go into national programs that will teach them nursing on leadership or nurse executives, you know, or graduate programs.

The stories of these women revealed that their career development path to the nursing executive suite included factors such as a strong family foundation, friends, peers, and mentors, and an understanding of the important role of self and what it takes to accomplish one's goals The interdependence of self, family, organizations, race, and the ability to move forward despite challenges were necessary ingredients in propelling their career success. Regardless of the challenges encountered, these women operated from a position of strength and were confident and never allowed these challenges to stand in the way of their true passion, their commitment to nursing and to patients. Involvement in the community provided the participants with the opportunity to learn by participating on projects, networking, and enhancing their visibility within their communities and in their career development. Further, the community organizations provided support, learning, and a means to give back to give back to their profession and their communities.

The propensity for excellence was described by several participants as a critical characteristic for leadership. They were competitive with others and themselves and 
always wanted the best, to do their best, and be the best. Their commitment to excellence allowed them to build their careers by identifying gaps within their organizations and communities. Then, fixing these gaps created opportunities and opened doors for leadership roles starting at a unit level. Choosing to remain employed over an extended period in an organization allowed participants to gain credibility and allowed others in the organization to identify participants' talents, knowledge, skills, and abilities. Thus, opportunities for career advancement were offered.

Although the career development paths of these women were varied, a key to the success of the women in this study was that they had developed unique perspectives and abilities for dealing with barriers. These barriers did not interfere with their career development. They sacrificed personally to achieve their goals. Fortunately for them, mentors were noted by many of the participants. Because failure was not seen as an option for these individuals, it was left to them to learn and to develop the knowledge and the skills necessary to perform in their new roles. Whether it was obtaining the education or the training, these women showed initiative and created their futures. They enrolled in classes, took advantage of continuing education offered by organizations, and also learned by observing other leaders, staff, and managers. As children, the importance of education was emphasized for these individuals. They loved to learn and saw the value of education more as a preparation for opportunities, the unknown next step in their careers. These were determined and willing individuals who worked hard to achieve their goals. As a group, it can be said that they had a can-do attitude.

While none of the participants explicitly aspired to the executive suite, once they became leaders and executives, they understood that titles were less important than the 
work they were performing. The scope of their work responsibilities allowed them to make a difference in the nursing care their patients received. In addition, these leaders wanted to inspire other Black nurses, and nurses in general, to leadership positions. They viewed being at the bedside as the best position for a nurse, where nursing was valued. Their identity and sense of self, who they were as individuals, were critical to their success as nurse executives.

\section{Summary}

The participants were raised to believe that they were important. Even though some were raised in a segregated society, their family members emphasized and reinforced to them that they could accomplish anything they wanted, become whatever they wanted, and that they were never less than anyone else. Their racial identity was a source of strength. As a group, they were determined individuals who saw opportunities in every event in their career development paths. They showed that they had the ability to adapt and to change with the challenges placed in front of them. In chapter 5, the researcher presents a summary, discussion, and recommendations. 


\section{CHAPTER V}

\section{SUMMARY, DISCUSSION, AND RECOMMENDATIONS}

In this chapter, the researcher presents an overview of the study and discusses the major findings, along with an overview of the purpose and methodology of the study. The purpose of the study was to investigate, analyze, and describe the career development of Black female chief nurse executives. Implications are made for adult education, human resource development, nursing practice, and organizational policies. Recommendations for further studies are offered.

\section{Review of the Study}

Through the phenomenological approach of qualitative inquiry and in-depth interviews, the study addressed the need for understanding the experiences, barriers, and facilitators of Black female chief nurse executives’ career development in attaining their current executive positions. Today's $21^{\text {st }}$ century, chaotic, ever-changing healthcare environment requires chief nurse executives who are flexible and can respond effectively to changes. Jobes and Steinbinder (1996) stated that "today's turbulent, chaotic health care environment necessitates dramatic changes in the roles of nurse executives. These role changes are rapidly being cast upon individuals who are pressured to react, accept, and adapt quickly” (p. 80). This sentiment is still relevant in today’s healthcare environment. In particular, Black female chief nurse executives are needed to ensure the provision of culturally competent care, to address the realities of healthcare disparities, and to serve as mentors and role models to those aspiring to leadership positions. Today's nurse executives play a critical role, along with their organizations, in the early identification, mentoring, development, monitoring, and evaluation of those interested 
and preparing for future nursing leadership and executive roles. This investigation and description of the career development experiences of Black female chief nurse executives provides insights into the factors which facilitate and hinder nurses in becoming executives.

The guiding research question was: How do Black female chief nurse executives in the study describe their career development? Responses to this study question provided the framework for an exploration of the multifaceted elements of the career development of Black female chief nurse executives. In support of this overarching question, the participants were asked to describe their career development related to: (a) What particular individuals and events in Black female chief nurse executives' backgrounds have influenced their career development? (b) How has the career development of Black female chief nurse executives been facilitated or hindered? (c) How have healthcare organizations the Black female chief nurse executives' facilitated or hindered their career development? (d) How do Black female chief nurse executives perceive their career development at different life stages? (e) What strategies can Black female nurse executives in healthcare organizations utilize in order to enhance their leadership opportunities?

Using the snowball technique, Black female chief nurse executives were recruited to participate in the study. Twelve were identified in a national search; ten agreed to participate while the other two did not respond to telephone and email requests to participate. The nurse executives worked in healthcare organizations throughout the United States. The individuals were chief nurse executives, and they held the titles of vice president of nursing, chief nursing officer, nurse executive, or similar titles. 
Using an interview guide, data were collected through one telephone interview with each participant. Data were collected and analyzed simultaneously. Individual profiles were constructed and then in a cross-case analysis, four themes emerged from the data that reflected how the participants made it to the top. These themes were (a) support systems, (b) guidance, (c) diversity, and (d) servant leadership.

\section{Deidre}

Why any of us in a leadership or administration or a bedside position, why we really should be showing up everyday. It's because there is real need and we owe the communities and the people that we serve, systems of care that deliver the highest quality and the highest degree of service to them, regardless of their ability to pay for it, and so I chose nursing as an entrée really and it's a grounding thing that drives me and shapes all the decision that I make as a leader

Because the interview guide was designed to answer the research questions, themes which emerged also addressed the research questions. In this section, the researcher describes the extent to which the findings addressed each research question. The findings related to the first research question (What particular individuals and events in Black female chief nurse executives’ backgrounds have influenced their career development?) are discussed first. The most influential individuals who shaped the participants’ career development were their parents, grandmothers, the extended family, and teachers, as indicated by the participants. These individuals were major influences in their childhood and through their high school experiences. Mother, family members, and friends in the church and community who were nurses, specifically, were influential in identifying nursing as a potential career for them. Additional early childhood career choices for three participants were either a teacher or a physician. Parents stressed the importance of education. At times parents were role models for nursing careers. Several 
participants discussed their parents' roles in their choosing nursing careers; for example, obtaining a nurse doll or taking a participant to the hospital.

However, most participants did not indicate any specific career advice from parents or teachers regarding their career choice. The data did not reveal that parents forced their children into a specific career. Rather, their influence was, in Faye’s words, "getting a good education” so that "you can take care of yourself” with a goal of having a better life than their parents. It appears from the findings that career choice was determined by the participants. Contrary to popular beliefs of the time, the data did not indicate that any of the women were expected to become housewives and mothers and care for their husbands. Spouses were found in this study to be very supportive and facilitative of the careers of their wives. The findings of this study are supported by Ezzeedeen and Ritchey's (2008) study of 20 executive-level women regarding the support from their spouses. In that qualitative study, the spousal support received and valued by executive women was that these men listened, assisted with household chores, helped family members, and provided career and emotional support.

In a study that addressed the career planning, career decision making, and work history of women in both female-dominated and gender-neutral careers, Whitmarsh (2007) found that women in the female-dominated group of that study experienced positive reinforcement for their career choices from family members, while those in the gender-neutral group experienced support and mentoring from outside the family. Like the participants in the current study, the participants in the female-dominated group of that study did not identify any significant obstacles to career advancement. The challenge remains to get qualified individuals who are also Black into executive positions. 
In a qualitative study of how nurses became leaders, Allen (1998) identified three similar factors that facilitated development of nurses into nurse leaders: (a) selfconfidence, (b) influence of significant people, including their managers, and (c) personal life factors, such as the impact of family. Harms (1988) found that parents (in particular, mothers) were the most significant variable influencing leadership development among presidents of selected nursing organizations and were the most influential mentors in the participants' lives. Additionally, Jean-Marie’s (2004) participants explained the importance of family and community on their development and how the success of the participants was interpreted as the success of the family and community. Similarly, the current study revealed that parents were influential, especially during the participants' childhood career decision and development and for some participants, throughout their careers.

Other influences that facilitated participants in arriving at the executive suite, such as mentors, role models, peers, and colleagues were identified as influential at different stages in the participants' career progression. Similar to results of other studies (ByrdBlake, 2004; Kuo-Rice, 2005; Madsen, 2007b), mentoring relationships in this study were found to have a considerable impact on career development. However, it has also been noted that for many individuals, in particular those from minority populations, mentoring relationships are at times lacking. However, the majority of the participants in this study reported that they had mentors, and for those who did not, the absence of mentors was not viewed as a barrier in their career development. The findings from the current study demonstrated that, while having a mentor is important in one's career development so as to learn the requisite knowledge and skills to perform in one's role, the 
absence of mentoring relationships does not necessarily impede one’s ability to succeed in one's career.

For the majority of the participants in the current study, mentors and role models were critical to their success. They served in roles such as advisor, educator, confidante, and friend. In many instances, mentors helped them with career choices. This study supports the findings of numerous other studies on the role of mentoring in one career (ACHE, 2002; Cook et al., 2002; Goodin, 2003; Mullen, 2007). Especially for Black female students who aspire to nursing leadership positions in the current shortage, role models serve as reminders that, despite the many barriers to career advancement, they can still reach their goals of leadership positions (Goodin, 2003). The participants in this study discussed significant mentoring relationships, including cross-cultural mentoring relationships. The mentoring relationships had been established in college, within and outside the workplace. In addition, mentoring relationships were formed when participants joined professional organizations and community boards.

Mullen’s (2007) study, which explored the mentoring of physician students, revealed that opportunities for a mentoring relationship and improving the process may include "comentoring, cohort learning, cross-cultural mentoring, telementoring, and e-mentoring” (p. 36). These procedures could apply to the mentoring of aspiring and current chief nurse executives. Other studies (ACHE, 2002; Cook et al., 2002) noted that same-race mentors are important to the career development of minorities. While some of the participants in this study did not have the benefit of same-race mentors, they recommended that mentors and role models, regardless of race, be provided to stimulate 
the development of nurse leaders. However, Cook et al. (2002) added, “Whites should not neglect opportunities to mentor people of color” (p. 241).

For one participant in the study, a White mentor opened the door to her achieving her first chief nurse executive position. However, for the majority, the current study did not reveal if the individuals who recommended the participants for career advancement or advised them of opportunities for career growth were same-race or a different race. The researcher's assumption was that same-race mentors would provide the benefit of an understanding of what it is like to be Black. There is a bond based on their common heritage and could provide advice on how to navigate the challenges of life that a different race mentor cannot provide. According to Fouad and Byars-Winston (2005), "Racial and ethnic minority clients are entering a labor market in which people of their own racial/ethnic group are concentrated in lower level positions and unskilled occupations influencing their perceptions of the opportunity available to them” (p. 225). This observation also underscores the value of same-race mentors and same-race role models in the career development of Black women.

However, while mentors were mentioned by the majority of the participants in this study as important for their career development, no participant specifically noted the importance of same-race mentors and role models or this lack of same-race mentors or role models as a barrier to their career development. However, Gunn (2005) conducted a quantitative study of 468African American women on the barriers that these women faced as they sought executive positions that involve policy formation. Gunn found that having African American male mentors and role models were positive predictors of their success. 
Another finding in this study was the value of role models on the career development of these women. While formal education and learning were critical to the preparation and the career development of the participants, role models served a major function in the informal learning of the women. The women learned from individuals whose behaviors they wanted to emulate.

To summarize the findings for the second research question (How has the development of Black female chief nurse executives been facilitated or hindered?), the participants reported a variety of facilitators and barriers to their successful career development. Barriers were anything which impeded the individual’s career development, and facilitators were anything which enhanced or propelled the individual's career development. Family, friends, colleagues, mentors, and racism contributed as facilitators and barriers to the participants’ career development. Educational support was reported by the majority of the respondents as the most frequent healthcare organization (HCO) facilitator of their careers. Overall, few perceived that they had any barriers; others were explicit in how they dealt with barriers. Overwhelmingly, these women were unanimous in their view that barriers were challenges, which, with effort, and time, can be overcome.

To summarize the findings related to the third research question (How have the healthcare organizations of Black female chief nurse executives facilitated or hindered their career development?), the participants in the current study perceived that educational support was the major way in which organizations facilitated their career development. Their organizations paid for a myriad of educational activities, including initial nursing training, undergraduate and graduate degree programs (at both the master's 
and doctoral degree levels). Paid time off was given to attend these programs in addition to national yearlong fellowship programs, such as the Robert Wood Johnson Executive Nurse Fellow program. Overall, organizational support was positive for the career development of these executives once their leadership talent was identified. Progression into leadership and, thus, executive positions followed, especially for those with longevity in the organization. Challenges related to racism and, to a lesser extent, gender were noted by some participants.

The findings related to the fourth research question (How do Black female chief nurse executives see their career development at different life stages?) emphasized the dynamic recursive nature of career development. One study participant, Inspiration, defined career development this way:

It is about a journey, and those individuals that see the position or the acquisition of a certain degree as the journey, are short-sighted. It's about a journey towards leadership and that journey towards leadership is one that is always evolving. It has lots of twists and turns. It has potholes that you will step into, but if you can continue to keep moving forward on a journey, and learning every step of the way, you will enjoy becoming a leader. It's about becoming a leader, not an end-point. So I'm always indicating to others about leadership journeys. That it is not particular. It's not assigned to you're the nurse executive or you're this or you're the that. It is about doing and always evolving.

Inspiration's definition reflected what the stories of the participants' reveal. These women were continuously evolving in their career paths. The women were at different stages of Super's (1990) five stages of career development (i.e., growth, exploration, establishment, maintenance, and disengagement) and Gottfredson’s (2002, 2005) career stages of circumscription and compromise. None of the participants demonstrated linear progress through Super's stages. Instead, there was a continuous movement from growth 
to maintenance, and with each new position, the individuals began again to move through the stages.

In the establishment stage, the participants established nursing as a career. In the establishment stage, the participants established themselves in the career of nursing and continued their desire to learn, grow, and be challenged, but had not established the defined roles within nursing. The maintenance phase did not result in stagnation but, instead, became a search for opportunities to grow, explore, and establish new directions. While career longevity, staying in one organization throughout one's career or one role for an extended period of time, was noted, career complacency was not. The participants were willing to take risks and even to take on a lower position that provided broadened knowledge and skills.

As the individuals prepared to retire or to disengage, according Super's (1990) final stage, these participants were making plans for post-hospital careers. Knowledge and skills learned throughout their careers would be used in the new roles, such as in academia. As an example, recall Deidre’s retirement plan, “I want to teach people who want to have careers in health care and I see my past as a working professional sort of in the operational setting and in the health care setting itself and the hospital systems then in the academic setting when I get to that point in my life and time.” Conversely, disengagement could be considered a positive step, as in Jesusica’s case, when she left an organization that had no promotional opportunities for her. She recounted that her boss made the comment, “Jesusica, I’d never really given it a thought, because you're so good. I didn’t think we could keep you here.” Jesusica explained that she saw that statement as a compliment, but also "like an oxymoron; because if I'm that good, you should be trying 
to keep me.” Jesusica continued “I would ever leave any part of my nursing foundation, because I would always be a nurse.”

Two participants reflected Gottfredson’s compromise (2002, 2005) stage when Tasha Allen declined a promotional opportunity to move with her husband to Germany, and Deidre decided to delay having children so that it would not impact her career.

Deidre had lived with the impact of growing up without the presence of her mother, a nurse, and she did not want her daughter to be subjected to her absence. Deidre explained her career compromise this way:

My only child is a five-year-old little girl and so that really, even the decision of when to start a family and so forth, was shaped around my career and those choices that I made and my own experiences being a child who had a mother who was not there at a key time before I started school.

The participants were willing to make compromises, and even take on lower positions that provided enhanced knowledge and skills.

The findings related to the fifth research question (What strategies can Black female chief nurse executives in healthcare organizations utilize in order to enhance their leadership opportunities?) were derived from a summary of responses across all participants. The researcher summarized the responses to Questions 22 and 23 of the interview guide. The participants identified several specific strategies that they believed were required to enhance their leadership opportunities. One strategy they identified was to maintain their objectivity, especially when working with others with whom they might have disagreed. A second strategy they described was to understand the mission and vision of the organization and how one's specific role could help the organization accomplish its mission and vision. A third strategy was to make sure they were 
educationally prepared by earning advanced degrees and certifications. A fourth strategy focused on communication skills such as active listening. When the participants shared their strategies to enhance leadership opportunities, they also described what might better be termed personal characteristics. For example, they indicated that, in order to succeed and to advance to the executive suite, an individual must have a strong sense of personal integrity and character. Other characteristics they named included being a risk-taker, a global thinker, a life-long learner, flexible, goal-oriented, fair, and honest.

The skills and attributes that participants identified were similar to those revealed by Carroll (2005). Carroll conducted a mixed-method study to compare the perceptions of women leaders and nurse executives about the skills and the attributes required to succeed in the $21^{\text {st }}$ century. The women leaders and nurse executives identified six skills and attributes required for success which corroborated the findings of this study. The six skills and attributes were: (a) personal integrity, (b) strategic vision/action orientation, (c) team building/communication skills, (d) management and technical competencies, (e) people skills (empowering others, networking, valuing diversity, working collaboratively), and (f) personal survival skills/attributes (political sensitivity, selfdirection, self-reliance, courage, candor).

The participants in this study were raised to believe that they were important. Even though some were raised in a segregated society, their family members emphasized and reinforced to them that they could accomplish anything they wanted, be whomever they wanted, and that they were never less than anyone else. As a group, they were determined individuals who saw opportunities in every event in their career development 
paths. They showed that they had the ability to adapt and to change with the challenges placed in front of them.

\section{Discussion}

The purpose of the stu dy is to explore the career paths of Black female chief nurse executives with a view of understanding the factors which both facilitate and hinder the career development of these leaders in healthcare organizations. The participants told their stories of their career development, which were analyzed, and codes and themes emerged, including what influenced their career choices, the influences of support systems, guidance, diversity, and servant leadership on their career development. As the women in this study advanced in their career development and became successful in their organizations, they encountered both facilitators and barriers to their career development. This study found that some of the facilitators to their career development were the overwhelming degree of family support ranging from parents to extended family, peers and institutions.

The Lirio et al. study of 30 successful women explored the career-life success and family social support of successful women in Canada, Argentina, and Mexico. The findings revealed that, similar to the findings of this study, women were supported by their families. The men in the family in the current study were particularly supportive in terms of finance and interpersonal support but less supportive with household chores. Adaptive goals, family influence, security needs, and support factors were the findings of a study conducted by Hite and McDonald (2003). Focus group interviews were conducted with 26 women to explore the non-managerial women's perspective of their career and the factors that facilitated and hindered their career plans. The study findings 
of Hite's (1998) study confirmed the findings of this dissertation regarding the role of family influence and support factors in one's career development.

The women in the current study were successful and thriving in their roles within their organizations and their communities mainly through the roles of self, voice, visibility, and risk-taking. More important, their success could be attributed to their unwillingness to appear victimized. The study findings did not reveal a clearly defined decision-making career process with family or significant others in their lives. Family members did not force a career on their children or appear to make suggestions about a career.

Several participants alluded to their early interests in a nursing career and even remembered that they had "played nurse" as children because they wanted to care for others. Additionally, for some, their choice of a nursing career was viewed as a way to help others, the means to gain independence, and make money. However, family provided the support necessary for the participants to pursue their careers. During the college years, several pursued advanced degrees because of the bonds and influence of friends. Once the participants became registered nurses, colleagues and bosses provided career advice and recommendations for advancing roles and offered support and encouragement. Education, including degrees and certification, was the vehicle to prepare for these roles. Neither pay, prestige, nor personal rewards were mentioned by any participants as reasons for advancements.

The participants identified several barriers to their career development. These barriers and challenges included issues of race, youth and inexperience, politics, gender, physicians, and unethical colleagues. This study identified race, gender, lack of finances, 
youth and inexperience, mentoring, organizational politics, gender, physicians, and unethical colleagues as barriers to the career development of the participants. However, except for mentoring, findings of this study differed from the findings of the Federal Glass Ceiling Commission (1995) report which revealed several major barriers to the advancement of women in organizations. These findings included (a) lack of active recruitment of women and minorities, (b) corporate climates which eliminated and isolated women, (c) lack of mentoring, (d) lack of management training, (e) lack of visibility on major committees, and (f) lack of opportunities for career development. While the Federal Glass Ceiling Commission report indicated that their participants perceived they had "hit the glass ceiling" for career advancement, this was not a finding in this study. The next section discusses the application of Super (1990), Gottfredson (2002, 2005), and CRT $(1992,2000)$ to the findings of this study.

Implications for Theory and Career Development

Super

As the women started their career journeys, they were shaped by the early influences of the immediate and extended families who created a nurturing environment. Many of these individuals, as described by Super's (1990) early stages of growth and exploration, had already made career choices by the time they were in high school, and some even earlier. According to Super's exploration phase, which occurs from ages 15 to 24, individuals identify and crystallize their career.

Career establishment, the third stage of Super's (1990) career stages, occurs between ages 25 to 44 and represents gainful employment. However, while these individuals were gainfully employed as nurses, they continued their career growth by 
taking diverse roles within the nursing profession. The majority of the participants were currently in the establishment stage and disengagement phase of Super's stages.

Three of the participants were at the stabilization phase and were already looking for the next opportunity and challenge. These nurse leaders were dynamic individuals who described themselves as loving a challenge, ambitious, passionate, and intense. According to Super (1990), stabilization reflected the individual's ability to settle down in the new role, perform work to validate the career choice, and to use the knowledge, skills, and abilities acquired in performing this role. Next, the individual consolidated this role and, finally, had the opportunity for advancement. Career changes for these women occurred in less than the specifically defined time frame articulated by Super's life-span career stages. Prior to taking on a new role, the Black chief nurse executives assessed their talents; educational and role preparation, and required skills needed for the role. Being qualified and prepared for the role were important to these individuals.

As the participants told their stories, the role of "self," or their character, emerged. Who were these individuals? How did these individuals define themselves, their interests, and values, which changed over time and with experience? For Super (1990), selfdefinition was how one's defined self was influenced and formed early in life by the influence and feedback, positive and negative, of one's environment. The internal environment encompassed parents, family, friends, the external environment encompassed, colleagues, organization, mentors, employers, and employees. Both the internal and the external environment in turn influenced one's career interest. A defined self is not static but flexible as both external and internal factors force the individual to adapt. For these participants, self-identity in their career development was framed by 
family, religion, personalities, values, race, and life's barriers and facilitators. The influence of self in the context of the environment of these individuals defined how these individuals viewed barriers. Each woman described herself in terms of positive attributes: woman of faith, honest, determined, positive, energetic, progressive, confident, risktaker, innovator, creative thinker, conscientious, goal-directed, focused, hardworking, and the ability to set high standards. Strong self-definition was dominant among the participants in this study. Starting from their childhood and shaped by their nurturing families and communities, these women were confident and determined throughout their lives.

While recognizing the value of positive relationships and feedback in organizations, the women were not dependent on positive feedback from colleagues to survive in organizations. Career resilience is part of the concept of self which is at the core of the themes. The participants showed career resilience, a required skill if one is to be successful not only in one's career but in life. The findings from this study revealed that the participants of the study demonstrated career resilience, the ability to bounce back from career adversity. London and Noe (1997) defined career resilience as "the ability to adapt to changing circumstances, even when the circumstances are discouraging and disruptive" (p. 62).

A study by Fisher and Stafford (2000) of 467 graduate and undergraduate students, including 68 African American students, addressed the effects of career-related factors and ethnic background on career resilience. This study findings supports the findings of Fisher and Stafford's study regarding the influence of family and community in developing the participants. A 102-item Career Influence and Resilience Inventory was 
used to examine the students' career resilience and the effect of parent, teacher, and peer attitudes and supportiveness on the students' career resilience. The results showed that the African American students had high levels of career resilience, which were associated with having a strong sense of one's cultural roots and ethnic pride.

Conner's (1992) book, Managing at the Speed of Change, discussed his study about how resilient managers succeed and prosper when others fail. Conner's study noted that individuals who were resilient required a shorter time period to transition through their adversity. Similar, to the participants in this dissertation, Conner's findings showed that there was no sense of victimization during these difficult periods. As Conner explained, "Rather than becoming victims of change, people who demonstrate resilient characteristics often prosper during disruption and disorder” (p. 65). According to Conner, the five characteristics of resiliency are (a) positiveness, (b) focus, (c) flexibility, (d) organization, and (e) proactivity, which are characteristics attributed to this study's participants. Becoming career resilient is an important characteristic for the successful employee.

The role of self-concept in influencing one's career development integrates with roles and situations, vocational identity, and occupational self concept. The role of self in influencing career is that one takes on roles which reflect one's definition of self. The women learned early in life the importance of success and doing their best while not allowing others to define who they were. These women were forced to prove that they were twice as good as their other colleagues. The participants remained focused on their career development through self-reliance, hard work, resilience, and determination. 
Collard, Epperheimer, and Saign (1996) explained that career resilience is "the result of the outcome of being self-reliant” (p. 34). As discussed earlier, Super's selfconcept, role of self, is critical for one's career development and one's ability to depend on self will determine one's career resilience. Alfred's (2001a) term character structure is used to refer to the role of self displayed by the participants in the current study. As they created and attained their career goals, their character structure was evidenced by their pride, resolve, self-confidence, and self-reliance.

The findings in this study support the personal and situational determinants of Super’s (1990) archway model and their impact on career decisions and, hence, career development. The archway model was designed to address the biological, psychological, and socioeconomic variables influencing career choice and development and includes developmental stages and learning theory. The societal determinants, the right column of the arch, represent the role of family, peers, school, community, and society on one's career development and were congruent with the findings of this study. This study demonstrated the dominant role played by support systems in the participants' career development. Variables on the left column of the archway represent the personal determinants of needs, values, and interest. A keystone of the archway model is selfconcept and the role of self, the crucial element for career development.

According to Super (1990), ongoing dynamic interactions occurred among the variables self, life-roles, and the environment which, in turn, influence one's career development. Super's nine life roles occur and several reoccur across the career developmental life span and include child, student, leisurite, citizen, worker, spouse, homemaker, and pensioner. All roles operate in either the environment of home, work, 
community, and school. Except for the role of pensioner, the participants had navigated through the majority of the eight roles which were influenced and shaped by their environment, both the personal and situational determinants identified by Super.

As described in chapter 4, under the Servant Leadership theme, the role of citizen is best reflected in the participants' desire to give back to their communities and to demonstrate servant leadership, their life purpose and meaning. Jean-Marie (2006) referred to this as one's calling. Servant leadership is about a commitment to providing service first while leading and developing others. Greenleaf (1977) introduced the concept of servant leadership in his seminal work on servant leadership where he described the servant leader as follows:

Servant first.... It begins with the natural feeling that one wants to serve first. Then conscious choice brings one to aspire to lead. That person is sharply different from one who is leader first, perhaps because of the need to assuage an unusual power drive or to acquire material possessions. The difference manifests itself in the care taken by the servant-first to make sure that other people's highest priority needs are being served. (p. 13)

The best test for servant leaders is:

Do those served grow as persons? Do they, while being served, become healthier, wiser, freer, more autonomous, more likely themselves to become servant? And, what is the effect on the least privileged in society; will they benefit, or, at least, not be further deprived? (p. 14)

For the participants in the current study, servant leadership was exhibited at many stages of their career development. Servant leadership was demonstrated by many of the participants. For some, including Tasha Allen, Faith, Inspiration, and Hope, servant leadership was demonstrated from the beginning of their nursing careers and continued throughout their careers. Others participants indicated that a major reason for pursuing nursing leadership was to try to correct the wrongs that they had witnessed inside and 
outside their organizations. Healthcare disparities, injustices, and the treatment of Black patients formed the impetus for their servant leadership, particularly Tabman, Faye, and Deidre. Overall, the participants' servant leadership behavior was characterized by a need to improve their communities, organization, and profession.

Washington, Sutton, and Field (2006) studied 288 followers and 126 leaders on the relationship between followers' ratings of the leaders' servant leadership and characteristics, such as empathy, integrity, competence, and agreeableness of the servant leader. Washington et al. found that followers perceived that African American leaders demonstrated more servant leadership than White leaders. A similar finding occurred in the present study. One explanation for this finding was African Americans experience interconnectedness and sense of community and belonging. According to Washington et al., "African Americans develop dominant characteristics of cooperation and interdependence - both hallmarks of the agreeable personality found to positively relate to servant leadership in the current study” (p. 712). It can be seen from the participants' profiles that the 10 Black female chief nurse executives in this study could be said to have an agreeable personality.

According to Greenleaf (1996), while serving as servants and stewards and in service to others, servant leaders must demonstrate 10 characteristics. These characteristics include: (a) have followers, (b) have goals, (c) have the ability to listen and understand, (d) have the ability to learn, (e) have the ability to be empathetic, (f) have an awareness of what is known and unknown, (g) have the ability to show foresight, (h) have the ability to trust, (i) have the ability to show awareness and perception, (j) have the ability to be persuasive, (k) have the ability to be healing and serving, and (j) have the 
ability to build community. For the Black female chief nurse executive, Greenleaf explained further, that building hospitals was for the benefit of the physicians and families and not the patients. "Only community can give the healing love that is essential for health” (p. 37). The leadership characteristics identified by Greenleaf were similar to the strategies identified by the participants in the current study where the participants described the strategies they used to enhance their leadership opportunities.

In a related study, Bridges (1996) conducted interviews to determine the characteristics and perceptions of career achievement perceived by 175 African American college administrators regarding the importance of personal characteristics and career activities leading to career achievement. The results showed that critical characteristics for college administrators included the following: (a) communicating in writing and speaking, (b) demonstrating flexibility, (c) expressing sensitivity, and (d) using confrontational skills, and exhibiting diplomacy. Additionally, 51\% of the college administrators believed that a mentoring relationship was important for success, and 54\% had a mentor for advice and supportive parents. The results of the current study resonated soundly. For example, according to Inspiration:

Each path I have taken has contributed to the journey. It is what we can do as servant leaders. Servant leadership is about using your knowledge, skills and spirituality to help humans be the best they can be. We have to value knowledge and be on a quest for knowledge. It's like a river, turning and twisting. Always finding another way. You have to integrate that quest with an appreciation for human beings in all their diverse forms and celebration of diversity.

At the core of these women's career paths to the executive suite was how their executive role allowed them to create a better world for others in their organization and community. To that extent, they were willing to be active participants in transforming the 
lives of others. Having a passion for nursing and the interest in and facilitating the professional growth of others were qualities exhibited by the present study participants throughout their careers. The chief nurse executive role became the right career fit because it cemented the relationship among the defined self, the expectations of self, the environment, and one's career goals.

Moreover, the recursive nature of Super's (1990) developmental stages was evidenced in the participants' careers which are in motion throughout the various stages. As the participants made the transition through these various developmental stages, they demonstrated resilience and an abounding sense of optimism regarding their career development. The current study supported the Super's situational and personal determinants of life experiences, family, education, community, work organization, other roles, such as wife, mother, child, and influential events, society, and the environment in shaping career choice and development.

A recurring theme for the participants was the role of education in their lives and career development paths. They were continuously learning from experiences. They were self-directed learners. For Super (1990), learning was a critical element for career development as individuals learned from the interaction with their environments. Nurse executives, while in that fixed defined role, must continue the ongoing process of emerging, learning, growing, and changing in order to fill the requirements of the nurse executive role. Nurses who aspired to this role must know that there is not only the opportunity to obtain an education through both formal and experiential learning but the support and the commitment from their organizations to enhance their success. 
One's ability to learn is another important factor in one's career development. As the participants moved into various roles and situations, they learned not only formally but through observations of role models, family members, peers, colleagues, and from the established organizational culture. The current study's findings supported Bryans and Mavin who found that the majority of learning occurred in informal situations. According to Bryans and Mavin (2003), "It is estimated that only 20 percent of learning relevant to the jobs of individuals occurs in formal situations; 80 percent of learning therefore occurs in informal ways” (p. 115). Regarding learning, this study findings also supported the results reported by Madsen (2007a, 2007b). According to Madsen, drive, determination, and a desire for continuous learning and development, whether self-initiated or offered by the organization, and the ability to manage challenges and changes, were characteristics of women in leadership.

\section{Gottfredson Theory}

Gottfredson’s (1981, 1996, 2002) stages of circumscription and compromise are concerned with individuals' career development and aspirations. For Gottfredson (1981, 1996, 2002), occupational choices reflect one's self-concept (Who am I?). Self-concept is influenced by one's gender, social class, intelligence, interests, and values. Self-concept interacts with occupational image, which is comprised of sex type, prestige, and field of work, to determine occupational preference. Two participants made adjustments to their career goals, compromise, because of the expectation and the importance they placed on family. According to Gottfredson, they compromised as they relinquished their most preferred alternatives for less compatible but more accessible ones. Often, women are forced to make choices between career and family. In some cases, because of the 
husbands' career move, women relocated, giving up their promising careers. Deidre, as a participant with a professional mother who was a nurse, identified with the conflict caused between family and career as she grew up with a mom absent from important days in her life.

Another element in Gottfredson's theory was circumscription, defined as "the process by which children progressively eliminate from consideration occupations they think unacceptable to themselves” (1990, p. 214). According to Gottfredson, from age 6, gender influences occupational choices. In the time period, 1960s and 1970s, that these women were becoming aware of jobs and careers, they were limited in career choices because of gender. As a result, they lacked significant alternative career choices. For three participants, early career choices were teacher or physician. The findings of the current study yielded support for the career development theories of both Super (1990), and Gottfredson $(2000,2005)$, especially the critical role of self in defining career.

\section{Critical Race Theory}

Critical race theory (CRT) is built on three basic premises. First, racism is seen as normal and as part of the national social fabric. The second premise is that the majority group supports advances for Blacks only when they also advance the causes and interests of Whites, the majority group (Bell, 1992). The third premise is that storytelling provides an important format for the ongoing exploration, understanding, and discourse of and about racism. Regardless of how the participants, all of whom were born in the United States, self-identified their ethnicity, they all discussed racism. Those of Caribbean heritage frequently referred to the influence of both cultures, American and Caribbean, in their lives. The impact of both cultures was to instill and to solidify their sense of 
achievement, determination, and pride. While several of the participants willingly discussed race and segregation when growing up, only one remarked that issues of race created paralyzing challenges to her career development.

Several participants told stories about racism and the treatment they received as Black nurses and nurse leaders. At times, they were treated differently than their White colleagues. For example, they were less likely to be promoted, even when more qualified than their White counterparts. In their early nursing careers, physicians and White patients did not want to receive care from Black nurses. Although all the participants agreed with the first tenet of CRT, that racism was seen as a normal phenomenon and a permanent fabric of people's lives, they learned early and throughout their lives that the problem of racism, while it could impact their lives negatively, was more about the other person who manifested the hatred and not about the participants. As Jesusica stated, "I am who I am, Black; I can't change that; I have to keep moving forward.”

The second premise of CRT posits that the majority group supports advances for Blacks only when they also advance the causes and interests of the majority group. It should be noted that two participants were appointed, and one of the two was appointed twice to executive positions. In the researcher's experience, it is unusual for people to be appointed to these positions. These two participants believed that they were chosen because they were the best qualified candidates for their roles. They had the credentials needed for their roles. They were appointed in organizations where appointments were made by White individuals. These two participants did not believe that race had played a role in their advancement. Faith explains, in achieving her leadership position, "the 
[organization] culture supported everybody having to pay their dues" and "spending a whole lot of time building leader credibility.” Inspiration added:

So I think that if I had been, someone else who had been here a long time, if they had the educational credentials and had the portfolio in terms of teaching, research, and clinical practice, they would have been in this chair and would have been the chief nursing officer. In fact, my predecessor was, had been in the institution a long time and was the chief nursing officer, and she was White.

In addition, overall from the stories of the participants, it is clear that they believed that they were promoted on the strength of their educational attainments, knowledge, and skills. In contrast to the second tenet of CRT, they expected to be treated fairly in their organizations and to be given the same opportunities for career advancement as any other leaders.

These women did not see their race as an insurmountable barrier, but they were not naïve to the realities of racism. They perceived that being Black was a positive attribute. As individuals with dynamic personalities, they were raised to believe that they were not inferior. Neither did they allow themselves to be treated in an inferior manner. They did not perceive themselves as victims nor did they portray a victimization status. The researcher listened to these women as they shared similar but unique life stories. Those who were born and raised in segregation also experienced the civil rights movement, which raised their level of "Black consciousness.” Deidre evoked vivid memories of the Ku Klux Klan riding through the neighborhood. Their life experiences, along with a nurturing upbringing, did not allow the participants to perceive themselves as passive, marginalized tokens in this society based on their race, class, or gender. Rather, they perceived themselves as being active players in their lives and career paths, though, at times, they were faced with challenges related to their being Black women. 
As Black women, their prevailing self-definitions of worthiness and capability were created by the nurturing they experienced within their segregated environments. Like the women in this study, the Black women in Alfred's (2001a) study refused to be identified as marginal. The contextual aspects of career development, community, church, family, political or societal events of civil rights, segregation and integration, the experiences with the Ku Klux Klan, all influenced the participants' career development. Similar to Mayor's (2004) study of leading Black nurse executives in England, the strategies used in career development by the participants in the current study included (a) self-funding of professional education and academic study and (b) developing networking and social structures. However, the current study did not find, as did Mayor, that a career development strategy was to mimic the career development of men. In dealing with racism, the participants in both studies acknowledged (a) the need for individuals to have a voice and to challenge inequalities and discrimination and (b) the need to hold people accountable so as to improve employment practices. The participants in the current study perceived that, as a result of their race and gender, they had to work twice as hard to advance, even though they did not perceive themselves as being inferior to Whites. The inequalities included lack of mentoring and lack of promotional opportunities, even when Blacks were more qualified than their White counterparts. As Deidre explained:

I think that's one thing as well. I think there needs to be a real dialogue about this in health care, because if you for instance, and you could not find one in your area, a chief nurse executive, that's not by accident. That is by design. And if anyone puts it on the table, in that regard or not, I think that, you know, you can't change what you don't say. So I think there needs to be a real dialogue about the disparity and the lack of diversity in health care and leadership if you want to make a real change. 
Surprisingly, for the researcher, segregation rather than integration was viewed as a positive impact on their lives. They had the support and the commitment of their communities. They experienced a sense of belonging. The women of this study were comfortable in their own skin and did not allow others to define who they were or prevented them from their reaching their goals. With all of the challenges, they proceeded forthright with accomplishing their personal and organizational missions for the benefit of their nurses and their patients. The participants were confident in their talents, knowledge, aptitude, skills, and attributes to perform at the executive level in their organizations. The problem of their race was that it was a problem for others and not a problem for the participants. As the researcher interviewed these women, their passion and their voices of confidence became evident. The participants discussed the impact of their race and racism and, to a lesser extent, gender, on their career development. Although race was clearly a presence in their lives, it was never viewed as an obstacle to their career advancement. They were determined that neither their race nor gender would interfere with their career advancement because they were equally as competent and qualified as any of their colleagues. They were socialized to the executives' roles by knowing the people, building relationships, and understanding the mission and the organizational culture of their respective healthcare organizations.

The communities provided social interaction for these women to grow and learn. Growing up in segregated all-Black communities, the women learned the meaning of hard work and understood at an early age that they were expected to work hard in order to be successful. A recurring expression the women heard from their family members and teachers was that they needed to be better and twice as good as Whites to be 
successful. These women developed a strong sense of self. In addition, the women did find the world of work, in general, supportive and nurturing.

The findings of this study partially supported the findings by Cook et al. (2002), who stated that women of color faced racial discrimination, and both women of color and White women faced gender discrimination. In turn, according to Cook et al., gender discrimination "has created social, psychological, institutional, political, and economic barriers that seriously erode the actual control many individuals have over career choice and satisfaction” (p. 292). While most of the women in the current study did not perceive that they had experienced racism, there was some evidence that they had experienced challenges to their career development because of their race. However, these challenges did not erode the control the individuals had on their careers. On the contrary, the participants appeared to have strengthened their resolve to gain more control of their careers as they responded to the challenges.

The president of National Coalition of Ethnic and Minority Nurse Associations (NCEMA) alluded to the perception that people of color were not promotable. In an interview with Steefel (2008), Williams stated, “It’s been promoted that people of color don't have the mental capability needed to succeed; they can't conceptualize; they're just not quite as good. If you're good, you're an exception, and you live your life as an exception because there's something special about you. It’s a big lie” (p. 4). Sandra Webb-Booker, RN, Ph.D., coordinator for the Chicago public schools practical nursing program concurred, "Minorities, underrepresented in the nursing workforce, aren't given the same consideration [for job opportunities]. For example, nurses and physicians [from other units] seek out Caucasian RNs when looking for the person in charge," she said. 
The absence of Blacks in administrative positions fosters this attitude, she believed.

Williams added, "Few minorities at the top of nursing’s academic strata is another reason why faces of color aren’t multiplying. There just aren't enough minority professors to nurture the flock" (p. 3).

On a positive note, healthcare organizations are seeking out ways to hire and, if necessary, train and retain minorities. Additionally, healthcare organizations are including diversity and discrimination training in their strategic planning, human resource development policies, and education and training plans. According to Steefel (2008), healthcare leaders were opening discussions on the topic of racism and believe that:

Attitudes are changing. Nursing leaders in hospitals and in schools of nursing are creating workplace and educational programs to help nurses overcome discriminatory feelings they may consciously or unconsciously hold toward colleagues or patients. They are fostering open environments in which students can discuss racism and how it might affect their own nursing practice when they enter the healthcare workplace. (p. 1)

An example of one school with such a program is the University of North Carolina School of Nursing where students are introduced in orientation and given the knowledge and necessary tools needed so that upon graduation, they can care for diverse patients and equally work with diverse groups of colleagues (Steefel, 2008).

\section{Social Cognitive Theory}

Another theory that was useful for interpreting the findings of this study was social cognitive theory (Bandura, 1986). Bandura described an individual's self-efficacy as the beliefs about their capacity “as a person’s judgment of their capabilities to organize and execute courses of action required to attain designated types of performance” (p. 391). According to Hackett and Betz (1981), whose social cognitive career theme is 
based on Bandura's work, the implication of self-efficacy on one's career influences career choice, effort, persistence, and career performance reflects one’s ability to succeed.

London's (1993) theory of career motivation reflected the interaction of the individual characteristics and situational variables as evidenced by one’s career decisions and behaviors. Individual characteristics represent three domains: (a) career identity, (b) career insight, and (c) career resilience. Career identity is how central one’s career is to one's identity. Career insight is the extent to which the person has realistic perceptions of himself or herself, the organization, and his or her career goals. Career resilience is a person's resistance to career disruption in less than an optimal environment. Career vulnerability, the opposite of career resilience, is the inability to manage when confronted with less than optimal environments.

Self-efficacy, risk-taking, and dependency constitute career resilience. Selfefficacy has as its subdomains autonomy, need for autonomy, adaptability, internal control, need for achievement, initiative, need for creativity, inner working standards, and development orientation. The risk-taking subdomains are risk-taking tendency, fear of failure, need for security, and tolerance of uncertainty and ambiguity. Competitiveness, career dependency, and the need for supervisor and peer approval constitute the dependency subdomain and are considered negative characteristics of career resilience. The women in this study reflected high levels of self- efficacy and resilience demonstrated by their willingness to take on roles which were perceived as real challenges. 
Super, Gottfredson, and CRT provided the theoretical framework for this study. The findings from the current study show that Super's developmental theory, Gottfredson's developmental theory, and the premises of CRT all have relevance to the career development of Black female chief nurse executives and, together, provide a comprehensive overview of the career development of Black female chief nurse executives.

Spirituality

Spirituality, the influence of God, bible, prayers, and a belief in a higher power, was critical as a connection and a direction to work and to the career development of these women. Contemporary career theorists have viewed career development as less than an individual endeavor and as more of the interaction among the individual, the community, and the environment of career development through a holistic and systems view (Patton \& McMahon, 1999). The beginning of the $21^{\text {st }}$ century has seen a growing body of evidence surrounding the important role of faith, God, religion, or spirituality on the career development of individuals (Jean-Marie 2004; Stewart, 2007). Several of the participants in the current study believed that there was a divine intervention and plan for their careers. Jesusica described herself, "In terms of, first of all my spiritual being, that I am someone that do believe in the Lord and so I think a lot of my foundation and a lot of my value systems actually come from my faith.”

But spirituality was not only seen as influencing career choice but also influencing the making of leadership decisions. The participants referred to praying and seeking advice from a higher power to guide their leadership decisions. The roles of God and church were powerful influences on the career development of these participants. 
Further career development studies must continue to include the influence of spirituality on career development. Church and school provided not only a sense of community but for some participants, their initial foray into leadership and service. Their spiritual foundation, belief in God, and adherence to biblical principles enabled the women to manage the challenges in their life. For the women, the mantra was "with God all things are possible" as well as the notion that their career path was destined and influenced by God.

The findings of this study contributed to an understanding of the career development of Black female chief nurse executives. It is among one of the first studies to address the career development of this group. With the increasingly diverse population, concurrent increasing diversity in nursing, ongoing healthcare disparities, and patient safety concerns, it is imperative that organizations attract, hire, develop, retain, and advance qualified Black nurses.

The findings from this study could inform other studies to address not only the career development of Black nurses but also nurses in general. The storytelling by the women in this study allowed them to give voice to their career development. While there were comparable stories from the women who were raised in an era of segregation and integration, their stories were not intended to reflect a single homogenous view of Black women's career development. Rather, through their similar stories, others may learn how they managed their careers and the important roles of family, friends, church, and community on their career journeys. They were unified by strong Black families, the importance of school, home, church and society, their faith, and spiritual grounding. Furthermore, education was valued, and there was a commitment to excel. The women in 
this study demonstrated perseverance and resilience in the face of racial and

organizational barriers.

\section{Risk-taking}

Jesusica described herself as a risk-taker, creative thinker. When I say creative thinker is that I have a tendency just not to accept it that it's cool about things, but I believe in looking outside of the box. I believe in coming up with new ideas and new ways of doing things and including coining new words. I like to think that I appreciate and respect history, but I also feel that history is the foundation for us to operate in the present but I also for us to look into the future. So I just don't like, just say, let's do the same thing the same way just because that's the way we've been doing it.

The quote from Jesusica illustrates an important finding in this study. The participants described themselves as risk-takers. The participants embodied risk-taking behaviors. They sacrificed to accomplish their goals in school, college, and career. In spite of obstacles, they showed courage and faith as they took risks to accomplish their goals. They had taken risks throughout their entire lives. Additionally, their passion to excel and their achievement of excellence served as the impetus for their risk-taking.

As pioneers in their profession, they are the first Black women to serve in the chief nurse executive role. They utilized their risk-taking abilities to change healthcare practice. Tasha Allen learned from her mentor how to take risks, how to "think outside the box." She added, "Well, whenever there was a difficult chance or a challenge to be met, I always volunteered for it. I never turned down an assignment, even the assignments that were not considered desirable.” For Deidre, her risk-taking propensity allowed her to take on challenges when confronted with injustice. Tabman's example of risk-taking emerged from her decision to attend a corporate training on her own:

I went to training on my own, corporate training, and so I think he did influence that aspect in me and I'm glad that he was able to set me very right in terms of my need to sometimes get out of the box, be an advocate. 
While taking risks, the participants helped to shape their environments. Their careers and organizations benefited from their risk-taking behaviors. They promoted values, attitudes, and beliefs required for change and success. As successful executives, they understood the benefit of risk-taking in order to grow, learn, and develop. In order to be successful and to make changes, the researchers reported that some degree of risk-taking was expected.

Other researchers have identified the importance of risk-taking. Chen (2007) studied 112 Taiwanese high-tech entrepreneurial teams and found that entrepreneurs who were higher risk-takers encouraged creativity in their team members. In another study by Kontoghiorghes, Awbrey, and Feuing (2005), risk-taking in learning organizations was a predictor of the organization's ability to adapt to change. According to Jacobson (2008), “Strong leaders are smart risk-takers. Decisions are well thought out and supported by logic” (p. 18).

The participants in the current study were aware that mistakes and failures were associated with risk-taking. However, mistakes and failures did not deter them from riskbased decisions since they could learn from their mistakes. They were also aware that their organizations and their careers would survive their risk-taking activities. The participants of the current study were able to collaborate with other stakeholders; they listened; they sought advice; and they took the necessary action to create the changes they envisioned. Chief nurse executives like these 10 women are needed in today's healthcare environments where daily challenges emerge that require executives who are accountable risk-takers for promoting positive and successful changes in healthcare organizations. 
Implications for Practice, Policy, and Research

Exploring the lived experiences of Black female chief nurse executives in terms of their career development within multiple theoretical perspectives is significant, first, because the results shed light on the applicability of various theories of career development to Black female chief nurse executives. Second, the findings added to the knowledge base concerning the career development of Black female chief nurse executives in healthcare settings. The findings yielded an understanding and the knowledge of the barriers and the facilitators which supported or hindered Black female chief nurse executives in ascending to executive positions. Third, identification of important factors in the Black female chief nurse leaders' career development will aid the mentoring of and by Black nurses, as well as identify support systems for enhancing their career goals. Further, the findings will contribute to human resource development departments implementing strategies to identify, recruit, train, and retain qualified Black nurses for leadership and executive positions. The results have additionally provided indicators for changes in institutional policies in the selection and the promotion of Black nurses to executive positions. Based on the findings, the researcher identified implications for (a) nursing, (b) education, (c) organizational policy, (d) human resource development, and (e) an emerging model of career development of Black female chief nurse executives.

\section{Implications for Nursing}

In the current healthcare environment of lower healthcare reimbursement, nursing shortages, and the emphasis on and the accountability for the delivery of safe and quality patient care, chief nurse executives have significant responsibilities in ensuring that the 
expectations of their stakeholders are met. The chief nurse executive role is very stressful, with a high turnover rate (AONE, 2006). Nursing must be prepared through training and development and succession planning to fill vacant chief nurse executive positions. The AONE core competencies, or strategies, can serve as a guide for developing future nurse executives. The core competencies indicate a minimum education and training requirement which should be included in both undergraduate and graduate curricula. These findings are congruent with several of the subthemes from the AONE core competencies. The AONE has established a set of nurse executive and leadership competencies which it views as essential knowledge and skills for all nurse leaders and executives. The AONE competencies are (a) communication and relationship management, (b) knowledge of the healthcare environment, (c) leadership, (d) professionalism, and (e) business skills and principles.

The findings of the study are congruent with several of the subthemes required to indicate competency for each of the AONE (2006) core competencies. Diversity, community involvement, building relationships and influencing others are subthemes of the communication and relationship management competency. Diversity is defined in terms of gender, race, religion, ethnicity, and sexual orientation, and reflects the need for nurse leaders to "create an environment which recognizes and values differences in staff, physicians, patients, and families” (AONE, p. 4).

Nurse executives are also expected to confront inappropriate behaviors and attitudes toward diverse groups, be engaged with the community, influence others serving as mentors, and role modeling the behaviors and skills required as nurse executives. The significance of race in shaping the career development of these women cannot be 
ignored, and race and its impact must be openly discussed in nursing if one is committed to a successful organization. In the category of knowledge of the healthcare environment, the AONE (2006) core competencies and the study results both indicate that role modeling as lifelong learners and knowledgeable of healthcare economics and healthcare policies are identified by the participants as required skills. Additionally, both the AONE core leadership competency and the findings of the study conclude that nurse executives must (a) learn from failures and successes and (b) establish mechanisms that provide for early identification and mentoring of staff with leadership potential.

The researcher underscores AONE's (2006) recommendation that future nurse executives assess their personal, professional, and career goals, and undertake career planning and seek mentorship from respected colleagues. These statements reflect the importance of active involvement in career planning rather than in career happenstance. Many of the participants were asked to serve in leadership positions through career happenstance. Actively seeking a mentoring relationship with someone can provide guidance for the nurse executives' career paths. Mentors are influential; they open doors and provide support for their mentees. Ophelia Long is president of Long \& Associates, an organization which specializes in healthcare, strategic planning, management development, and development of physician practice groups. As reported by Hugg (2005), Long (as cited in Hugg, 2005) observed that mentoring opened doors for her that would have otherwise remained closed. Long noted that her most influential mentor was a White male hospital administrator. Similarly, Pearl Moore, the executive director of the Oncology Nursing Society, revealed that she actively sought mentors who would have the most significant influence on her leadership development (Padezanin, 2007). 
A participant in Lee and Nolan’s (1998) study stated, "If a woman wants to go into management/administration, she must be resourceful enough to find the people to be mentors, or she doesn't have what it takes to be a manager” (p. 11). However, Hansman (1998) cautioned that a mentoring relationship may be difficult for women when the only available mentors are males. To facilitate mentoring among African Americans in a predominantly White university, the Sisters Mentoring Sisters Program is recognized the importance of self-empowerment and self-determination. Women in the program were encouraged to seek mentors and were provided with techniques and strategies for finding and, later, serving as mentors (Green \& King, 2001).

Mentoring relationships can occur not only in the traditional mentor-protégé or coach-sponsor relationships but also among peers and colleagues, support groups, role models, serving on committees and works projects, through training programs, and as a junior member serving as mentor to a senior colleague (Hall, 2002). The mentor-protégé relationship is an intentional relationship focused on developing the protégé's learning of self, role, and the organization. These relationships are important for reciprocal learning, co-learning, both by the mentee and those serving in the mentor role. For succession planning, mentoring and coaching future leaders through early assessment of the need and identification of future leaders were subthemes of both the AONE (2006) competencies and the findings of the current study. AONE's professionalism theme, participating in professional nursing organizations providing networking, and both formal and informal learning opportunities and developing a plan for one’s own career development, are critical for success in one's career development. Finally, championing a diverse workforce was a human resource development skill noted in the AONE core 
competency business skills theme. Identification of these important factors in Black female chief nurse executives’ career development will aid the mentoring of Black nurses.

\section{Implications for Education}

Because of their commitment to their executive roles, the participants viewed learning as a significant and central construct in their lives. Organizations are critical to the development of chief nurse executives and can provide and facilitate the learning required for preparation to these roles. In addition, the AONE (2006) core competencies and the participants' responses in this study emphasized knowledge of finance, understanding people, the ability to listen, recognition of talent, and developing others as additional skills of nurse leaders.

These competencies are acquired through both formal and informal learning processes, on-the-job training, graduate school education, certification exams, conferences, and service in community organizations. In this study, informal learning provided a mechanism for learning and gaining required job competencies. Meaningful learning also occurs through community and committee assignment and in the mentoring relationship. Additional learning opportunities can be obtained from role models and colleagues exhibiting the traits and the characteristics necessary for developing leadership skills.

Parents and friends can be sources of knowledge for these individuals about relationship building, finance, and conflict resolution. The women in this study, from diverse career paths, gained valuable experience from their various roles and assignments, which allowed them to learn, gain knowledge, skills, and abilities. 


\section{Implications for Organizational Policy}

The findings of the current study revealed that organizations must do a better job mentoring and promoting Black female chief nurses into positions of executive leadership and need to establish specific policies and procedures which address their career advancement. Organizations must value diversity. They must create strategic plans that reflect a commitment to diversity, which, in turn, is communicated to all employees. In the 2006 report, advancing diversity in leadership in healthcare, Witt and Kieffer identified that, according to minority leaders, a lack of commitment by top management, the board, and human resource departments are barriers to diversity recruitment, retention, and the leadership development of minorities.

Recommendations from the advancing diversity in leadership in healthcare report for enhancing diversity recruitment included (a) being sensitive to cultural differences, (b) mentoring employees, (c) establishing a specific diversity recruitment program, and (d) developing relationships with search firms committed to diversity. Since most of the participants of the current study were advanced as internal hires within their organizations, it is imperative that the organizations provide the infrastructure for career advancement. This infrastructure must include procedures to (a) scan the environment, (b) identify those with leadership potential, (c) create a plan for structured and unstructured mentoring, and (d) provide training and development. Organizations with the required expertise can create internal leadership programs and provide opportunities to attend external fellowship and leadership programs. The training and development programs can include the strategies identified by the participants in this study for their career advancement. Black nurses interested in leadership positions benefit from 
leadership training and development programs but healthcare organizations also benefit by ensuring prepared, qualified, and ready individuals will ascend into leadership and executive roles.

The AONE (2006) reported that hospitals are expected to suffer a large attrition of nurse leaders because of an aging workforce. As a result, organizations must be proactive in developing their needed workforce. Critical to the success of developing the workforce is the role of mentors in helping to prepare these nurses for future nursing leadership positions. Organizations must provide the management and the leadership development, the networking and the mentoring experiences required to develop future nurse leaders. Hite (1998) explained that since "women of color are twice removed from the ranks of dominant culture, based on race as well as gender, their potential need for the benefits of mentoring would appear to be even greater than that of their White female colleagues" (p. 786). Mentor-mentee relationships, regardless of race or gender, can be created either through assessment and selection or volunteering. With a comprehensive set of goals and objectives to be accomplished, time must be dedicated to this important endeavor. Depending on the scope and the needs of mentees, informal mentoring could be relevant for attaining the required developmental goals. Strengthening the collaboration between organizations and the community may provide networking opportunities. Organizations must facilitate a culture where issues of racism and diversity can be addressed and policies and strategies created and implemented to address these issues.

Implications for Human Resource Development

Based on the study findings, human resource development specialists are encouraged to address the issues and the concerns of minorities in the context of their 
career development, including their family, spirituality, racism, community, work, and organization. It is particularly important to address the issue of race and racism. According to Byrd (2007), "HRD is neglecting the development of leaders in addressing conflict emerging from racial differences” (p. 277). This neglect cannot continue if organizations are to be successful.

The findings can contribute to human resource development departments that want to implement strategies to identify, recruit, train, and retain qualified Black nurses for leadership positions. Organizations and HRD specialists can work together (a) to uncover possibly prejudicial policies in healthcare organizations regarding promotion of Black female nurses and other minority nurses to leadership positions and (b) to create the venue for open discussion and the policies that support the expectation of the hiring of minorities. Study findings may provide guidance for creating institutional policy related to the selection and the promotion of Black nurses to executive positions. Further, the study findings are clear about the support systems necessary for enhancing their career goals.

The findings of the current study emphasize the role of parents, family, church, and community in the career development of Black female nurse executives. Career development practitioners should collaborate with elementary and high school students and faculty to foster early career development discussions. However, caution should be taken in understanding that careers, as defined by a specific role for one's entire life, is an anomaly in today's work environment. Rather than placing someone in a specific career, today's work environment requires that individuals become adaptable and flexible and acquire skills that are transferable to many careers. Employees are also looking to work 
for employers who are flexible, where there is ongoing learning and work-life balance. Several of the participants in this study, including Inspiration, Hope, and Tabman, had selected and formed nursing career goals before they were 10 years old or all by the time they graduated high school. However, unlike today's career environment, career choices for the women in the study were limited.

\section{Implications for Research}

Based on the findings of the study and the literature, there are several implications for future research. First, in the area of career development, future studies should focus on the impact of risk-taking and resilience on the development of individuals and the career development of nurse leaders and executives.

Second, based on a limitation of this study of interviews with only 10 participants, another study should be replicated with participants from other regions of the country to determine any differences in findings. Such a study would expand the transferability of the findings from the present study.

Third, for nursing, the role of spirituality in the lives of lives, careers, and career development of nurse should be explored. Finally, studies on the career development of Black female nurse managers and leaders should be investigated.

Career Development of Black Female Chief Nurse Executives:

\section{An Emerging Model}

Based on the findings of the present study, the researcher developed an emerging model to explain the career development of Black female chief nurse executives. As shown in Figure 1, there are five interacting components to the model, explained in detail 
as follows. Notwithstanding the importance of the total environment on one's career development, the role of self was critical to the career development of the participants.

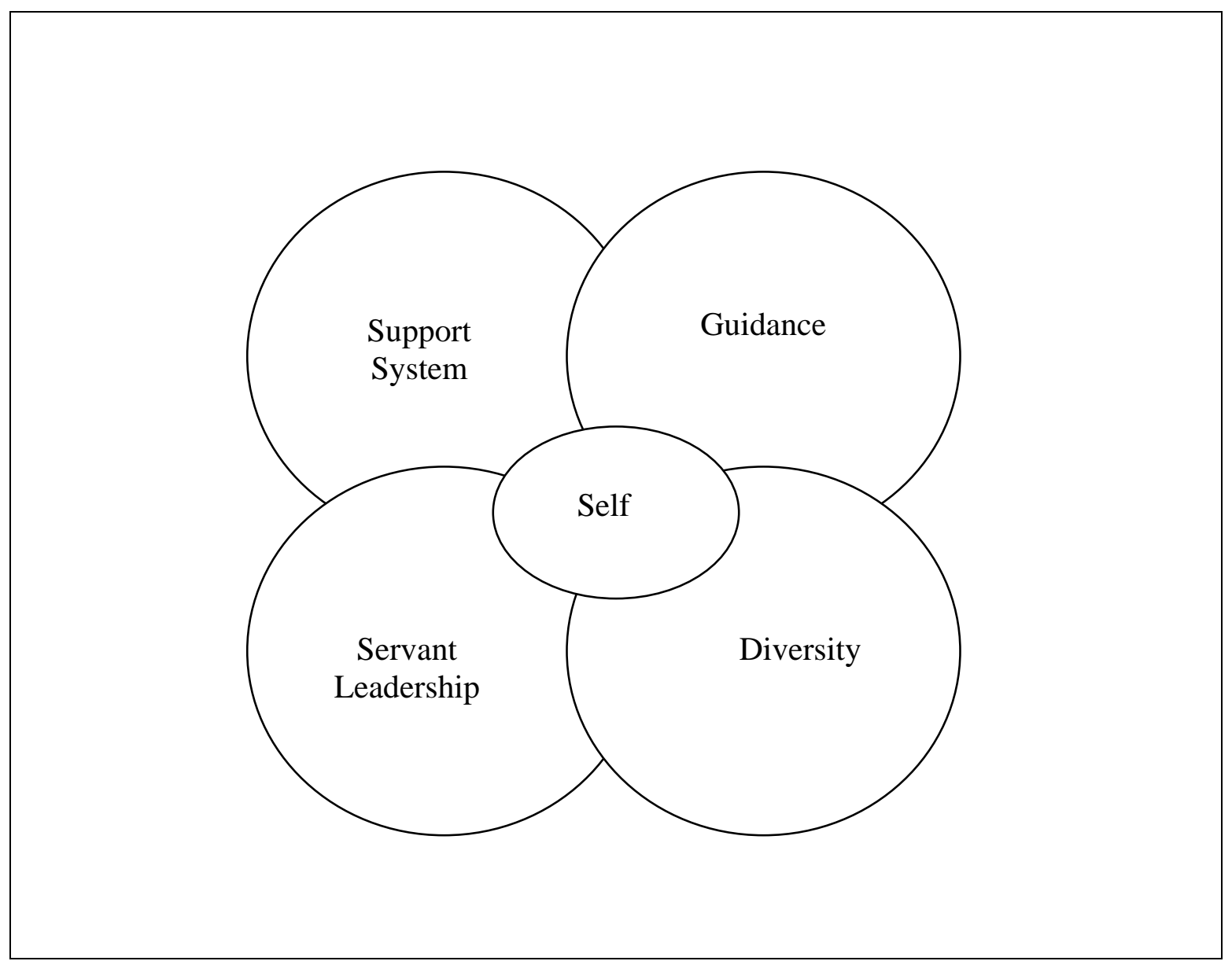

Figure 1. An emerging model to explain the career development of Black female chief nurse executives.

The role of self takes a prominent place in the center of the model. Self encompasses both the race and the gender of these Black women, their values, and beliefs (including belief in God), attitudes, needs, and personality. Self is revealed by those who (a) are resilient, (b) take risks, (c) are determined and passionate, and (d) show the ability to remove obstacles. The role of self as leader was shaped by (a) the nurturative family environments of these Black female chief nurse executives, (b) their families, schools, 
churches, and communities, and (c) the larger context which includes the history and the politics of the time, encompassing both segregation and integration. In later years, self was shaped by colleagues, peers, organizations, and the challenges of diversity.

As shown, Figure 1 displays the five elements as overlapping spheres -- support systems, guidance, servant leadership, diversity, and self. These five overlapping spheres reflect the themes derived from the participants' descriptions of how they learned, explored, established, and then maintained their careers. Throughout the participants' careers, but more evident once they reached the pinnacle of their career, was their need to provide service, servant leadership. The participants valued helping others, their communities, their organizations, their patients, and their nurses. These individuals took responsibility for their career development. There notion of self as a servant leader developed over time.

The participants' movement through their career development was nonlinear as evidenced by their varying career paths. Career development is shaped by the dynamic recursive interaction between the environment and the individual, with the environment providing feedback to the individual and the individual exerting an influence on his or her environment. The salient factor and foundation in the career development of these individuals was their strong self-definition. The self-definition was influenced, supported, and nurtured primarily by their parents and, subsequently, by the extended family, teachers, mentors, role models, friends, colleagues, community, and the healthcare organization that employed them.

Once the participants identified their careers, they were aided in their career development by their support systems. Initial career development required educationally 
prepared individuals and a commitment to ongoing staff development. Throughout their lives, they were faced with barriers and challenges, mainly the impact of racism. In spite of their experiences with racism, none of the participants viewed their experiences with racism from a victim perspective. Instead, as suggested by critical race theorists, they viewed racism as part of the fabric of the society in which they lived and worked. As they moved along their career paths, these individuals harnessed the strength to meet challenges, found their voices, and demonstrated career resilience. As evidenced from the participants in the current study, career resilience is created through learning and preparation. Similarly, London and Smither (1999) described self-determined careerrelated continuous learners as:

They regularly assess their work environment to identify what they need to know. They develop alternative visions of the future and to anticipate what they will need to know tomorrow. They seek feedback and assess their current skills and knowledge to determine learning gaps. They search for development opportunities and set learning objectives. (p. 89)

Regardless of the adversities the participants faced, they were prepared to cope with the adversities experienced during their career development by their strong sense of self and belief in self, their upbringing, their support systems, and their faith in God prepared them to cope. These results resonate with the results of a study by Jean-Marie (2003). Jean-Marie studied Black women who became school administrators, noting, "Black women being first in their families to attain a higher level of education and represent the black community demonstrate how these women administrators have been involved in altering the economical, intellectual, and social capital of the Black race” (p. 8).

The women maintained several roles over their life spans, including career and family roles. Theoretical frameworks and concepts offered by Super, Gottfredson, and 
critical race theories, together, provide a structure for understanding their career development. As these individuals achieved their positions as chief nurse executives, they began to demonstrate altruism, or servant leadership, the desire, by the participants, to serve and to give back to their communities as evidenced by their passion for nursing, the need to mentor and develop others, and the need to serve their communities. With nursing as a caring, helping, and serving profession, these participants placed the needs of the organization and the followers ahead of their own needs.

\section{Limitations}

Three limitations are acknowledged for this study. First, the sample was comprised of 10 Black female chief nurse executives employed in several metropolitan areas in the United States. Although overall generalization of study findings could not be made to larger populations, specific findings of the study were generalizable, especially to aspiring chief nurse executives in healthcare settings similar to those of the participants (Creswell, 2003; Donmoyer, 1990; Guba \& Lincoln, 1981; Polkinghorne, 1991; Tashakkori \& Teddlie, 2003). Mayring (2007) described this type of generalization as consisting of two components: first, identification of typical material from prior considerations; in the present case, the participants' career paths; and triangulation of results from the qualitative interviews and the quantitative demographic questionnaire data. Second, although it was not possible to extract and to record the "essence" of the participants' lives, their salient experiences, insights, and feelings were recorded and transmitted. Additionally, researcher bias may have influenced interpretation of the study results. Because, of the researcher's own role as a Black nurse leader, precautions were employed to minimize her personal biases. 
Despite the limited generalization of results to larger populations, transferability of the results may be possible, as Eisner (1991) suggested. The researcher's deconstruction of the participants' lives and reconstruction within the theoretical frameworks illuminated the uniqueness of each participant's experiences, while the crosscase analysis developed insights that exceeded the limits of particular situations or experiences. Barone (1998) elaborated on this concept by adding that if the researcher could represent the participants' career development experiences as vivid portrayals, readers could identify with many aspects of the experiences, and a "naturalized" identification could take place. The researcher attempted to decrease the impact of her subjectivity on the results by maintaining a researcher log of feelings and biases. The participants were provided with transcripts of their interviews and were asked to give feedback to the researcher. The participants did not provide feedback. Although the interviews were conducted by telephone, the emotions of the participants were heard as they related their stories.

\section{Summary}

These successful women were all thriving in their career development. Once these women identified and embarked on their career development, they did not deter from their goals. Even with challenges, these women were in control of their lives and their career development. The themes that emerged from the analysis of the interviews with these women emphasized the importance of support, self, diversity, servant leadership, and guidance. These themes combined to help them deal with the challenges they faced as they gained access to the executive suite. These women's career development reflect the interdependence and interconnections among self, family, and the organization. How 
do Black female chief nurse executives make it to the top? They make it through various career paths and with the ability to overcome barriers. The presence of a support system consisting of family, friends, and colleagues was critical to their success. In addition, several participants mentioned the importance of a spiritual foundation. It is important for not only Black women but also for all women and men to hear the stories of these women so that they know that it is not only possible to aspire to but to achieve these executive positions. The participants understood that career development was not static, linear, or irreversible.

The findings from this study can serve as a roadmap for charting one's career development, as depicted by the emerging career development model of Black female chief nurse executives. The results of the study are encouraging not only for Black female chief nurse executives but for all women. Nurses aspiring to the executive suite would benefit from networking with those who have made it and are successful in these roles. Aspiring, nurses would also benefit from those who can facilitate their career development and help them to navigate the barriers to their career development. They must be flexible and able to adapt quickly to the changes in one's career development. Once established in their careers, the participants’ work provided purpose and meaning toward the betterment of the stakeholders whom the participants’ served.

The nurse executives were now committed to servant leadership. They wanted to transform not only their nurses but their organizations, and the community. On developing future leaders, these experienced executives suggested that nurses interested in leadership (a) advance their education by attending graduate school, (b) volunteer for 
additional assignments, (c) network and interact with nurse leaders and executives, and (d) be visible.

This study addressed career development in the context of “work” by asking, how did the participants make it to the top? In today’s world, one’s career is not just about the world of work but the intersection of work and one's life. The findings of the current study underscore the interconnection between the role of self influences one's career choice and thus one's career.

From the individual stories of these participants, themes emerged which were similar to themes which have emerged in other studies. Although the themes that emerged from the stories of the 10 participants are quite similar, this should not imply that there are no differences among these women or that similar themes would emerge from other Black women, or even all women. Additionally, the researcher is aware that other Black women could have endured more paralyzing challenges and barriers in making it to the top and may have had fewer support systems or nonexistent support systems. The successful organization must be able to prepare its workforce to get the best results from all employees in the organization. They must identify and create the opportunities to develop future leaders and nurse executives. In the end, these women shaped their worlds and careers with such support.

In nursing, a female-dominated profession, women are expected to rise to the top in the chief nurse executive role. Anecdotally, studies and articles have indicated a lack of minority representation in the chief nurse executive role. This study focused on how Black female chief nurse executives have navigated their environment, both personal and situational, to become successful and achieve the chief nurse executive role. Rather than 
single events catapulting the participants to the executive suite, it was the interaction of several factors that were critical to their career development. In the end, their ability to learn, take risks, effectively manage challenges and barriers, self-define, commit to the mission and vision of organization and community, and work with supportive individuals propelled these individuals to the top. 


\section{REFERENCES}

Agency for Healthcare Research and Quality. (2004, February). National Healthcare Disparities Report: Summary. Rockville, MD Retrieved November 11, 2008, from http://www.ahrq.gov/qual/nhdr03/nhdrsum03.htm

Alfred, M. V. (1995). Outsiders-within: The professional development history of Black tenured female faculty in the White academy. Unpublished doctoral dissertation, University of Texas at Austin.

Alfred, M. V. (2001a). Expanding theories of career development: Adding the voices of African American women in the White academy. Adult Education Quarterly, 51(2), 108-127.

Alfred, M. V. (2001b). Reconceptualizing marginality from the margins: Perspectives of African tenured female faculty at a White research university. The Western Journal of Black Studies, 25(1), 1-11

Allen, D. W. (1998). How nurses become leaders: Perceptions and beliefs about leadership development. Journal of Nursing Administration, 28(9), 15-20.

American College of Healthcare Executives. (2002). A race/ethnic comparison of career attainments in healthcare management. Retrieved November 11, 2008, from http://www.ache.org/PUBS/Research/pdf/RaceEthnicStudy2002.pdf

American Hospital Association. (2003). Scope and standards for nurse administrators ( $2^{\text {nd }}$ ed.). Washington, DC: American Nurse Publishing.

American Organization of Nurse Executives. (2006). AONE nurse executive competencies. Retrieved November 11, 2008, from http://www.aone.org/aone/pdf/February \%20Nurse\%20Leader--final\%20draft-for\%20web.pdf

Bandura, A. (1986). Social Foundations of thought and action. Englewood Cliffs: New Jersey: Prentice-Hall.

Bandura, A. (1997). Self-efficacy: The exercise of control. New York: W. H. Freeman.

Barone, T. E. (1998). A narrative of enhanced professionalism: Educational researchers and popular storybooks about school people. Educational Researcher, 21(8), $15-24$.

Bass, B. M., \& Avolio, B. J. (1994). Shatter the glass ceiling: Women may make better managers. Human Resource Management, 33(4), 549-561. 
Bell, D. (1992). Faces at the bottom of the well: The permanence of racism. New York: Basic Books.

Bessent, H. (2002). Minority nurses in the new century. Characteristics and workforce utilization patterns: A survey. Washington, DC: American Nurses Association.

Bieber, V. H. (2003). Leadership practices of veterans health administrations nurse executives: An exploration of current practices and professional development needs. Unpublished doctoral dissertation, East Tennessee State University, Johnson City, TN.

Bogdan, R. C., \& Biklen, S. K. (1998). Qualitative research in education ( $3^{\text {rd }}$ ed.). Boston: Allyn \& Bacon.

Borg, W. R., \& Gall, M. D. (1989). Educational research: An introduction. New York: Longman.

Bridges, C. R. (1996). The characteristics of career achievement perceived by African American college administrators. Journal of Black Studies, 26(6), 748-767.

Bryans, P., \& Mavin, S. (2003). Women learning to become managers: Learning to fit in or to play a different game. Management Learning 34(1), 111-154

Burke, R. J., \& McKenn, C. A. (1997a). Benefits of mentoring relationships among managerial and professional women: A cautionary tale. Journal of Vocational Behavior, 5, 43-57.

Burke, R. J., \& McKenn, C. A. (1997b). Not every managerial woman who makes it has a mentor. Women in Management Review, 12(4), 136-140.

Byers, J. F. (2000). Knowledge, skills, and attributes needed for nurse and non-nurse executives. Journal of Nursing Administration, 7(8), 354-356.

Byrd, M. (2007). Educating and developing leaders of racially diverse organizations. Human Resource Development Quarterly, 18(2), 275-279.

Byrd-Blake, M. (2004). Female perspectives on career development. Advancing women network. Retrieved November 11, 2008, from http://awinstitute.advancingwomen.com /awl/spring2004/Byrd_Blake.html

Carroll, R. L. (2005). Leadership skills and attributes of women and nurse executives: Challenges for the $21^{\text {st }}$ century. Nursing Administration Quarterly, 29(2), 146153. 
Cheatham, H. E. (1990). Afrocentricity and career development of African Americans. Career Development Quarterly, 38(4), 334-346.

Chen, M. H. (2007). Entrepreneurial leadership and new ventures: Creativity in entrepreneurial teams. Creative and Innovative Management, 16(3). 239-249.

Coleman, C. (2006). The management path. Retrieved November 11, 2008, from http://www.minoritynurse.com/features/nurse_emp/05-15-00a.html

Collard, B., Epperheimer, J. W., \& Saign, D. (1996). Career resilience in a changing workplace (Report No. CE-072-052). Columbus, OH: ERIC Clearinghouse on Adult, Career, and Vocational Education. (ERIC Document Reproduction Service No. ED396191).

Conner, D. R. (1992). Managing at the speed of change. How resilient managers succeed and prosper when others fail. New York: Villard Books.

Constantine, M. F., \& Greer, R. M. (2003, Winter). Personal, academic, and career counseling of African American women in college settings. New Directions for Student Services, 104, 41-51.

Cook, P. E., Heppner, M. J., \& O’Brien, K. M. (2002). Career development of women of color and White women: Assumptions, conceptualization and interventions from an ecological perspective. Career Development Quarterly, 50(4), 291-305.

Courtney, M., Yacopetti, J., James, C., Walsh, A., \& Finlayson, K. (2001). Comparison of roles and professional development needs of nurse executives working in metropolitan, provincial, rural or remote settings in Queensland. Australian Journal of Rural Health, 10(4), 202-208.

Crenshaw, K. (Ed.). (1995). Critical race theory: The key writings that formed the movement. New York: New Press.

Creswell, J. W. (2003). Research design: qualitative, quantitative and mixed methods approaches $\left(2^{\text {nd }}\right.$ ed.) Thousand Oaks, CA: Sage.

Delgado, R. (2000). Storytelling for oppositionists and others: A plea for narrative. In R. Delgado, \& J. Stefancic (Eds.), Critical race theory: The cutting edge ( $2^{\text {nd }}$ ed., pp. 60-70). Philadelphia: Temple University Press.

Delgado, R., \& Stefancic, J. (2000). Critical race theory: The cutting edge $\left(2^{\text {nd }}\right.$ ed.). Philadelphia: Temple University Press. 
Donmoyer, R. (1990). Generalizability and the single-case study. In E. W. Eisner and A. Peshkin (Eds.), Qualitative inquiry in education: The continuing debate (pp. 175200). New York: Teachers College Press.

Du Bois, W.E.B. (1903). The souls of Black folk. Chicago: A. C. McClurg \& Co.

Dudziak, M. L. (2000). Desegregation as a Cold War imperative. In R. Delgado and J. Stefancic (Eds.), Critical race theory: The cutting edge ( $2^{\text {nd }}$ ed., pp. 106-117). Philadelphia: Temple University Press.

Eisner, E. (1991). The enlightened eye: Qualitative inquiry and the enhancement of educational practice. New York: Macmillan.

Erickson, J. I., \& Ditomassi, M. (2004). Mentoring the minority nurse leader of tomorrow. Nursing Administration Quarterly, 28(3), 165-170.

Ezzeedeen, S. R., \& Ritchey, K. G. (2008). The man behind the woman: A qualitative study of the spousal support received and valued by executive women. Journal of Family Issues, 29(9), 1107-1135

Farella, C. (2002, March 11). Erase the hate: The truth about racism in nursing. Retrieved November 11, 2008, from http://www2.nursingspectrum.com/articles/article.cfm?aid=6137

Federal Glass Ceiling Commission. (1995). Good for business: Making full use of the nation's human capital. Retrieved November 11, 2008, from http://digitalcommons.ilr.cornell.edu/cgi/viewcontent.cgi?article=1118\&context= key_workplace

Fisher, T. A., \& Stafford, M. E. (2000, April 26). The impact of career and ethnic influences on career resilience. Paper presented at the Annual Meeting of the American Educational Research Association Conference, New Orleans, LA:

Fouad, N. A., \& Byars-Winston, A, M. (2005). Cultural context of career choice: Metaanalysis of race/ethnicity. Career Development Quarterly, 45(2), 223-233.

Fressola, M. C. (1998). How nurse executives learned to become nurse leaders. Unpublished doctoral dissertation, Teacher's College, Columbia University, NY.

Gall, M. D., Gall, J. P., \& Borg, W. R. (2003). Educational research: An introduction (7 $7^{\text {th }}$ ed.). Boston: Allyn \& Bacon.

Georges, A. C. (2004). African American nurse leadership: Pathways and opportunities. Nursing Administration Quarterly, 28(3), 170-172. 
Ginzberg, E. (1972). Toward a theory of occupational choice: A restatement. Vocational Guidance Quarterly, 20, 169-176.

Giorgi, A. (1985). Sketch of a psychological phenomenological method. In A. Giorgi (Ed.), Phenomenology and psychological research (pp. 8-22). Pittsburgh, PA: Duquesne University Press.

Goodin, H. J. (2003). The nursing shortage in the United States of America: An integrative review of the literature. Journal of Advanced Nursing, 43(4), 335-350.

Gottfredson, L. S. (1981). Circumscription and compromise: A developmental theory of occupational aspirations. [Monograph]. Journal of Counseling Psychology, 2(6), 545-579.

Gottfredson, L. S. (1996). Gottfredson's theory of circumscription and compromise. In D. Brown and L. Brooks (Eds.), Career choice and development ( $3^{\text {rd }}$ ed., pp. 179-232). San Francisco: Jossey-Bass.

Gottfredson, L. S. (2002). Gottfredson's theory of circumscription, compromise, and selfcreation. In D. Brown (Ed.), Career choice and development (pp. 85-148). San Francisco: Jossey-Bass.

Gottfredson, L. S. (2005). Applying Gottfredson's Theory of Circumscription and Compromise in career guidance and counseling. In S. D. Brown and R. W. Lent (Eds.), Career development and counseling: Putting theory and research to work (pp. 71-100). New York: John Wiley.

Green, C. E., \& King, V. G. (2001). Sisters mentoring sisters: Afrocentric leadership development for Black women in the academy. The Journal of Negro Education 70(3), 156-165.

Greenleaf, R. K (1977). Servant leadership: A journey into the nature of legitimate power and greatness. Mahwah, NJ: Paulist Press.

Greenleaf, R. K. (1996). On becoming a servant-leader. The private writings of Robert K. Greenleaf. (D. M. Frick and L. C. Spears Eds.). San Francisco, CA: Jossey-Bass Publishers.

Guba, E., \& Lincoln, Y. (1981). Effective evaluation. San Francisco: Jossey-Bass.

Guest, G., Bunce, A., \& Johnson, L. (2006). How many interviews are enough? An experiment with data saturation and variability. Field Methods, 18, 50-82. 
Gunn, L. J. (2005). African American women striving to break through invisible barriers and overcome obstacles in corporate America. The Business Review, Cambridge, 3(2), 27-34.

Gutteridge, T. G. (1986). Organizational career development systems: The state of the practice. In D. T. Hall (Ed.), Career development in organizations (pp. 50-94). San Francisco: Jossey-Bass.

Hackett, G., \& Benz. G. (1981). A self-efficacy approach to the career development of women. Journal of Vocational Behaviour, 16, 326-339.

Hall, D. T. (1996). Protean careers of the 21st century. Academy of Management Executives, 10(4), 8-16.

Hall, D. T. (2002). Careers in and out of organizations. Thousand Oaks, CA: Sage.

Hansman, C. A. (Winter, 1998). Mentoring and women's career development. Directions for Adult and Continuing Education, 80, 63-71

Harms, N. A. (1988). Variables influencing leadership development among presidents of selected nursing organizations. Unpublished doctoral dissertation, University of Nebraska, Lincoln.

Hill, J. J. (2004). The role of mentoring in the development of African American nurse leaders. Unpublished doctoral dissertation, Louisiana State University and Agricultural and Mechanical College, Baton Rouge.

Hite, L. (1998). Race, gender, and mentoring patterns. In 1998 proceedings of the Academy of Human Resource Development Conference, Oak Brook, IL.

Hite, L. M., \& McDonald, K. S. (2003). Career aspirations of non-managerial women: adjustment and adaptation. Journal of Career Development, 29(4), 221-235

Hoepfl, M. C. (1997). Choosing qualitative research: A primer for technology education researchers. Journal of Technology Education, 9(1), 47-63.

Huff, M. A. (1998). Minority nurse leaders: Perspectives, development attributes and level of self-efficacy for leadership. Unpublished doctoral dissertation, Indiana University, Indianapolis, IN.

Hugg, A. (2005). Forging ahead. African American nurse leaders. Nursing Spectrum. Retrieved November 11, 2008, from http://community.nursingspectrum.com /MagazineArticles/article.cfm?AID=14499 
Institute of Medicine. (1994). Balancing the scales of opportunity: Ensuring racial and ethnic diversity in the health professions. Washington, DC: National Academy Press.

Institute of Medicine (2003) Unequal treatment: Confronting racial and ethnic disparities in healthcare. Washington, DC: National Academy Press.

Isaksen, J. L. (2000). From critical race theory to composition studies: Pedagogy and theory building. Legal Studies Forum, 24(3/4), 695-710.

Jacobson, G. P. (2008). Career wise. Best Review, 109(4), 18.

Jean-Marie, G. (2004). Black women administrators in historically Black institutions: Social justice project rooted in community. Journal of Women in Educational Leadership, 2(1), 37-58.

Jean-Marie, G. (2006). Welcoming the unwelcomed: A social justice imperative of African American female leaders. Educational Foundations, 20(1/2), 85-104.

Johnson-Bailey, J., \& Tisdell, E. J. (Winter, 1998). Diversity issues in women's career development. New Directions for Adult and Continuing Education, 80, 83-94.

Jordan, J. (1992). Technical difficulties: African American notes on the state of the union. New York: Pantheon.

Jobes, M., \& Steinbinder, A. (1996). Transitions in nursing leadership roles. Nursing Administration, Quarterly, 20(2), 80-84.

Kerka, S. (2003). Career development of diverse populations. ERIC Clearinghouse on Adult Career and Vocational Education. Columbus, OH. ERIC Digest No. 249. (ERIC Document Reproduction Service No. EDO-CE-03-249)

Kontoghiorghes, C., Awbrey, S. M., \& Feuing, P. L. (2005). Examining the relationship between learning organization characteristics and change adaptation, innovation and organizational performance. Human Resource Development Quarterly, 16(2), 185-212.

Kuo-Rice, Y. L. (2005). Career experiences and career development among Chinese American professional women: A qualitative study. Unpublished doctoral dissertation, Western Michigan University.

Ladson-Billings, G. (1998). Just what is critical race theory and what's it doing in a nice field like education? Qualitative Studies in Education, 2(1), 7-24. 
Lane, N. (1998). Barriers to women's progression into nurse management in the National Health Service. Women in Management Review, 13(5), 184-190.

Lee, J. H., \& Nolan, R. E. (1998). The relationship between mentoring and the career advancement of women in cooperative extension. Journal of Career Development, 25(1), 3-13.

Levinson, D. J. (1978). The seasons of a man's life. New York: Alfred A. Knopf.

Leong, T. F. (1995). Career development and vocational behavior of racial and ethnic minorities. Mahwah, NJ: Lawrence Erlbaum Associates.

Lindholm, M., Sivberg, B., \& Udén, G. (2000). Leadership styles among nurse managers in changing organizations. Journal of Nursing Management, 6, 327-335.

Lirio, P., Lituchy, T., Monserrat, S.I., Olivas-Luján, M.R., Duffy, J.A., Fox, S., et al. (2007). Exploring career-life success and family social support of successful women in Canada, Argentina and Mexico. Career Development International, 12(1), 28-50.

London, M (1983). Toward a theory of career motivation. Academy of Management Review, 8(4) 620-630.

London, M., \& Noe, R. A. (1997). London's career motivation theory: An update on measurement and research. Journal of Career Assessment, 5(1), 61-80.

London, M., \& Smither, W. (1999). Career-related continuous learning: Defining the construct and mapping the process. Research in Personnel and Human Resources Management, 17, 81-121.

Madsen, S. R. (2007a). Developing leadership: Exploring the childhoods of women university presidents. Journal of Educational Administration, 45(1), 99-118.

Madsen, S. R. (2007b). Women university presidents: Career paths and educational background. Academic Leadership, The Online Journal, 5(1). Retrieved November 11, 2008, from http://www.academicleadership.org/empirical_research/ Women_University_Presidents_Career_Paths_and_Educaitonal_Backgrounds.sht $\mathrm{ml}$

Marshall, C., \& Rossman, G. B. (1999). Designing qualitative research. Thousand Oaks, CA: Sage.

Mathis, M. C. (2001). Advancing women in business organizations: Key leadership roles and behaviors of senior leaders and middle managers. Journal of Management Development, 20(4), 371-390. 
Mayer, L. C. (2001). Predictors of women's success in achieving senior-level administrative positions in CSREES. Journal of Extension, 39(2). Retrieved October 7, 2008, from http://www.joe.org/joe/2001april/rb6.html

Mayor, V. (2004). Climbing high: A look at strategies used by leading Black nurses in their career development. Nursing Standard, 18(34), 104.

Mayring, P. (2007). On generalization in qualitatively oriented research. Forum: Qualitative Social Research, 8(3), Article 26. Retrieved November 11, 2008, from http://www.qualitative-research.net/fqs/

McDonald, K.S., \& Hite, L. M. (1998). Exploring the glass ceiling: An exploration of gender differences in managing development experiences. Journal of Management Education, 22(2), 242-254.

McMillan, J. H., \& Schumacher, S. (2005). Research in education: Evidence-based inquiry $\left(6^{\text {th }}\right.$ ed.). Boston: Allyn \& Bacon.

Merriam, S. B., \& Simpson, E. L. (2000). A guide to research for educators and trainers of adults. Malabar, FL: Kreger Publishing,

Moran, P., Duffield, C., Beutel., Bunt, S., Thorton, A., Wills, J., et al. (2002). Nurse managers in Australia: Mentoring, leadership and career progression. Canadian Journal of Nursing Leadership, 15(2), 14-20.

Morse, J. M., Barrett, M., Mayan, M., Olson, K., \& Spiers, J. (2002). Verification strategies for establishing reliability and validity in qualitative research. International Journal of Qualitative Methods, Article 2. Retrieved November 11, 2008 from http://www.ualberta.ca/ ijqm

Morse, J. M., \& Field, P. A. (2003). Nursing research: The application of qualitative approaches $\left(2^{\text {nd }}\right.$ ed). Cheltenham, UK: Stanley Thornes.

Mullen, C. A. (2007). Trainers, illusionists, tricksters, and escapists: Changing the doctoral circus. Educational Forum, 71(4), 300-315

Newman, I., \& Benz, C. R. (1998). Qualitative-quantitative research methodology: Exploring the interactive continuum. Carbondale, IL: Southern Illinois University Press.

O’Neil, D. A., Billmoria, D., \& Saatcioglu, A. (2004). Women's career types: Attributions of satisfaction with career success. Career Development International, 9(5), 478-500. 
Onwuegbuzie, A. J., \& Leech, N. L. (2006). Linking research questions to mixed methods data analysis procedures. The Qualitative Report, 11(3), 474-498. Retrieved November 11, 2008, from http://www.nova.edu/ssss/QR/QR113/onwuegbuzie.pdf

Padezanin, S. (2007). Legacy of a leader: An interview with Pearl Moore. Leadership \& professional development. Oncology Nursing Forum, 34(1), 23-25.

Patton, M. (1990). Qualitative evaluation and research methods ( ${ }^{\text {nd }}$ ed.). Newbury Park, CA: Sage.

Patton, W., \& McMahon, M. (1999). Career development and systems theory: A new relationship. Pacific Grove, CA: Brooks/Cole.

Peshkin, A. (1988). In search of subjectivity--One's own. Educational Researcher, 17(7), $17-21$.

Phelps, R. L. (2005). Using a formal mentoring program to develop nurse leaders: An action research study. Unpublished doctoral dissertation, Capella University, Minneapolis, MN.

Polkinghorne, D. E. (1991, April). Generalization and qualitative research: Issues of external validity. Paper presented at American Educational Research Association Meeting, Chicago.

Riley, K., \& J. White. (1994). Pathways to leadership: Issues for women chief executives'. Public Money and Management, 14(3), 39-44

Rose, S., \& Larwood, L. (1988). Women's careers: Pathways and pitfalls. New York: Praeger Publishers.

Sears, S. (1982). A definition of career guidance terms: A national vocational guidance association perspective. Vocational Guidance Quarterly, 31, 137-143.

Schreiber, P. (1999). The nature of career development for women who telecommute. Unpublished doctoral dissertation, University of Georgia, Athens.

Seago, J. A., \& Spetz, J. (2005). Job satisfaction and advancement of minorities in nursing. Retrieved November 11, 2008, from http://www.minoritynurse.com /vitalsigns/aug05-1.html

Simpson, G. (1996). Factors influencing the choice of law as a career by Black women. Journal of Career Development, 22(3), 197-209. 
Skodra, E. E. (1992). Ethnic/immigrant women and psychotherapy: The issue of empowerment. Women and Therapy, 13(4), 81-97.

Steefel, L. (2008, June 16) Unmasking racism in nursing. Retrieved November 11, 2008, from http://include.nurse.com/apps/pbcs.dll/article?AID=/20080616/NATIONAL01/10 6160064/-1/frontpage

Steefel, L. (2006, 24 April). National Coalition of Ethnic Minority Nurse Association creates leaders to close the disparity gap. Nursing Spectrum, 13.

Stewart, C. A. R. (2007). The role of a Christian church in the career development of its congregants. Unpublished doctoral dissertation, Florida International University.

Sullivan Commission on Diversity in the Healthcare Workforce. (2004). Missing persons: Minorities in the health professions. Retrieved November 11, 2008, from http://www.kaisernetwork.org/health_cast/uploaded_files /092004_sullivan_diversity.pdf

Super, D. E. (1976). Career education and the meaning of work: Monographs on career education. Washington, DC: Office of Education, The Office of Career Education.

Super, D. E. (1990). A life-span, life-space approach to career development. In D. Brown, L. Brooks (Eds.), Career choice and development: Applying contemporary theories to practice ( $2^{\text {nd }}$ ed., pp. 197-261). San Francisco: JosseyBass.

Tashakkori, A., \& Teddlie, C. (2003). Handbook of mixed methods in social and behavioral research. Thousand Oaks, CA: Sage.

Taylor, E. (1998). A primer on critical race theory. Journal of Blacks in Higher Education, 19, 122-124.

Thomas, V. G. (2004). The psychology of Black women: Studying women's lives in context. Journal of Black Psychology, 30(3), 286-306.

Trusty, J. (2002). Counseling for career development with persons of color. In S. G. Niles (Ed.), Adult career development: Concepts, issues and practices ( $3^{\text {rd }}$ ed., pp. 190213). Broken Arrow, OK: National Career Development Association.

U. S. Department of Health and Human Services. (2004). The registered nurse population, March 2000: Findings from the National Sample Survey of Registered Nurses. Rockville, MD: Author. 
Van Dyke, M. (2006). Management plan. Retrieved October 7, 2008, from http://www.minoritynurse.com/features/nurse_emp/11-01-03b.html

Villarruel, A. M., \& Peragallo, N. (2004). Leadership development of Hispanic nurses. Nursing Administration Quarterly, 28(3), 173-180.

Waring, A. L. (2003). African American female college presidents: Self-conceptions of leadership. Journal of Leadership and Organizational Studies, 9(3), 31-44.

Washington, R. R., Sutton, C. D., \& Field, H. S. (2006). Individual differences in servant leadership: The roles of values and personality. Leadership \& Organizational Development Journal 27(8), 700-716.

Wentling, R. M. (1992). Women in middle management: their career development and aspiration. Business Horizons, 35(1), 47-54.

West, C. (1995). Foreword. In K. Crenshaw, N. Gotanda, G. Peller, and K. Thomas (Eds.), Critical race theory: The key writings that formed the movement (pp. xixii). New York: New Press.

Whitmarsh, L (2007). Choices and challenges: A qualitative exploration of professional women's career patterns. Career Development Quarterly. Retrieved November 11, 2008, from http://findarticles.com/p/articles/mi_m0JAX /is_3_55/ai_n18791407/print

Wilson, P. A. (2004). The career development of senior-level African American women in community and technical colleges in the United States. Unpublished doctoral dissertation, University of Georgia, Athens.

Wing, A. K. (2003). Introduction. In A. K. Wing (Ed.), Critical race feminism: A reader $\left(2^{\text {nd }}\right.$ ed., pp. 1-19). New York: New York University Press.

Woods, K. B. (2006) From CNA to CEO. A successful nurse executive shares the story of her journey to the highest rung of the nursing career ladder. Retrieved November 11, 2008, from http://www.minoritynurse.com/features/other/082406c.html

Worth, P. (2004). The evolution of diversity in nursing and nurse anesthesia. American Association of Nurse Anesthetists Journal, 72(2), 101-105. 
APPENDICES 
APPENDIX A 


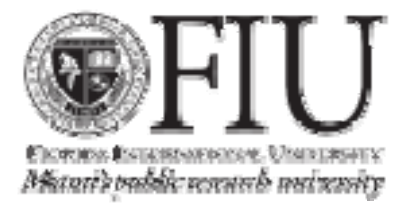

FIU IRB approval \#061407-01 June 14, 2007

LETTER TO PARTICIPANTS

THE CAREER DEVELOPMENT OF BLACK FEMALE NURSE EXECUTIVES IN HEALTHCARE ORGANIZATIONS

Joan Osborne

MSN, BSN, BS, RN, BC, CNA, ARNP

14055 Langley Place

Davie, FL 33325

Name of Participant, Title

Address

City, State, Zip Code

Dear Name:

I am a nurse and former nurse executive at a large healthcare institution and a doctoral candidate in Adult Education Administration at Florida International University. My dissertation is entitled "The Career Development of Black Female Nurse Executives in Healthcare Organizations.” As a nurse executive, you have been suggested as someone who might be helpful in participating or in identifying appropriate participants for this study.

My research has indicated an under-representation of Black female nurse executives, although a number of Black women have managed to overcome the odds and acquire positions at the executive level. As a Black female nurse executive myself, I am very much aware of many of the difficulties facing Black nurse executives. Therefore, I will investigate factors which contribute to surmounting cultural roadblocks to success.

My investigation will take a biographical approach and explore the various personal, community, and organizational experiences that have enhanced or hindered the career development of Black female nurse executives. If you agree to participate, we will have an informal conversation and interview focusing on your life and career experiences. This interview should take 60 to 90 minutes and will be conducted either in person or by telephone or video conference. In addition, after the interview, you will be given the opportunity to review and correct a transcript of your interview. This second meeting should take no more than 45 minutes. 
Your anonymity will be protected and your organization, as well as the state in which you are employed, will remain anonymous. You may withdraw at any time with no detrimental effects to you with regard to either your institution or position. The risks of participation are minimal, and you may find the interview enjoyable and benefit from additional insights about your life and career choices.

In addition, after the interview, the audiotapes will be destroyed and transcribed data will be accessible only to me and my doctoral supervisor and stored in a locked box in my office, accessible only to me. If any reports are published following from the dissertation, your approval will be sought first, and your identity will be fully protected.

Please see the enclosed Informed Consent for further details on protection of your anonymity and procedures to ensure confidentiality of records.

By participating, you will be adding to the understanding of some of the obstacles Black females face in reaching the executive ranks and helping to provide information that will enhance their career opportunities.

I would appreciate meeting or speaking with you at your convenience to answer any questions or discuss any concerns you may have about the study. I will call you to schedule an appointment for our meeting. Alternatively, you may call me at 954 4748703 or email me at josbor01@fiu.edu or my dissertation advisor, Dr. Ann Nevin (Phone: 954-885-7662 or email: nevina@bellsouth.net) or Dr. Patricia Price, the Chairperson of the FIU Institutional Review Board at 305-348-2618 or 305-348-2494.

Sincerely yours,

Joan M Osborne MSN, BSN, BS, RN, BC, CNA, ARNP

Doctoral Candidate

Florida International University 
APPENDIX B 


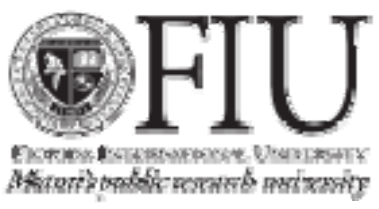

FIU IRB Approval \#061407-01 June 14, 2007

INFORMED CONSENT

\section{THE CAREER DEVELOPMENT OF BLACK FEMALE NURSE EXECUTIVES IN HEALTHCARE ORGANIZATIONS}

\section{Dear Participant:}

You are invited to participate in a research study which examines the career development of Black female nurse executives. The investigator for this study is Joan Osborne, who is a doctoral student at Florida International University. This investigation is in fulfillment for the dissertation requirement for the doctoral program.

If you decide to participate in this study, two open-ended interviews will be required. The first interview should last 60 minutes, and the second approximately 45 minutes. At the start of the first interview, you will be asked to complete a short demographic questionnaire. This will include questions on your title, age, marital status, race/ethnicity, education, and work experience.

During the first interview, you will be asked to discuss your personal beliefs as they relate to your career development, as well as experiences you have encountered which may have contributed to your career development. In the second interview, you will have the opportunity to review the transcript of your first interview for verification of information and any clarification you wish to add.

All information that is obtained in connection with this study and can be identified with you will remain confidential and will be disclosed only with your permission. The interviews will be audio taped, and no mention will be made of your name during the sessions. After the tape is transcribed, it will be destroyed to further preserve your confidentiality. The transcribed data will be accessible only to the researcher and her supervisor and stored in a locked box in the researcher's office, accessible only to her. If any data derived from this dissertation project are published, your complete approval will be sought first, and your identity will be fully protected.

Risks from participating in this study are minimal, and no harm is expected to come to you from participation. You may choose not to answer any questions on the questionnaire or during the interview that you do not want to answer. If you are uncomfortable at any time during the interview, you may take a break or choose to end the interview. There is 
no cost or payment to you as a subject. If you choose not to participate, there will be no detrimental consequences to you nor will nonparticipation have any adverse effect on your position in your institution. You are free to discontinue participation at any time.

If you have any questions or would like more information about this research, you may contact Dr. Ann Nevin, the dissertation chair, at 954-885-7662 (or email nevina@bellsouth.net), or you may contact the researcher, Joan Osborne, at (954-4748703). If you would like additional institutional validation, you may contact Dr. Patricia Price, the Chairperson of the FIU Institutional Review Board at 305-348-2618 or 305348-2494.

Your signature below indicates that you have read the information provided above, that your questions have been answered, and that you have freely decided to participate in this study.

Signature of Participant

Printed Name

Date

I have explained to the participant the research procedure and the participant's rights and protection and have answered questions asked by the participant. I have offered the participant a copy of this informed consent form.

Signature of Investigator

Date

Joan Osborne

MSN, BSN, BS, RN, BC, CNA, ARNP 
APPENDIX C 


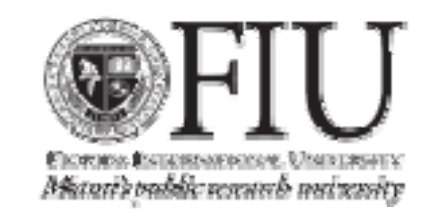

FIU IRB Approval \#061407-01 June 14, 2007

\section{DEMOGRAPHIC QUESTIONNAIRE \\ THE CAREER DEVELOPMENT OF BLACK FEMALE NURSE EXECUTIVES IN HEALTHCARE ORGANIZATIONS}

Thank you for agreeing to be a participant in this study. Please complete the following demographic information.

1. Your title:

2. Age:

3. Marital status:

4. Race/Ethnicity:

5. Highest degree earned: Nursing Other:

6. Country of formal schooling:

7. Country of nursing school:

8. Years of work experience as a nurse:

9. Years of work experience as a nurse executive:

10. Years in present position:

11. Number of individuals supervised in current role:

12. What is the race and ethnicity of individual(s) supervised?

13. Number of full-time employees in the organization (FTEs):

14. Type of Organization:
a. Joint Commission accredited Yes
No
b. (Select one) Region $\mathrm{SE}$, Rural, NE, _ SW,
c. (Select one) Both NW, $\underset{\text { Suburban }}{\text { MW }}$
d. Public Private Both 
15. Other information you would like the researcher to know about your role and organization: 
APPENDIX D 


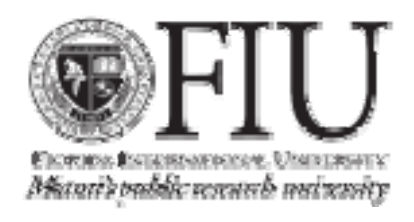

FIU IRB Approval \#061407-01 June 14, 2007

INTERVIEW GUIDE

\section{THE CAREER DEVELOPMENT OF BLACK FEMALE NURSE EXECUTIVES IN HEALTHCARE ORGANIZATIONS}

Self

1. Tell me about yourself - How would you describe yourself?

2. How does your view of yourself influence your careers choices?

3. How would you describe your childhood? Home and School?

4. What did/do you see as the greatest barrier to achieving your career objectives?

5. What did/do you see as the greatest facilitator to achieving your career objectives?

Career Development: Nursing

6. Why did you choose a nursing career?

7. Was there a particular event which influenced this career choice?

8. What role did your family, children, spouse, and friends, play in your career development?

Mentors/Role Models

9. Did you or do you have any role models?

10. If so, who are they and how specifically did they influence your career development?

11. Did you or do you have any mentors?

12. If so, who are they and how specifically did they influence your career development?

Race and Gender

13. What effect do you feel being Black and a woman have had on your career development?

14. As a Black female, what do you see as your greatest challenge to pursuing your career goals?

15. How do you confront these challenges?

16. Do you perceive a different career path than Whites? 


\section{Community}

17. How have organizations in your community and the larger society influenced your career development?

18. Who are some of the people in your community and/or the larger society who have influenced your career goals?

19. How have these individuals influenced you?

\section{Organization}

20. How have your organization and colleagues supported your career development?

21. How have your organization and colleagues hindered your career development?

22. What do you see as the best ways your organization can encourage Black female nurses to executive positions?

23. What strategies can Black female nurse executives in healthcare organizations utilize to enhance their leadership opportunities?

Other

24. What advice would you give to Black female nurses who desire to reach leadership positions?

25. Are there any additional comments you would like to share?

26. Are there any questions you would like to ask me? 
VITA

JOAN MARIA OSBORNE

1990

B.S. in Management

Nova Southeastern University

Fort Lauderdale, Florida

1993

B.S. in Nursing

Florida International University

Miami, Florida

1996

Nursing Research Leadership Award

Broward General Medical Center

Fort Lauderdale, Florida

1997

M.S. in Adult Nursing

Florida International University

Miami, Florida

2007

Outstanding Nursing Alumni Award

Florida International University

Miami, Florida

2001-2003

Medical-Surgical Clinical Nurse Specialist

Broward General Medical Center

Fort Lauderdale, Florida

2003-2005

Director of Education, Clinical Practice and Research

Broward General Medical Center

Fort Lauderdale, Florida

2005-Present

Administrative Supervisor

Broward General Medical Center

Fort Lauderdale, Florida

PUBLICATIONS AND PRESENTATIONS

Osborne, J., Blais, K., \& Hayes, J. (1999). Nurses’ perceptions: When is it a medication error? Journal of Nursing Administration, 29(4), 33-38.

Osborne, J. (2003, April). Nurses: Lifting spirits, touching lives. Vital Signs, 10.

Osborne, J. (2003, July). Staff development: Delegation of authority improves units, molds tomorrow's leaders. Vital Signs, 8. 
Osborne, J. (2003, November). Creating a safe environment: The Columbia accident report: Implications for health care organizations. Vital Signs, 10-11.

Osborne, J. (2004, March). Reducing medication errors: Strategies for nursing and healthcare organizations. Vital Signs, 8-9.

Osborne, J. (2003, September). Nurses' perceptions of medication errors. Paper presented at Academy of Medical Surgical Nurses Conference, Reno, NE.

Osborne, J. (2004, September). Nurses’ perceptions of medication errors. Paper presented at Ohio State University Medical Center, Medical-Surgical and Critical Care Nursing Conference, Columbus, $\mathrm{OH}$.

Osborne, J. (2006, January). Improving outcomes by giving and receiving feedback. Paper presented at Clinical Teaching Conference, University of Wisconsin, School of Nursing, Madison, WI.

Osborne J. (2006, April). The role of unit-based clinical nurse specialist in improving staff competence and clinical outcomes. Paper presented at Nurse Manager Update Conference, Las Vegas, NV.

Osborne, J. (2007, April). Creating performance excellence: Promoting individual and team growth by giving and receiving feedback. Paper presented at National Professional Educational Institute, Las Vegas, NV.

Osborne, J. (2007, May). Creating performance excellence: Promoting individual and team growth by giving and receiving feedback. Paper presented at South Florida Organization of Nurse Executives, Fort Lauderdale, FL.

Osborne, J. (2008, March). The career development of aspiring Black nurse leaders. Paper presented at American Educational Research Association (AERA), New York.

Osborne, J. (2008, August). The role of nurse executives in patient safety. Paper presented at American Organization of Nurse Executives Meeting, Cape Town, South Africa. 